\title{
PARTICIPACIÓN DEL PORO DE TRANSICIÓN DE PERMEABILIDAD MITOCONDRIAL EN LA RESPUESTA A LA ISQUEMIA Y REPERFUSIÓN MIOCÁRDICA DE RATAS HIPERTENSAS ESPONTÁNEAS (SHR)
}

IGNACIO ADRIÁN PEREZ NUÑ̃ZZ

DIRECTOR DE TESIS: DRA SUSANA M. MOSCA

CODIRECTOR DE TESIS: IRENE L. ENNIS

2014

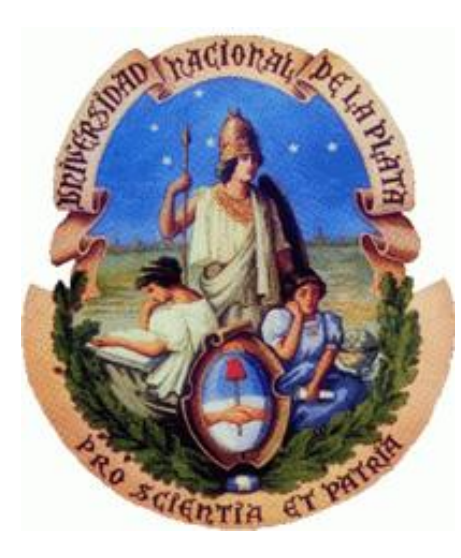




\section{ÍNDICE}

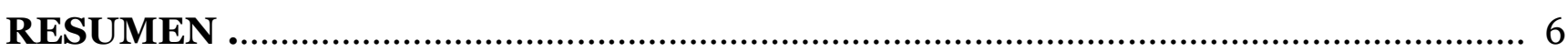

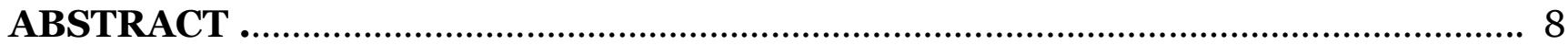

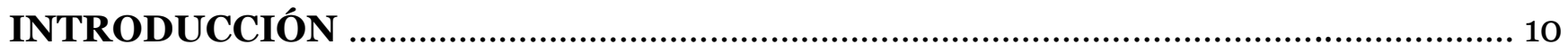

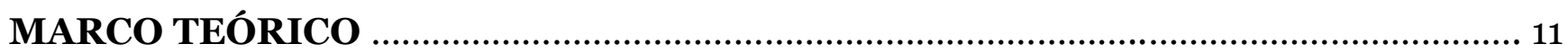

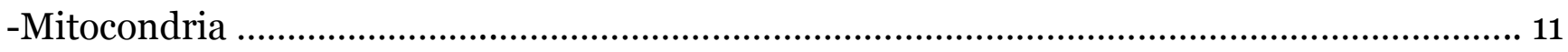

-Poro de permeabilidad transitoria mitocondrial (PPTM) ………........................................... 13

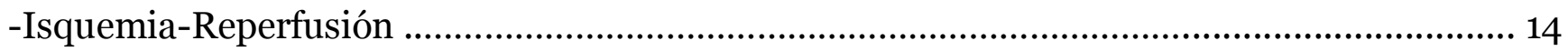

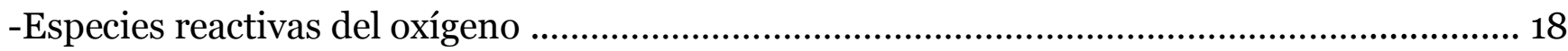

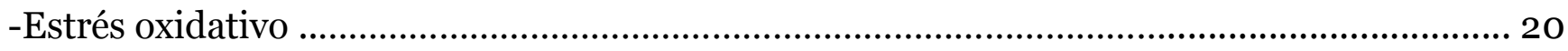

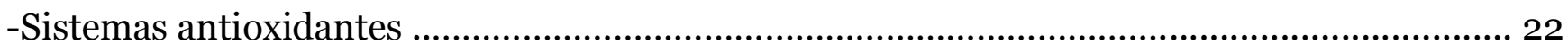

-Estrategias cardioprotectoras del daño por isquemia-reperfusión ............................................. 23

Preacondicionamiento isquêmico ………........................................................................... 23

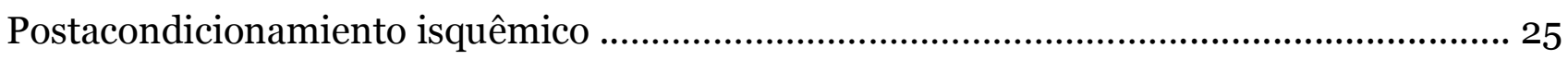

Preacondicionamiento y postacondicionamiento farmacológicos ..................................... 26

-La rata hipertensa espontánea (SHR) como modelo de hipertensión ...................................... 29

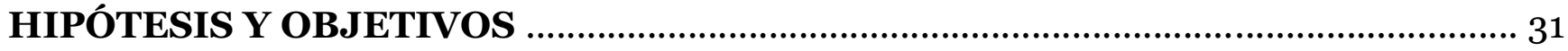

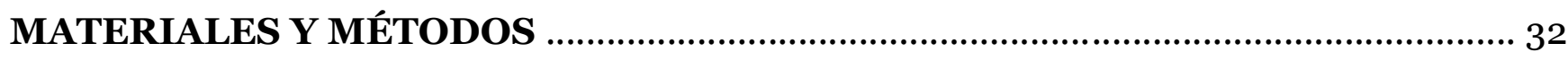

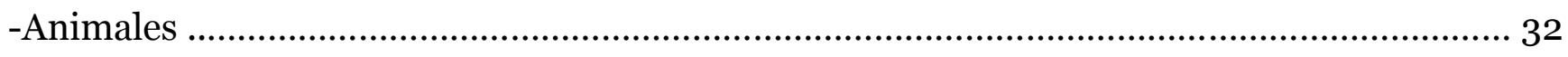

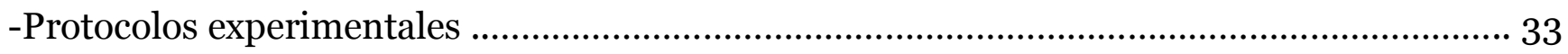

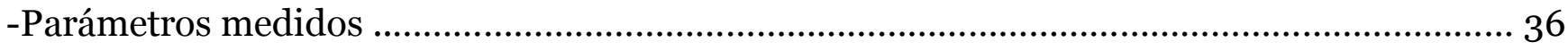

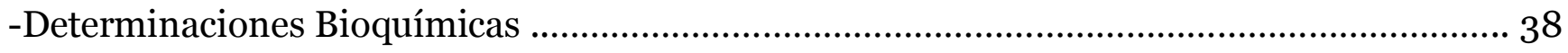

-Evaluación del daño oxidativo y sistema de defensa antioxidante .......................................... 38

Sustancias reactivas al ácido tiobarbitúrico (TBARS) …………...................................... 38

Contenido de glutatión reducido (GSH) …………….......................................................... 39

Actividad citosólica de la enzima superóxido dismutasa (SOD).............................................. 39 
-Expresión de las formas fosforiladas de Akt y GSK-3 $\beta$............................................................ 40

-Expresión de citocromo c en las fracciones citosólica y mitocondrial por western blot ......... 40

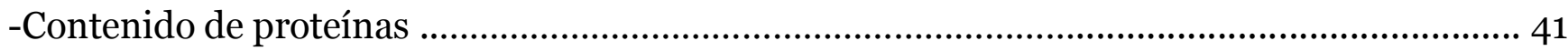

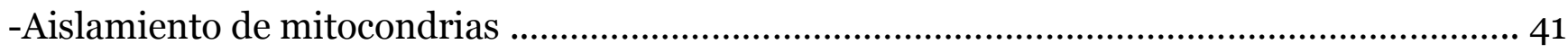

Determinación de la sensibilidad del poro de permeabilidad transitoria de la mitocondria (PPTM) al $\mathrm{Ca}^{2+}$

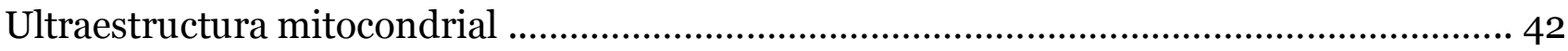

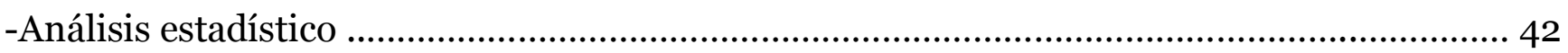

\section{RESULTADOS}

-Efectos de la isquemia-reperfusión y del preacondicionamiento y postacondicionamiento isquémicos (PI y PCI)

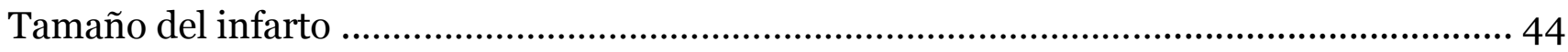

Función sistólica y diastólica ............................................................................................ 45

Evaluación del daño oxidativo y sistema de defensa antioxidante ......................................... 45

Sustancias reactivas al ácido tiobarbitúrico (TBARS) .................................................... 45

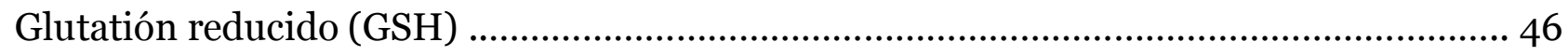

Actividad citosólica de Superóxido Dismutasa Total (SOD T) ............................................ 47

Actividad citosólica de Superóxido Dismutasa dependiente de Manganeso (SODMn).

Expresión de P- GSK-3 $\beta$ y P-Akt ....................................................................................... 48

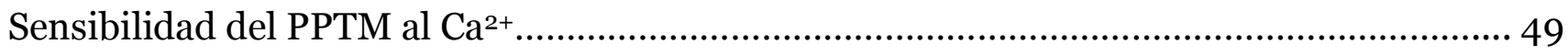

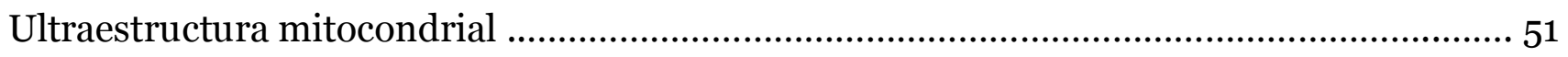

-Participación de la glucógeno sintetasa quinasa- $3 \beta$ (GSK-3 $\beta$ ) en isquemia-reperfusión, en el PI y en el PCI

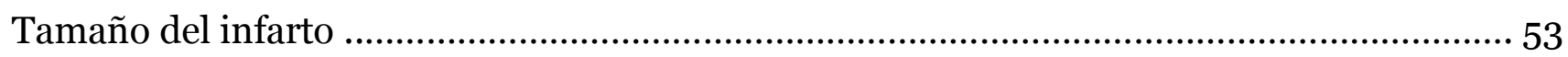

Función sistólica y diastólica ............................................................................................... 54

Evaluación del daño oxidativo y sistema de defensa antioxidante ......................................... 55

Sustancias reactivas al ácido tiobarbitúrico (TBARS) ........................................................... 55

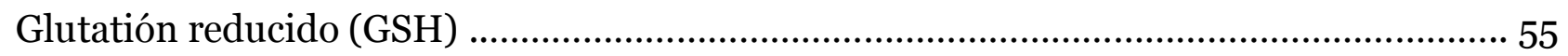

Actividad citosólica de Superóxido Dismutasa Total (SOD T) ............................................. 56 
Actividad citosólica de Superóxido Dismutasa dependiente de Manganeso (SODMn). 57

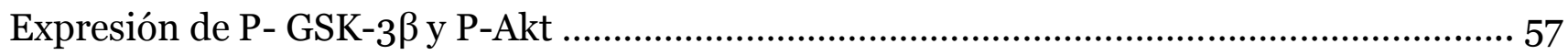

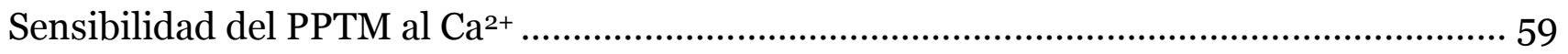

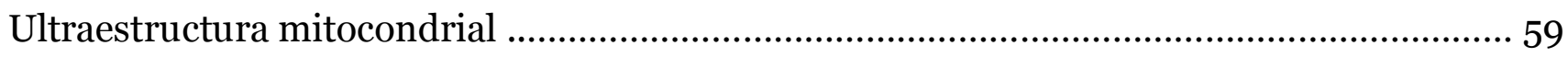

-Papel de PI3K/Akt en isquemia-reperfusión y en el pre y postacondicionamiento isquémicos (PI y PCI) 61

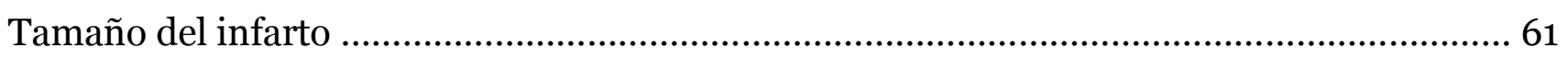

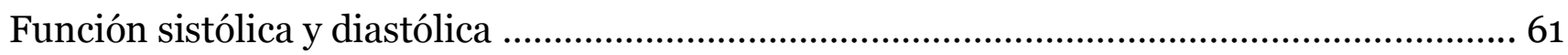

Evaluación del daño oxidativo y sistema de defensa antioxidante ................................... 62

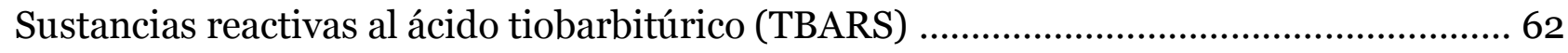

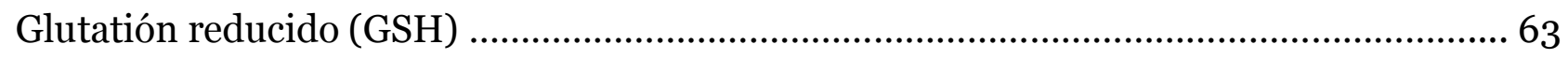

Actividad citosólica de Superóxido Dismutasa Total (SOD T) ................................... 63

Actividad citosólica de Superóxido Dismutasa dependiente de Manganeso (SODMn) 64

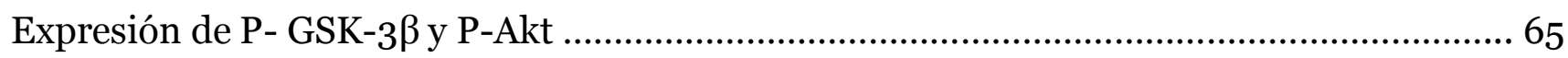

Sensibilidad del PPTM al $\mathrm{Ca}^{2+}$.............................................................................. 66

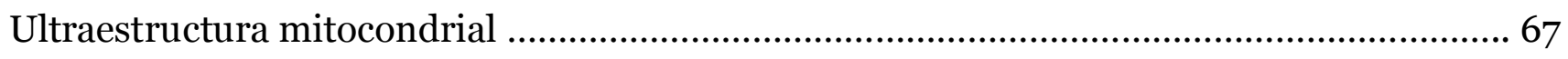

-Medida del contenido de citocromo c en las fracciones citosólica y mitocondrial................. 68

Relaciones entre variables en las distintas intervenciones ............................................. 70

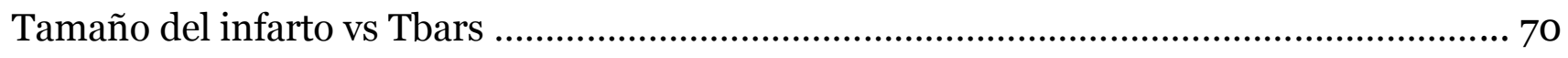

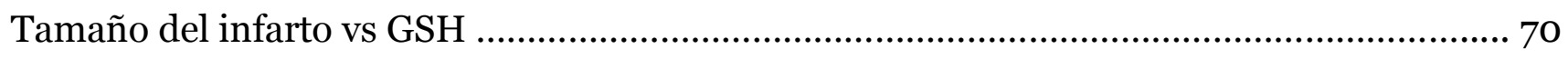

Sensibilidad del PPTM al $\mathrm{Ca}^{2+}$ vs tamaño del infarto .............................................. 72

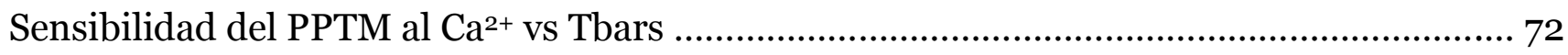

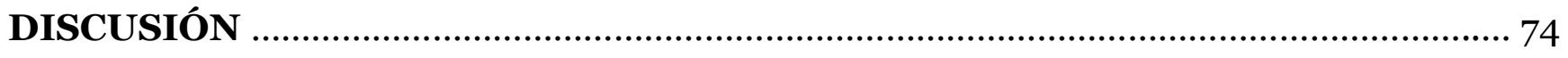

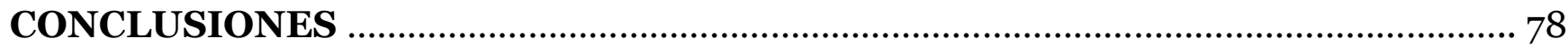

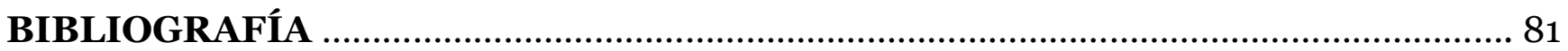


A la memoria de mi abuelo Miguelito, quien marcó mi vida para siempre 


\section{AGRADECIMIENTOS}

A mi directora Dra. Susana M. Mosca, a quien aprecio como una madre, por haberme abierto las puertas de su laboratorio, darme la posibilidad de aprender y progresar, su constante apoyo, comprensión y paciencia.

A Guillermo Schinella, por haberme enseñado muchas técnicas de ensayos realizados en el presente estudio, por su confianza en mi, sus consejos, las charlas, y fundamentalmente, por su amistad.

A mi co-directora Dra. Irene Ennis, por su su calidez y buena predisposición ante cualquier consulta.

A la Dra. Alicia Mattiazzi y al Dr Horacio E. Cingolani por haberme permitido trabajar en el Centro de Investigaciones Cardiovasculares.

A mis compañeras Juliana y Luisa, por su compañía, los momentos compartidos, y haber conformado un gran grupo de trabajo.

A Horacio Tournier, Daniel Fioravanti, Martín Dade, Daniela y Javier por haberme permitido utilizar su laboratorio, en donde realicé varios ensayos del presente trabajo, y hacerme sentir como uno más de su grupo.

A Gustavo, Alejandro, Martín, Omar, Mónica, Carolina, Romina, Yesica, Alejandro O, Luís, Gisel, Mariela, Lorena, Bernardo y Patricio; con quienes compartí gran parte de mis días en el CIC.

A Gustavo Rinaldi y Mariana Fritz por brindarme el lugar y los conocimientos para medir la presión arterial en los animales utilizados en este trabajo.

A Paulina, mi gran compañera, quien hace mis días más felices, por brindarme todo su amor y apoyo, y caminar a mi lado.

A mi madre, por su amor incondicional, su paciencia y constante ayuda. A mi padre, mis hermanos y al resto de la familia.

A mis amigos, por su lealtad, los momentos compartidos y enseñarme todos los días sobre la importancia y el significado de estos vínculos.

A Marina, quien semana tras semana colabora en la compleja tarea de conocer mas sobre nosotros mismos. 


\section{RESUMEN}

La información respecto a la respuesta del corazón aislado de ratas hipertensas espontáneas (SHR) a la isquemia-reperfusión y a los mecanismos de protección descriptos para ratas normotensas [pre y postacondicionamiento isquémicos (PI y PCI, respectivamente) y farmacológicos], es escasa. Por lo tanto, la participación de la vía PI3K/Akt/GSK-3 $\beta$ y del poro de permeabilidad transitoria de la mitocondria (PPTM) en los mecanismos responsables de la muerte ó la sobrevida de los cardiomiocitos de SHR, no están debidamente aclarados.

El objetivo general de este trabajo de tesis fue estudiar en corazones de SHR aislados y perfundidos con la técnica de Langendorff los efectos de la isquemia global (IG, $45 \mathrm{~min}$ )reperfusión (R, 60 min), del PI y PCI y del tratamiento con ClLi e IMI (inhibidores de GSK3ß) sobre el tamaño del infarto, el daño oxidativo, la sensibilidad del PPTM al $\mathrm{Ca}^{2+}$, la liberación de citocromo c al citosol y la ultraestructura mitocondrial.

El protocolo de IG-R produjo un tamaño del infarto de aproximadamente 50\% del área de riesgo y daño oxidativo, evidenciado por un aumento de la peroxidación lipídica (TBARS), una disminución marcada del contenido de GSH y un aumento de la actividad de SODT y SODMn. El contenido de P-GSK-3 $\beta$ y P-Akt y la sensibilidad del PPTM al $\mathrm{Ca}^{2+}$ disminuyeron, mientras que la expresión de citocromo c en el citosol aumentó. La microscopia electrónica reveló que la mayor parte de las mitocondrias estaban dañadas, con edema y destrucción de sus crestas. Las intervenciones PI y PCI y el tratamiento con los inhibidores de GSK- $3 \beta$ protegieron a los corazones de SHR de los daños antes mencionados. Por lo tanto, en los corazones intervenidos y tratados se observó una disminución del tamaño del infarto y del daño oxidativo evidenciado por la disminución de la peroxidación lipídica (TBARS), preservación parcial del contenido de GSH y disminución de la actividad de SODT y SODMn. La expresión de P-GSK $3 \beta$ y de P-Akt y de la sensibilidad del PPTM al $\mathrm{Ca}^{2+}$ aumentó mientras que el contenido de citocromo c en el citosol disminuyó. Por microscopia electrónica fue posible encontrar en estos grupos la presencia de algunas mitocondrias con ultraestructura conservada.

Los efectos beneficiosos del PI y PCI fueron anulados cuando la vía de señalización de $\mathrm{PI}_{3} \mathrm{~K} /$ Akt fue inhibida con wortmanina. Las variables mencionadas retornaron a los valores observados en los corazones isquémicos no tratados. 
De las relaciones examinadas surge que: a- el tamaño del infarto es mayor cuando la peroxidación lipídica aumenta y el contenido de GSH disminuye. En estas condiciones la sensibilidad del PPTM al $\mathrm{Ca}^{2+}$ es menor. La situación opuesta se da en presencia de intervenciones cardiorpotectoras. Por lo tanto, en ellas el tamaño del infarto es menor cuando la peroxidación lipídica disminuye y el contenido de GSH aumenta. En estas condiciones la sensibilidad del PPTM al $\mathrm{Ca}^{2+}$ tiende a recuperarse.

En base a los datos obtenidos se concluye que las alteraciones de la formación y/ó apertura del PPTM, participan y determinan la muerte ó la sobrevida celular en el corazón hipertrófico de SHR sometido a isquemia-reperfusión. Así, la disminución del tamaño del infarto obtenida con las intervenciones y/ó tratamientos utilizados fue el resultado de la disminución del daño oxidativo íntimamente asociada a la recuperación parcial de la integridad mitocondrial menor apertura del PPTM- vía P-Akt/P-GSK-3ß. Otro hallazgo interesante fue que la protección por el tratamiento con ClLi (fármaco ampliamente utilizado en psiquiatría) fue similar a la obtenida con las intervenciones de acondicionamiento isquémico (PI y PCI). Por lo tanto, esta droga podría ser una posible herramienta terapéutica para atenuar la injuria por isquemia $y$ reperfusión. 


\section{ABSTRACT}

Information regarding to the response to ischemia-reperfusion in isolated hearts from spontaneously hypertensive rats (SHR) as well as the effect of the protective mechanisms described in normotensive rats (ischemic and pharmacological pre and postconditioning, IP and IPC), is scarce. Therefore, the participation of $\mathrm{PI}_{3} \mathrm{~K} / \mathrm{Akt} / \mathrm{GSK}-3 \beta$ pathway and the mitochondrial permeability transition pore (mPTP) in the mechanisms responsible for cardiomyocyte death or survival are not properly clarified.

The objective of this investigation was to study in isolated hearts from SHR the effects of global ischemia (GI, $45 \mathrm{~min}$ ) and reperfusion (R, $60 \mathrm{~min}$ ), and the actions of IP, IPC, treatments with $\mathrm{LiCl}$ and IMI (GSK-3 $\beta$ inhibitors) on infarct size, oxidative damage, mPTP $\mathrm{Ca}^{2+}$ sensitivity, cytochrome $\mathrm{c}$ release to the cytosol and mitochondrial ultrastructure.

The protocol of GI-R produced an infarct size of approximately 50\%, increased oxidative damage as evidenced by an increase of lipid peroxidation (TBARS), a decrease of GSH content and an increase of Total SOD and MnSOD activity. The content of P-GSK- $3 \beta$ and P-Akt and the mPTP $\mathrm{Ca}^{2+}$ sensitivity decreased while the expression of cytochrome $\mathrm{c}$ in the cytosol increased. Electron microscopy showed that most of the mitochondria were damaged, presenting edema and destruction of the cristae.

IP, IPC and pharmacologic treatments with both GSK-3 $\beta$ inhibitors protected the hearts against reperfusion injury. Therefore, in the hearts treated we observed a smaller infarct size and reduced oxidative damage (decreased lipid peroxidation (TBARS), partial preservation of GSH and decreased Total SOD and MnSOD activity) compared to non-treated ischemic hearts. The P-GSK- $3 \beta$ and P-Akt expression and mPTP $\mathrm{Ca}^{2+}$ sensitivity increased while the cytosolic cytochrome c content decreased. By electron microscopy it was possible to find some mitochondria with normal ultrastructure.

The beneficial effects of IP and IPC were canceled when the PI3K/Akt was inhibited with wortmannin. All the parameters examined returned to the values observed in non-treated ischemic hearts.

Analyzing the relationships: Infarct size vs. TBARS and GSH, and mPTP $\mathrm{Ca}^{2+}$ sensitivity vs. Infarct size and TBARS, it arises that: the Infarct size increased when lipid peroxidation increased and GSH content decreased. Under these conditions the mPTP $\mathrm{Ca}^{2+}$ sensitivity 
decreased. The opposite situation occurs in the presence of the cardioprotective interventions. Therefore, the infarct size decreased when lipid peroxidation decreased and GSH content increased. Under these conditions the mPTP $\mathrm{Ca}^{2+}$ sensitivity tended to recover.

Based on the data obtained, we suggest that the alterations of formation and/or opening of the mPTP participate and determine cell death or survival in the hypertrophic heart of SHR subjected to ischemia-reperfusion. Thus, the reduction in infarct size obtained with the ischemic interventions and /or treatments derived from the decreased oxidative damage intimately linked to a partial recovery of mitochondrial integrity- less mPTP opening- via P-Akt/PGSK-3ß. Another interesting finding was that the protection by the treatment with LiCl (drug widely used in psychiatry) was similar to that obtained with ischemic interventions (IP and IPC). Therefore, this drug emerges as a potential therapeutic tool in reducing the post-ischemic changes. 
INTRODUCCIÓN 
La hipertensión arterial es una afección muy frecuente en el mundo occidental, siendo el principal factor de riesgo en la muerte relacionada con ataque cardíaco y/o accidente cerebro vascular. Se la puede definir como la presión arterial sistólica (PAS) igual o superior a $140 \mathrm{~mm}$ de $\mathrm{Hg}$, y/ó una presión arterial diastólica (PAD) igual o mayor a $90 \mathrm{~mm}$ de $\mathrm{Hg}$ (Chobanian y col., 2003). Se trata de un síndrome complejo genético y adquirido, con comprobadas implicancias metabólicas y electrolíticas. En el 90\% de los casos la causa es desconocida y se la conoce como "hipertensión arterial esencial". La hipertensión arterial esencial tiene un patrón hereditario importante, que con frecuencia permite reconocer el antecedente en uno o varios miembros de la familia (Tumberlake y col., 2001). Es el factor de riesgo más importante de la cardiopatía isquémica y muy especialmente del infarto del miocardio como así también de la enfermedad cerebro vascular, de la insuficiencia renal y de la insuficiencia arterial periférica. La hipertensión arterial en el hombre es usualmente un trastorno paulatino, cuya prevalencia aumenta con la edad y varía marcadamente con el género y la raza. Se la asocia también a ciertos hábitos de vida, como pueden ser un elevado consumo de sal en la dieta, la obesidad, el tabaquismo y la falta de ejercicio, actuando sobre una predisposición genética. Los genes específicos responsables de la hipertensión arterial no han sido identificados, pero se ha sugerido que una porción sustancial de la variación fenotípica en la presión sanguínea está determinada genéticamente. Los hipertensos con frecuencia desarrollan a largo plazo otros factores de riesgo cardiovascular, incluyendo elevados niveles de colesterol, reducida cantidad de lipoproteínas de alta densidad, diabetes mellitus, hipertrofia ventricular izquierda y obesidad.

La hipertrofia cardíaca es el aumento anormal de la masa cardiaca que se diferencia a nivel funcional, mecanístico, histológico y molecular del crecimiento embriogénico y postnatal normal del corazón. Ocurre en general en respuesta a situaciones de sobrecarga hemodinámica pudiendo de este compensar la sobrecarga de trabajo en los estadios iniciales. Sin embargo, en estadíos avanzados las propiedades diastólicas, y eventualmente sistólicas del ventrículo izquierdo se deterioran, constituyendo la hipertrofia cardíaca uno de los principales factores independientes de riesgo cardiovascular asociado al desarrollo de arritmias, insuficiencia cardiaca y muerte (Levy y col., 1990; Schillaci y col., 2000). La causa más común de hipertrofia cardíaca es la hipertensión arterial.

Dada la importancia de estas patologías cardiovasculares los objetivos de este trabajo de Tesis estuvieron dirigidos a estudiar los efectos de la isquemia-reperfusión y de distintas 
intervenciones en ratas hipertensas espontáneas (SHR), con la finalidad de hallar posibles herramientas terapéuticas.

\section{MARCO TEÓRICO}

\section{Mitocondria}

Las mitocondrias son organelas citoplasmáticas de aspecto variable (tubular, ovalado, esférico) cuyo tamaño oscila entre $0,5-1,0 \mu \mathrm{m}$ de diámetro y $1-7 \mu \mathrm{m}$ de longitud, con funciones que engloban desde el abastecimiento energético a la célula (en forma de ATP), hasta la regulación citoplasmática de los niveles de segundos mensajeros, tales como el $\mathrm{Ca}^{+2} \mathrm{y}$ las especies reactivas del oxígeno (ROS).

En los cardiomiocitos ocupan aproximadamente entre un 30-40\% del volumen celular (Murphy y Steenbergen, 2007). Su capacidad de asociación a microtúbulos las convierte en organelas móviles y plásticas, capaces de desplazarse por el citoplasma y adquirir la morfología y localización celular más adecuadas para que el aporte energético a la célula sea lo más eficiente posible.

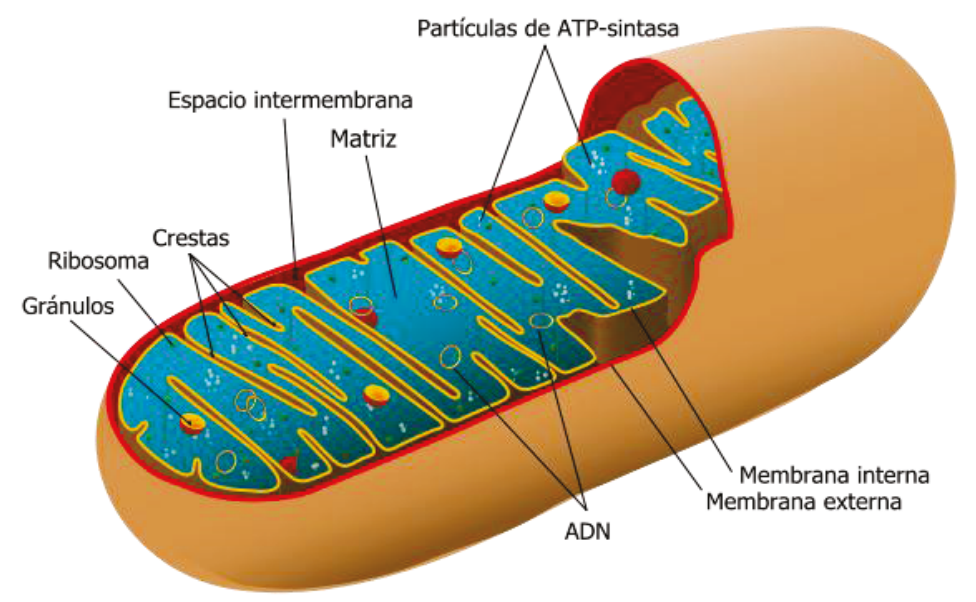

Figura 1: Estructura de una mitocondria

Las mitocondrias presentan una estructura con dos compartimentos bien definidos, matriz y espacio intermembrana, delimitados por dos membranas, interna y externa, con características morfológicas y funcionales muy diferentes (Figura 1). En la matriz se localizan 
varias copias del genoma circular mitocondrial, los ribosomas y numerosos complejos enzimáticos necesarios tanto para las funciones energéticas, como para la expresión y la replicación de genes. En el espacio intermembrana se localizan las enzimas que median el tránsito de sustancias entre la matriz mitocondrial y el citosol, y alguno de estos complejos presenta actividad quinasa. Del mismo modo, sus membranas ofrecen también diferencias significativas. La membrana interna se caracteriza morfológicamente por presentar unas invaginaciones denominadas "crestas", con multitud de complejos enzimáticos (los componentes de la cadena transportadora de electrones, entre los cuales encontramos a la ATP sintasa) y proteínas que regulan el paso de metabolitos (Figura 2).

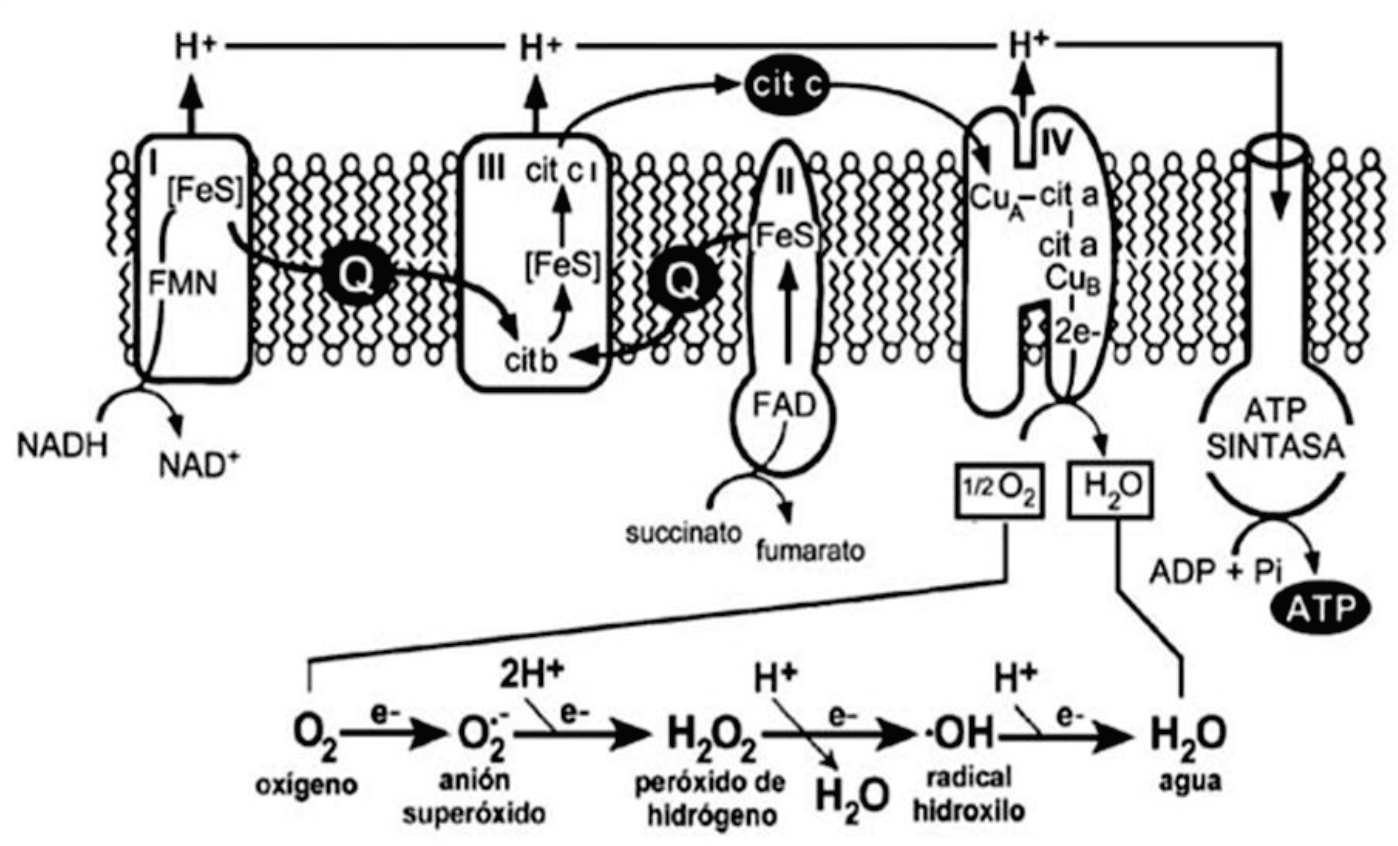

Figura 2: Cadena de fosforilación oxidativa de la mitocondria

La membrana mitocondrial interna resulta especialmente impermeable a iones gracias a su alto contenido del fosfolípido cardiolipina, característica esencial que le permite soportar el gradiente electroquímico necesario para el desempeño de la función energética. Por el contrario, la membrana externa carece de crestas mitocondriales y, en condiciones fisiológicas, es permeable al paso de iones y de metabolitos con pesos moleculares inferiores a $6 \mathrm{kDa}$. 


\section{Poro de permeabilidad transitoria mitocondrial (PPTM)}

El PPTM (Figura 3) es un canal complejo que se forma en la membrana mitocondrial conectando directamente la matriz con el citoplasma. Este megacanal inespecífico permite el paso de moléculas de hasta $1,5 \mathrm{kDa}$, y estaría formado por tres proteínas: el canal aniónico dependiente de voltaje (VDAC), la Adenina Nucleótido Translocasa (ANT) y la Ciclofilina D (CypD) (Muyphy y Steenbergen, 2007).

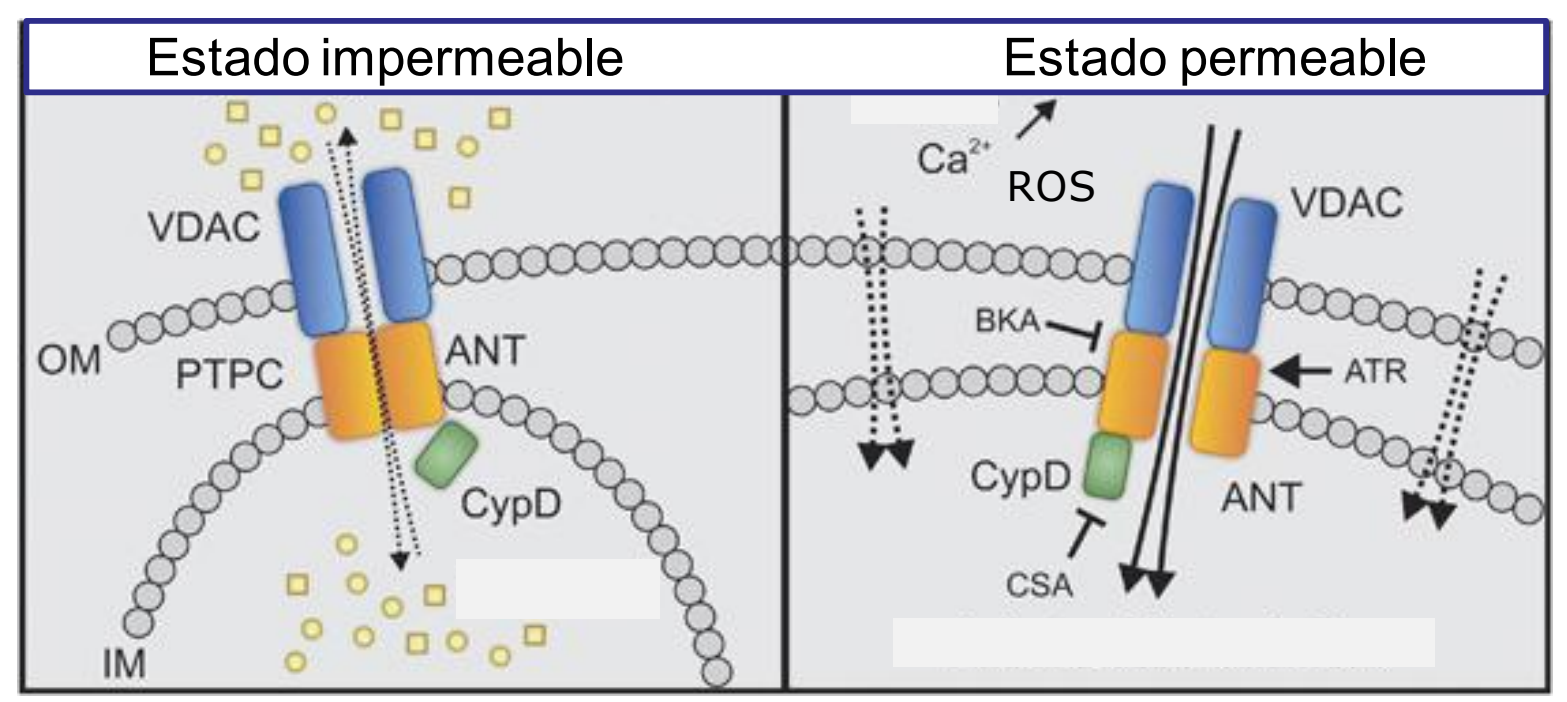

Figura 3: Esquema de los componentes del poro de permeabilidad transitoria de la mitocondria (PPTM) mostrando los estados impermeable (o cerrado) y permeable (o abierto). VDAC: canal aniónico dependiente de voltaje; ANT: adenina nucleótido translocasa; CypD: ciclofilina D. OM: membrana mitocondrial externa. IM: membrana mitocondrial interna. Inhibidores del PPTM: ácido boncréquico (BKA) y ciclosporina A (CsA). Activador del PPTM: atractilósido (ATR).

Canal aniónico dependiente de voltaje (VDAC): es la proteína de mayor abundancia en la membrana externa de la mitocondria. Posee un peso molecular de $36 \mathrm{kDa}$ y puede existir en distintos estados conformacionales de diferente selectividad y permeabilidad. Como su nombre lo indica es sensible al potencial de la membrana pero no es selectivo a iones, y puede transportar nucleótidos de adenina y $\mathrm{Ca}^{+2}$ entre otros metabolitos (Murphy y Steenbergen, 2007).

Adenina Nucleótido Translocasa (ANT): ubicada en la membrana interna de la mitocondria, tiene un peso molecular de $32 \mathrm{kDa}$. Su función es transportar ADP y ATP a través de la membrana interna mitocondrial y se une a CypD cuando se forma el poro. 
Ciclofilina D (CypD): Esta proteína tiene un peso molecular de $17 \mathrm{kDa}$, se encuentra en la matriz mitocondrial y posee actividad peptidilpropil cis-trans isomerasa. Posee un rol clave en la formación del poro.

\section{Isquemia- Reperfusión}

La isquemia miocárdica es, en la actualidad, la principal causa identificable de mortalidad y morbilidad cardiovascular en las sociedades occidentales. Se produce por un desequilibrio entre el aporte y la demanda de oxígeno. El daño del miocardio depende de la duración del período isquémico, siendo mayor cuando éste es más prolongado (Reimer y col., 1977).
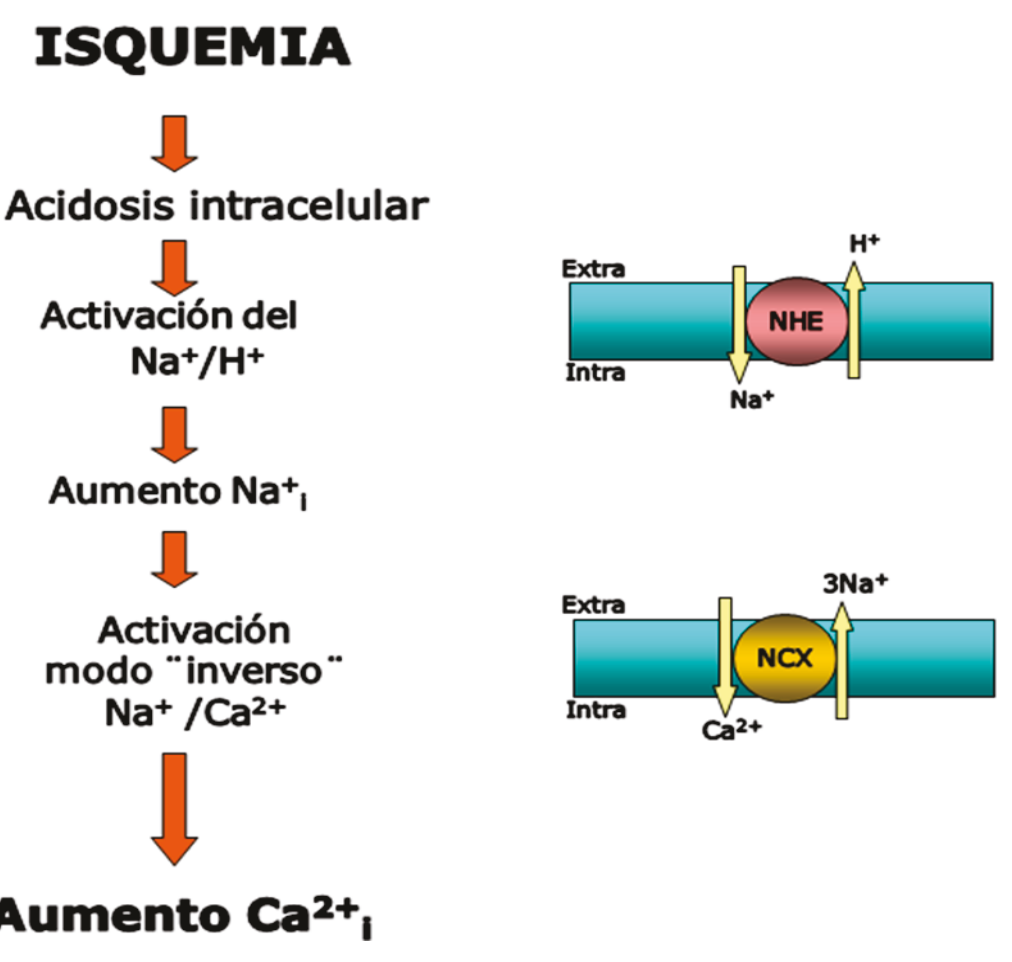

Figura 4: Eventos que ocurren durante la isquemia

Durante la isquemia, la ausencia de oxígeno o su escasa presencia en los tejidos, determina que el metabolismo aeróbico cese, dando lugar al metabolismo anaeróbico glicolítico. En este escenario, la demanda energética del cardiomiocito supera la energía aportada por la glicólisis anaeróbica y las reservas energéticas, con la posterior disminución de ATP y la creciente acumulación de ADP (Jennings y col., 1985). La acumulación de lactato y la disminución del 
pH intracelular por acumulación de $\mathrm{H}^{+}$, inhiben la glicólisis (Fleet y col., 1985). Además, la acidosis intracelular produce activación del intercambiador $\mathrm{Na}^{+} / \mathrm{H}^{+}$que transporta $\mathrm{H}^{+}$fuera de la célula y $\mathrm{Na}^{+}$hacia el interior (Tani y col., 1989; Levitsky y col., 2006). La acumulación intracelular de $\mathrm{Na}^{+}$lleva a la activación del intercambiador $\mathrm{Na}^{+} / \mathrm{Ca}^{2+}$ en su modo reverso, extruyendo $\mathrm{Na}^{+}$al medio extracelular y promoviendo la entrada de $\mathrm{Ca}^{2+}$ al medio intracelular (Tani y col., 1989; Eigel y col., 2004; Levitsky y col., 2006) (Figura 4). El $\mathrm{Ca}^{2+}$ libre intracelular se eleva en las etapas tardías de la isquemia, provocando hipercontractura miocárdica (Steenbergen y col., 1987; Inserte y col., 2002).

En la mitocondria, la ausencia de oxígeno produce un desacople en la fosforilación oxidativa aumentando los niveles de ácidos grasos no esterificados, como resultado del cese de su oxidación (Lopaschuk y col., 1990). La interrupción del ciclo de Krebs, permite la acumulación de NADH en el citoplasma, con un incremento de la relación NADH/NAD ${ }^{+}$.

\section{REPERFUSIÓN}

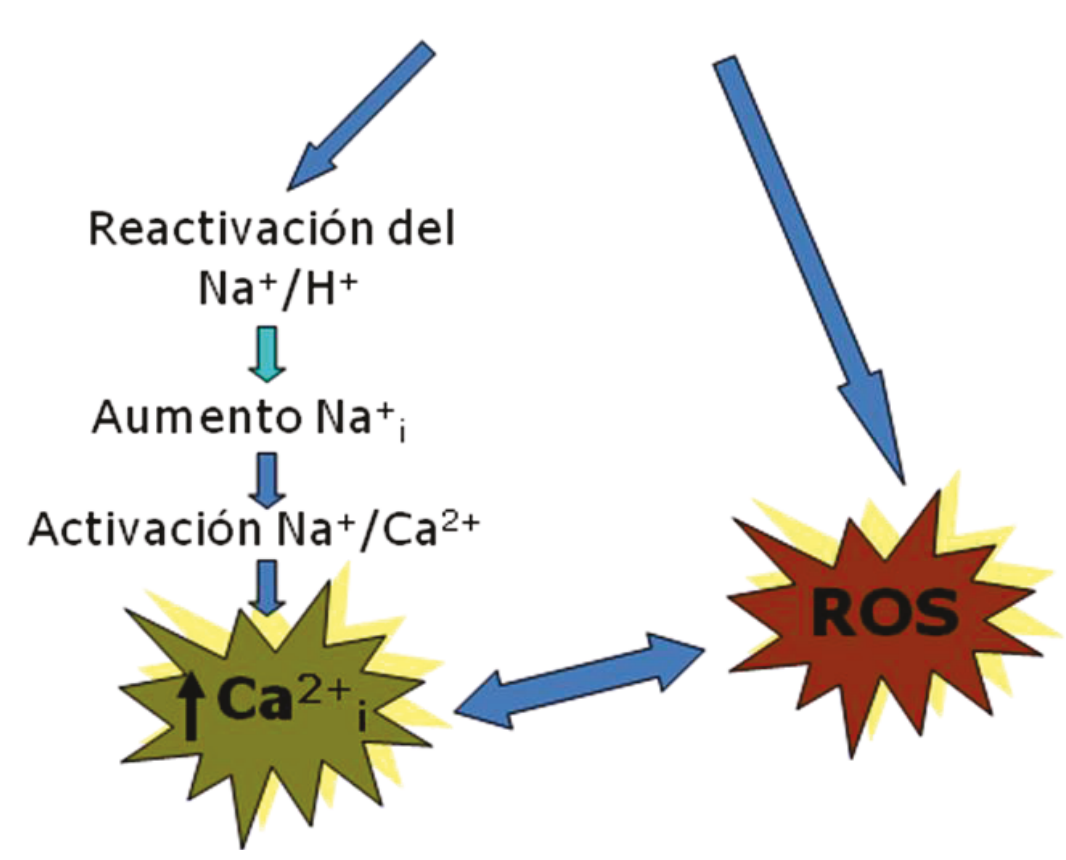

Figura 5: Acontecimientos que ocurren durante la reperfusión

La disminución de la oxidación produce la pérdida del potencial de membrana mitocondrial, acompañado de la disminución de la actividad del transportador de $\mathrm{Ca}^{2+}$ mitocondrial. La ATP 
sintasa comienza a funcionar como ATPasa y contribuye a la reducción de aproximadamente un $50 \%$ del ATP disponible.

La reintroducción de oxígeno (reperfusión) agrava la injuria isquémica. Por lo tanto, la sobrevida de los cardiomiocitos depende de los cambios moleculares que se generen durante la isquemia y durante la reperfusión (Halestrap y col., 2004; Levitsky, 2006; Piper y col., 1998; Hausenloy y col., 2004). En los primeros minutos de la reperfusión el lactato disminuye debido a su remoción por la circulación sistémica o por su oxidación a $\mathrm{CO}_{2}$ y $\mathrm{H}_{2} \mathrm{O}$, retornando el $\mathrm{pH}$ a los niveles basales rápidamente. En la mitocondria, a nivel de la cadena transportadora de electrones, se produce un daño en la actividad de los complejos I y III, generando especies reactivas del oxígeno (ROS). Este aumento en el desacople del metabolismo mitocondrial, se manifiesta como un exceso de oxidación de sustratos en comparación a la producción de energía, disminuyendo la eficacia metabólica en los corazones reperfundidos (Figura 5).

Aun cuando los eventos de isquemia y reperfusión involucran un gran número de moléculas y procesos celulares, el daño miocárdico resulta fundamentalmente de dos sucesos interrelacionados. $\mathrm{El}$ primero corresponde al aumento de $\mathrm{Ca}^{2+}$ intracelular secundario a la apertura o cierre de canales y la activación de transportadores de membrana; el segundo se debe al aumento de la producción de ROS.

Las alteraciones miocárdicas por isquemia-reperfusión dependen de la duración de la isquemia. Si la isquemia dura entre 15-20 minutos el daño miocárdico es reversible y se lo denomina "atontamiento", mientras que si la isquemia es mayor de 20 minutos ocurre la muerte celular conocida como "infarto" (Kloner y col., 1974; Jennings y col., 1990). La reperfusión contribuye a esta lesión letal. La idea de la lesión por reperfusión fue introducida por Jennings y col. (1990) quienes observaron alteraciones morfológicas significativas en la reperfusión que incluyen la hinchazón de los cardiomiocitos, edema mitocondrial, depósitos de fosfato de calcio, hipercontractura y la pérdida de la organización del sarcómero. En dicho trabajo los autores propusieron que la reperfusión podría acelerar la progresión de la injuria y/ó contribuir a la generación de nuevo daño.

El aumento de la concentración de $\mathrm{Ca}^{2+}$, el estrés oxidativo y la normalización del $\mathrm{pH}$ inducen la muerte celular, que dependiendo de la disponibilidad de ATP, puede ser del tipo "apoptosis" (niveles elevados de ATP) o "necrosis" (ausencia de ATP) (Kim y col., 2003; Piper y col., 1998; Halestrap y col., 2004). En los últimos años se ha centrado la atención en la 
mitocondria, ya que esta organela es considerada como el sitio donde convergen las diferentes vías de señalización y que, gracias a la capacidad de regular la permeabilidad de sus membranas, controla la liberación al citoplasma de señales capaces de activar cascadas proteicas que conducen a la muerte celular. Durante la isquemia el PPTM está cerrado debido a la acidosis generada, pero durante la reperfusión se establecen condiciones que favorecen su apertura (Griffiths y Halestrap, 1995).

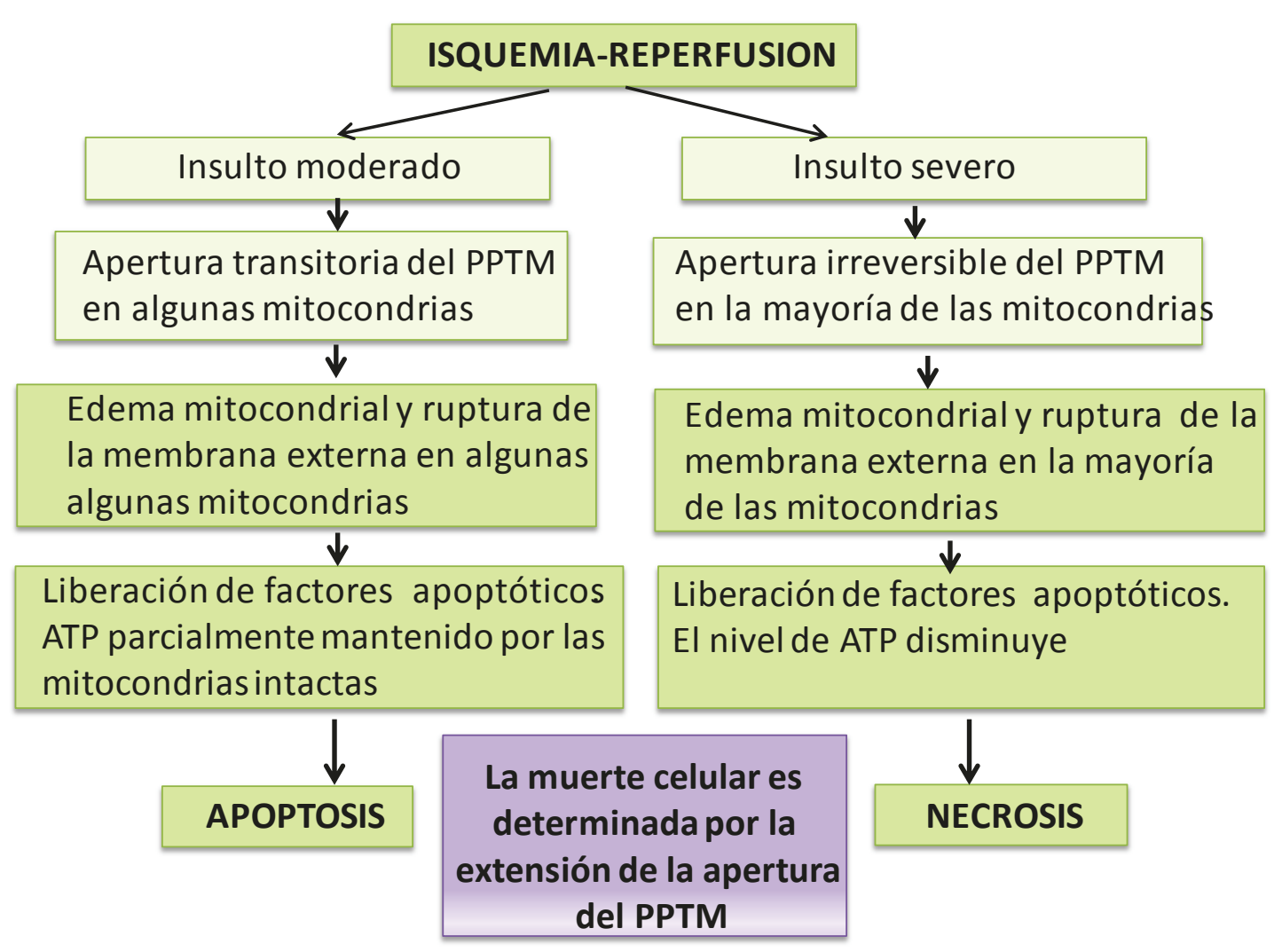

Figura 6: Cascadas que llevan a la muerte celular por isquemia-reperfusión

La sobrecarga de $\mathrm{Ca}^{+2}$ y el aumento de las ROS son los factores más importantes que desencadenan la formación y/ó apertura del PPTM. Aperturas transitorias del mismo

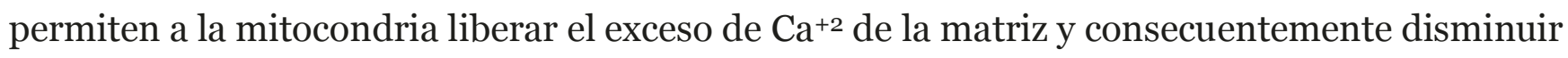
el daño miocárdico. En cambio, aperturas prolongadas provocan la permeabilización de las membranas mitocondriales, facilitando la liberación de ROS y factores pro-apoptóticos, entre ellos el citocromo c (Ott y col., 2007) provocando la muerte celular. En otras palabras, la 
apertura masiva del poro provoca un daño mitocondrial y miocárdico irreversible (Di Lisa y col., 2003; Crow y col., 2004; Halestrap y col., 2004) (Figura 6).

\section{Especies Reactivas del Oxígeno (ROS)}

Las ROS incluyen especies radicales y no radicales (Tabla 1). Por definición, un radical es una molécula o fragmento de molécula, que posee uno o más electrones desapareados en su orbital externo (van der Vliet y col., 1999). Esta propiedad le confiere una gran reactividad, brindándole una alta afinidad para reaccionar con moléculas de su entorno extrayendo o donando electrones con el fin de estabilizar sus orbitales externos.

Tabla 1. Principales especies reactivas del oxígeno (ROS) y nitrógeno (RNS)

\begin{tabular}{|c|c|c|c|}
\hline \multicolumn{2}{|c|}{ Radicales } & \multicolumn{2}{|c|}{ no Radicales } \\
\hline \multicolumn{4}{|c|}{ ROS } \\
\hline $\begin{array}{l}\text { Superóxido } \\
\text { Hidroxilo } \\
\text { Alcoxi } \\
\text { Peroxi } \\
\text { Lípido radical } \\
\text { Radical } \\
\text { carbonato }\end{array}$ & $\begin{array}{c}\mathrm{O}_{2}^{-{ }^{-}} \\
\mathrm{HO}^{\cdot} \\
\mathrm{RO}^{\circ} \\
\mathrm{ROO}^{\circ} \\
\mathrm{R}^{\cdot} \\
\mathrm{CO}_{3} \cdot-\end{array}$ & $\begin{array}{l}\text { Peróxido de hidrógeno } \\
\text { Hidroperóxidos } \\
\text { Hipoclorito } \\
\text { Oxígeno singlete } \\
\text { Ozono }\end{array}$ & $\begin{array}{c}\mathrm{H}_{2} \mathrm{O}_{2} \\
\mathrm{ROOH} \\
\mathrm{ClO}^{-} \\
{ }^{1} \mathrm{O}_{2} \\
\mathrm{O}_{3}\end{array}$ \\
\hline \multicolumn{4}{|c|}{ RNS } \\
\hline $\begin{array}{l}\text { Óxido nítrico } \\
\text { Dióxido de } \\
\text { nitrógeno }\end{array}$ & $\begin{array}{l}\mathrm{NO}^{*} \\
\mathrm{NO}_{2}\end{array}$ & $\begin{array}{l}\text { Peroxinitrito } \\
\text { Aducto } \\
\text { peroxinitrito } / \mathrm{CO}_{2}\end{array}$ & $\begin{array}{c}\mathrm{ONOO}^{-} \\
\mathrm{ONOOCO}_{2}\end{array}$ \\
\hline
\end{tabular}

El oxígeno molecular $\left(\mathrm{O}_{2}\right)$ es en sí mismo un radical libre, ya que posee una única configuración electrónica, con 2 electrones desapareados. Los dos átomos de oxígeno forman 
un enlace covalente doble, aportando cada átomo dos electrones. La reducción por un electrón de la molécula de di-oxígeno da lugar a la unión de dicho electrón con uno de los electrones desapareados, iniciando la producción de ROS. La reactividad del di-oxígeno es relativamente escasa debido a que los electrones apareados giran en sentido contrario neutralizándose su reactividad. Por acción de las radiaciones ionizantes, el espín de un electrón puede cambiar, lo que le confiere propiedades paramagnéticas y una gran reactividad al oxígeno al transformarlo en una molécula altamente reactiva llamada "oxígeno singulete".

La reducción del oxígeno mediante la transferencia de un electrón, produce el "anión superóxido ${ }^{*}\left(\mathrm{O}_{2}{ }^{-}{ }^{-}\right)$(Figura 7,1$)$. Existen diversas fuentes de producción de $\mathrm{O}_{2}{ }^{-}$siendo la más importante la generada en la mitocondria en la cadena de transporte de electrones. Aproximadamente 1-3\% de todos los electrones generados en la cadena de transporte escapan para generar $\mathrm{O}_{2}{ }^{-}{ }^{-}$y $\mathrm{H}_{2} \mathrm{O}_{2}$ (Buonocore y cols, 2010).

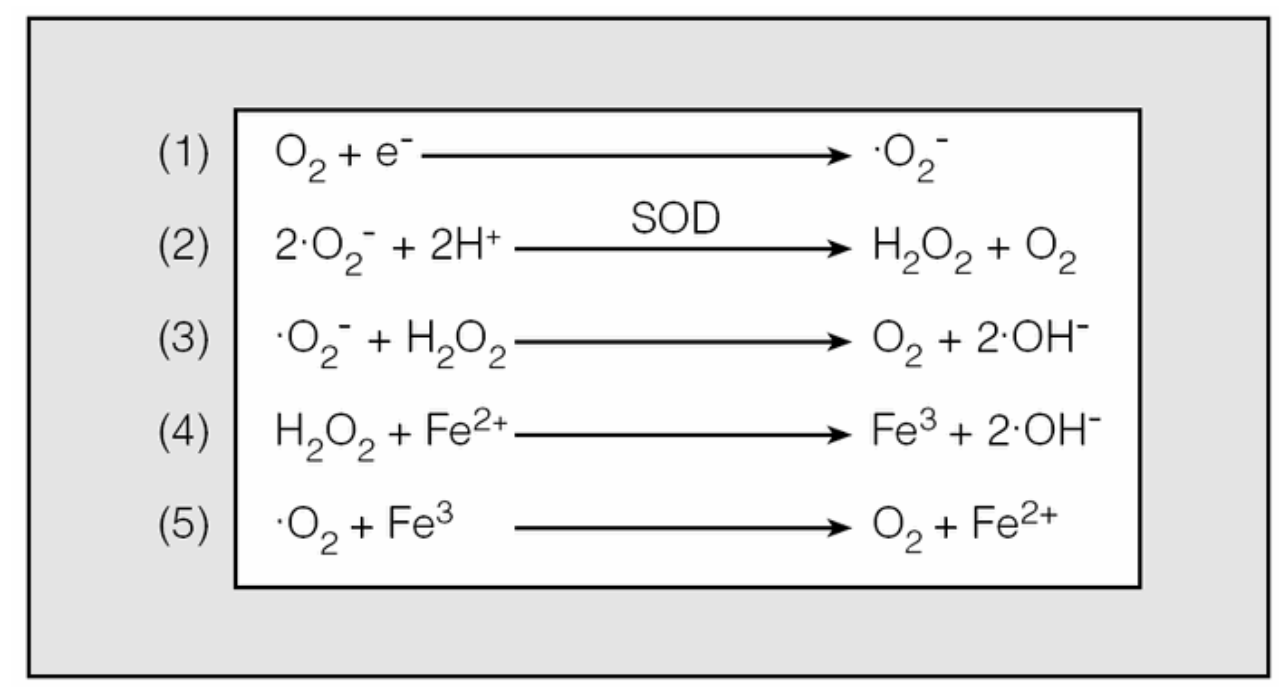

Figura 7: Vías de producción de ROS

El $\mathrm{O}_{2}{ }^{-}$es relativamente poco reactivo, pero potencialmente tóxico, ya que puede iniciar reacciones que dan lugar a otros intermediarios a su vez muy reactivos. De hecho, es considerado como la especie primaria de las ROS, pudiendo interactuar con otras moléculas para generar las secundarias (Valko y cols, 2007). La reducción por ganancia de dos electrones en el oxígeno molecular puede generar peróxido de hidrógeno $\left(\mathrm{H}_{2} \mathrm{O}_{2}\right)$.

En los sistemas biológicos dos moléculas de $\mathrm{O}_{2}{ }^{-}$reaccionan y dan como resultado $\mathrm{H}_{2} \mathrm{O}_{2}$ y $\mathrm{O}_{2}$ (Figura 7, 2). Esta reacción de dismutación puede darse espontáneamente, siendo catalizada 
por la presencia de la enzima superóxido dismutasa (SOD) (Cheeseman y Slater, 1993). El "radical hidroxilo" ('OH), la ROS más reactiva, resulta de la combinación del $\mathrm{H}_{2} \mathrm{O}_{2}$ con el $\mathrm{O}_{2}{ }^{-}$ (Figura 7,3 ) o de la descomposición del $\mathrm{H}_{2} \mathrm{O}_{2}$ en presencia de iones metálicos, como el $\mathrm{Fe}^{2+}$ (Figura 7, 4).

Existen también las especies reactivas derivadas del nitrógeno (RNS), dentro de las cuales las más relevantes son el óxido nítrico (NO) y el peroxinitrito (ONOO-), producto de la reacción entre $\mathrm{NO}$ y $\mathrm{O}_{2}{ }^{-}$.

\section{Estrés oxidativo}

El estrés oxidativo se define como un desequilibrio entre la producción y la remoción de ROS (Figura 8).

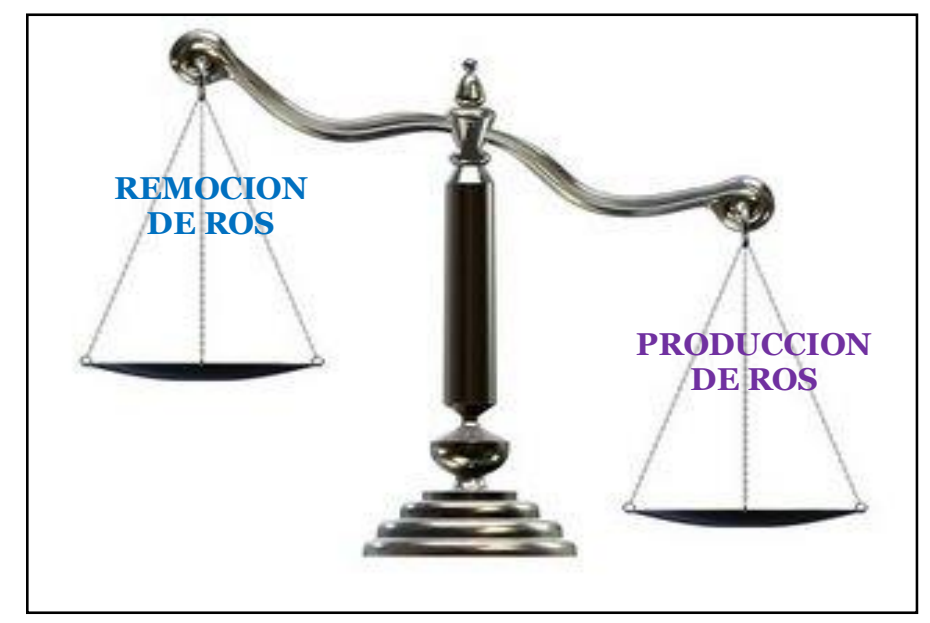

Figura 8: Desequilibrio entre la producción y la remoción de ROS

Puede originarse por un exceso de sustancias pro-oxidantes, una deficiencia de agentes antioxidantes, o la combinación de ambos factores (Valko y col., 2007).

A elevadas concentraciones, las ROS producen daño a estructuras celulares, ácidos nucleicos (Klaunig y Kamendulis, 2004), lípidos (Andreadou y col., 2009) y proteínas (Venardos y col., 2007). El producto de este daño molecular es, en general, mucho más estable que las ROS y por ello se utilizan como biomarcadores del estrés oxidativo. 
Los lípidos, y particularmente los ácidos grasos poliinsaturados, son los más susceptibles al ataque de las ROS (Cheeseman y Slater, 1993). Este proceso, denominado "peroxidación lipídica”, consiste en una reacción en cadena que comienza con el secuestro de un hidrógeno de un ácido graso que así es convertido en un radical libre (radicales alquilo, peroxilo e hidroperoxilo) y que a su vez secuestra el hidrógeno de otro ácido graso y así sucesivamente. Esto da lugar a la formación de un gran número de especies reactivas que atacan, sobre todo, grupos "aldehído", siendo el malondialdehído el producto más abundante de la peroxidación lipídica. Este compuesto es el marcador de estrés oxidativo más ampliamente utilizado como indicador de daño lipídico (Halliwell, 2000). La peroxidación de las membranas lipídicas produce alteraciones de sus propiedades biofísicas, de su grado de fluidez y puede conducir a la inactivación de los receptores de membrana que en conjunto alteran la función celular (Montuschi y col., 2004).

La célula, tiene varios mecanismos para restablecer el equilibrio entre las formas oxidadas y reducidas (ambiente redox). El mayor mecanismo implicado en esta regulación se basa en la inducción por las ROS de un aumento en la expresión de enzimas antioxidantes. Las proteínas y aminoácidos también contribuyen al restablecimiento del estado redox (Droge, 2002).

El estrés oxidativo tiene un papel muy importante en la fisiopatología de la injuria miocárdica por isquemia-reperfusión y por ello ha sido implicado en los mecanismos del atontamiento miocárdico, en la alteración microvascular, en las arritmias y en la muerte celular (Griendling y FitzGerald, 2003; Papaharalambus y Griendling, 2007; Ravingerová y col., 1999; Kalaycioglu y col., 1999).

Durante la isquemia, aún en los modelos de isquemia global, la concentración de oxígeno no desciende inmediatamente a cero, de tal manera que en el inicio es posible que se generen ROS, lo que ha sido observado en cardiomiocitos y en corazones aislados (Becker, 2004; Becker y col., 1999; Kevin y col., 2003). Sin embargo, los niveles de ROS durante la isquemia son escasos y desempeñan un papel importante en la señalización de cascadas cardioprotectoras (Carmody y Cotter, 2001; Vanden Hoek y col, 1998).

Las ROS son producidas en grandes cantidades en los primeros minutos de la reperfusión (Hare y Stamler, 2005; Mason y col., 2000) y contribuyen a la muerte celular (Becker, 2004; Murphy y Steenbergen, 2008; Ambrosio y col., 1991). 


\section{Sistemas Antioxidantes}

Estos sistemas comprenden a todas aquellas sustancias que, hallándose presentes en bajas concentraciones respecto a las de un sustrato oxidable (biomoléculas), retardan o previenen la oxidación de dicho sustrato. Los sistemas antioxidantes se dividen en dos grupos: enzimáticos y no enzimáticos. Los antioxidantes enzimáticos están representados por las isoformas de SOD, glutatión peroxidasa (GPx) y catalasa. La SOD cataliza la dismutación del $\mathrm{O}_{2}{ }^{-}$en $\mathrm{H}_{2} \mathrm{O}_{2}$ y $\mathrm{O}_{2}$. Su actividad fue descripta por primera vez por McCord y Fridovich en 1969. Se distinguen 2 isoformas en función del ion metálico de transición que encontremos en su estructura: CuZn-SOD, presente en el citosol y en el medio extracelular, y Mn-SOD, ubicada en la mitocondria (Figura 9).

$$
2 \mathrm{O}_{2}{ }^{-}+2 \mathrm{H}^{+} \sum \mathrm{H}_{2} \mathrm{O}_{2}+\mathrm{O}_{2}
$$

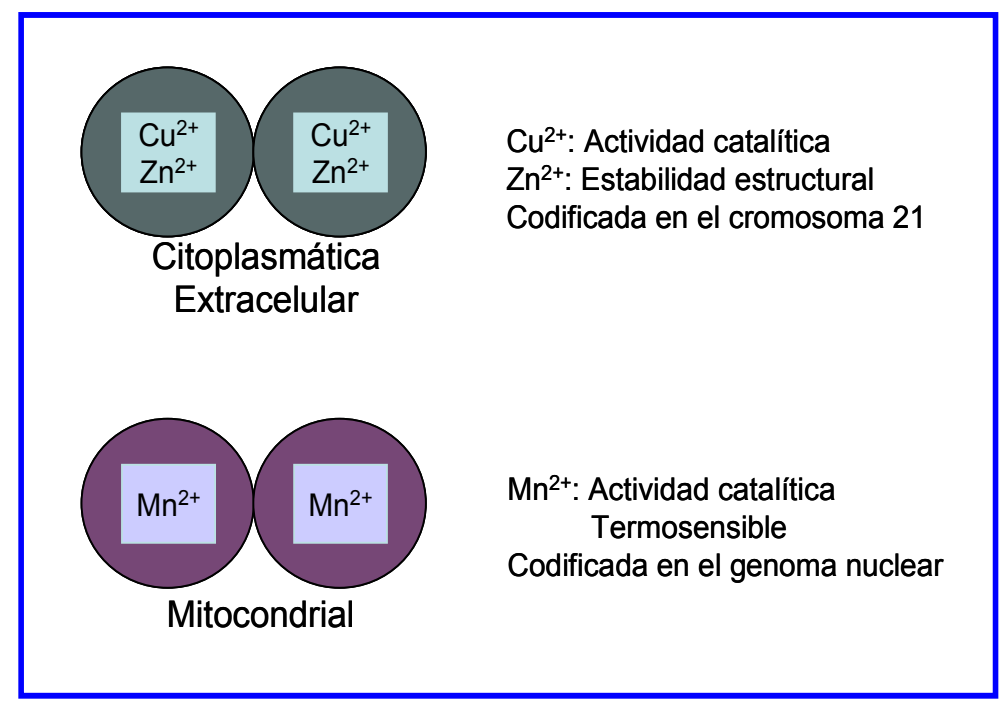

Figura 9: Isoformas de la enzima superóxido dismutasa

La GPx es la principal enzima eliminadora de hidroperóxidos orgánicos. La mayor parte se encuentra en el citosol, aunque también está presente en la matriz mitocondrial (Ketterer 1986). Existen dos isoformas y ambas requieren glutatión como dador de electrones.

La catalasa, al igual que la GPx, participa en la eliminación del $\mathrm{H}_{2} \mathrm{O}_{2}$ (Chance y cols, 1979) y se encuentra fundamentalmente en los peroxisomas. 
Entre los sistemas antioxidantes no enzimáticos están las vitaminas $\mathrm{E}$ y C, carotenoides, ubiquinona y se destaca el glutatión, un tripéptido formado por los aminoácidos ácido Lglutámico, L-glicina y L-cisteína (Glu-Gly-Cys) (Figura 10).

En su forma reducida (GSH) presenta un grupo tiol libre (-SH), que corresponde a la cisteína y es el que interviene en las reacciones redox (Viña y col., 1992). Las células eucariotas tienen 3 grandes reservorios de GSH: el citosol (85-90\%), las mitocondrias (10\%) y un pequeño porcentaje en el retículo endoplasmático (Lu, 2009). El GSH puede actuar sobre las ROS en forma directa o a través de reacciones enzimáticas.

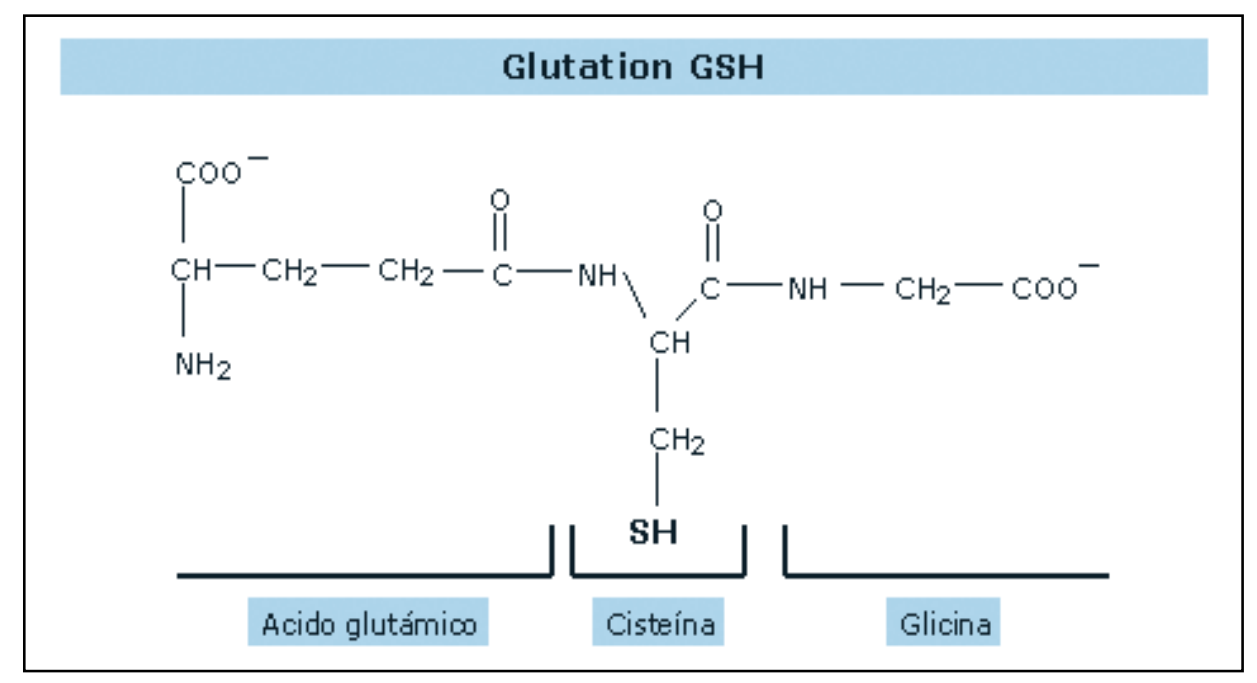

Figura 10: Estructura química del glutatión reducido (GSH)

\section{Estrategias cardioprotectoras del daño por isquemia-reperfusión}

\section{Preacondicionamiento Isquémico}

Numerosos trabajos señalan como un efectivo mecanismo cardioprotector al fenómeno llamado preacondicionamiento isquémico (PI, Figura 11), descripto por Murry y col. en el año 1986. Esta intervención consiste en la aplicación de breves episodios de isquemia seguidos de reperfusión, aplicados previamente a una isquemia más prolongada, con el objetivo de disminuir las alteraciones ocasionadas por la isquemia-reperfusión (Yellon y col., 1998; Yellon y Downey, 2003). 


\section{Isquemia Reperfusion}

Figura 11: Esquema del PI

La gran reproducibilidad de este fenómeno, utilizando una amplia variedad de protocolos experimentales, hizo que el PI sea considerado un mecanismo muy importante para la cardioprotección. Debido a que el PI requiere una intervención que tiene que ser implementada antes del inicio de la isquemia, su aplicación clínica ha sido, en gran parte, restringida a situaciones específicas, como la cirugía cardíaca, el trasplante cardíaco o incluso la angioplastía, en las que la injuria isquémica puede ser prevista.

Si bien los mecanismos del PI no están totalmente dilucidados, trabajos previos demuestran la presencia de múltiples vías de señalización que regulan el balance crítico entre la muerte y la sobrevida celular durante la isquemia-reperfusión. Se ha descrito la existencia de una "fase trigger ó gatillo " que estaría representada por la liberación de ligandos cardioprotectores y su fijación a receptores de membrana para activar vías de señalización intracelular. Una de las vías que lleva a la protección es la de la fosfoinositol- 3-quinasa ( $\mathrm{PI}_{3} \mathrm{~K}$ ) (Mocanu y Yellon, 2007), también conocida como la vía de salvataje de las lesiones de reperfusión, conocidas como RISK. Esta vía se compone de un receptor tirosina quinasa (RTK) que se activa mediante uno de los siguientes ligandos: factor de crecimiento epidérmico (EGF), factor de crecimiento de tipo insulina (IGF) y factor de crecimiento epidérmico humano 2 (HER2). La activación de RTK involucra a la PI3K, que se compone de dos subunidades: 110 a y p85 y que fosforila al fosfatidilinositol 4,5-bifosfato (PIP2) para dar fosfatidilinositol 3,4,5-trifosfato (PIP3), que recluta y permite la activación de la quinasa Akt (también llamada PKB). Akt es fosforilada por una proteína quinasa fosfoinosítico-dependiente (PDK1 y PDK2) que la activa. A su vez, Akt fosforila a la glucógeno sintetasa quinasa- $3 \beta$ (GSK- $3 \beta$ ) y la inactiva (Tong y col., 2002). Otras quinasas, tales como la proteína quinasa C (PKC) pueden ser activadas y así promover la protección y la supervivencia celular (Liu y col., 1994; Downey y col., 2007; García-Echeverría y Sellers, 2008). En isquemia-reperfusión la activación de PI3K protege a través de fosforilar e inactivar proteínas pro-apoptóticas y evitar la liberación del citocromo c 
al citosol, conservando el potencial de membrana mitocondrial (Hausenloy y Yellon, 2004; Hausenloy y col., 2004).

\section{Postacondicionamiento isquémico}

La existencia del daño letal por reperfusión es fuertemente apoyada por evidencias de la reducción del tamaño del infarto que se consigue mediante intervenciones que se aplican al inicio de la reperfusión. En este sentido, Zhao y col. (2003) mostraron que la aplicación de breves períodos de isquemia seguidos de reperfusión, al inicio de la reperfusión, era capaz de reducir el tamaño del infarto. Este fenómeno, llamado postacondicionamiento isquémico (PCI, Figura 12), ha proporcionado una herramienta que puede ser aplicada en el momento de la reperfusión, lo cual facilita su implementación en pacientes con infarto agudo de miocardio (Laskey, 2005; Staat y col., 2005; Thibault y col., 2008; Zhang y col., 2007).

\section{Isquemia}

Figura 12: Esquema del PCI

En estos estudios se demostró que si en la angioplastía se interrumpe la reperfusión miocárdica con ciclos de 1 min de inflaciones y deflaciones del globo, la perfusión miocárdica mejora, el tamaño del infarto se reduce y la fracción de eyección ventricular izquierda mejora. Sin embargo, se requiere de mayor investigación para determinar si verdaderamente el PCI tiene la capacidad de mejorar los resultados clínicos.

En cuanto a los mecanismos de protección, existen estudios que muestran que el PI y el PCI utilizan vías de señalización similares, y que ligandos involucrados en el PI, tales como la adenosina, también son capaces de inducir el PCI (Hausenloy y Yellon, 2007). Evidencias recientes sugieren que el objetivo de las quinasas que participan en dichas vías es la inhibición de la permeabilidad de la membrana mitocondrial interna, a través de la inhibición de la apertura del PPTM (Juhaszova y col., 2004; Davidson y col., 2006; Bopassa y col., 2006; 
Obame y col., 2008; Argaud y col., 2005; Smith y col., 2006; Feng y col., 2005; Pagel y col., 2006).

Aunque el mecanismo por el cual las quinasas inhiben al PPTM no está claro, se han propuesto y demostrado varios que podrían actuar en conjunto. Estos incluyen la generación de NO (Burwell y Brookes, 2008), la apertura de los canales mitocondriales de $\mathrm{K}^{+}$ dependientes de ATP (mitoKATP) (Murphy y Steenbergen, 2008; Costa y col., 2006), la fosforilación y/o formación de complejos con proteínas citosólicas, como PKC (Baines y col., 2003; Weiss y col., 2003) y la inhibición a través de la fosforilación en el residuo Ser9 de GSK$3 \beta$ (Juhaszova y col., 2004; Davidson y col., 2006; Bopassa y col., 2006; Obame y col., 2008). También ha sido descripto que dentro de las maniobras de protección del pre y postacondicionamiento isquémicos está la disminución de la producción de ROS (Kin y col., 2004; Penna y col., 2008).

\section{Preacondicionamiento y postacondicionamiento farmacológicos}

El conocimiento de las quinasas involucradas en las vías de protección del PI y PCI constituye una base sólida para la búsqueda de técnicas y agentes farmacológicos, cuya acción estaría ligada a la activación y /ó inactivación de algunos de los elementos participantes de dichas cascadas, para disminuir los daños por reperfusión.

Downey y col. (2007) mostraron que la estimulación de receptores de membrana dependientes de proteína $\mathrm{Gi}$ desencadena la ruta de activación de quinasas que limitan el riesgo miocárdico producido por los procesos de isquemia-reperfusión. Hausenloy y Yellon (2004) han revisado recientemente diversos agentes farmacológicos que activan la vía RISK cuando se administran durante la reperfusión miocárdica. Por ejemplo, cuando se administra insulina, factor de crecimiento similar a la insulina (IGF-1), factor de crecimiento transformante $\beta 1$ (TGF- $\beta 1$ ) o cardiotrofina-1 en la fase temprana de la reperfusión, se observa reducción del tamaño del infarto y de la apoptosis. Además, las quinasas p42/p44 MAPK (también conocidas como ERK1/2) activadas por fosforilación, se correlacionan temporalmente con la administración de los agentes antes mencionados y su eficacia en la reducción de tamaño del infarto, lo que llevó a la conclusión de que la capacidad de protección tiene que ver con la vía RISK (Baxter y col., 2001, Brar y col., 2001, Sack y Yellon, 2003; Hausenloy y Yellon, 2004). Cuando se administra estatinas durante la reperfusión temprana, 
tales como atorvastatina (un hidroxilo-3-metilglutaril (HMG) co-enzima-A (CoA) reductasa) también se induce la cardioprotección (Bell y Yellon, 2003a). La reducción resultante en el tamaño del infarto se asoció con un aumento de los niveles de P-Akt y de la enzima óxido nítrico sintasa endotelial (NOSe) conocidas como uno de los blancos de Akt (Bell y Yellon, 2003b). Gross y col. (2004) y Weihrauch y col. (2005) encontraron que los opioides fosforilan la GSK-3 $\beta$ (Serg) inactivándola y de esta manera promoviendo la protección de los cardiomiocitos.

Del mismo modo, la activación farmacológica de los mitoKATP puede atenuar el daño del miocardio inducido por isquemia-reperfusión mediante el control de la formación de ROS. Así, varios estudios han demostrado que la apertura del mitoKATP por diazóxido es cardioprotectora (Garlid y col., 1997; O'Rourke, 2004), aunque todavía existe controversia con respecto a los mecanismos subyacentes. Finalmente, varios abridores farmacológicos de los mitoKATP, tales como bimakalim, cromakalim, apricalium, el nicorandil y el pinacidil, también inducen cardioprotección (Yao y Gross, 1994; Yao y col., 1997; Grover y Garlid, 2000).

En los últimos años se ha centrado la atención en la GSK-3 $\beta$. Esta quinasa de residuos serina/treonina constitutivamente activa, aislada hace más de 2 décadas, fosforila e inactiva a la glucógeno sintetasa (Frame y Cohen, 2001). Ejerce, además, otros múltiples efectos, actuando a nivel de más de cuarenta sustratos, jugando un rol importante no sólo en el metabolismo del glucógeno, sino también en la proliferación, crecimiento y muerte celular (Harwood, 2001). En el sistema cardiovascular, esta enzima participa de la génesis de hipertrofia de los cardiomiocitos y de la muerte celular (Hardt y Sadoshima, 2002).

En contraste con la mayoría de las serina/treonina quinasas, la actividad de la GSK-3 $\beta$ se reduce por fosforilación y aumenta por desfosforilación. La actividad de esta enzima es determinante en el umbral para la formación y/o apertura del PPTM, disminuyendo su apertura cuando está fosforilada en el residuo Ser9 (Juhaszova y col., 2004). Uno de los mecanismos recientemente descritos es el de su localización en distintos compartimentos celulares. Aunque GSK-3 $\beta$ sea considerada una proteína citoplasmática, ésta puede translocarse al núcleo y también se ha descrito su localización mitocondrial (Bijur y Jope, 2003; Jope, 2003; Jope y Johnson, 2004). Sin embargo, la fosforilación, por distintas quinasas y en distintos residuos, es el mecanismo más conocido de regulación de la actividad de la enzima. La fosforilación en el residuo Ser9 puede ser mediada por PI3K/Akt, proteína 
quinasa A (PKA) ó PKC y lleva a su inhibición por bloqueo del centro activo de la quinasa (Jope y Johnson, 2004; Zurashvili y col., 2013). Por otra parte, la autofosforilación ó la fosforilación en el residuo tirosina 216 llevan a la activación de la quinasa.

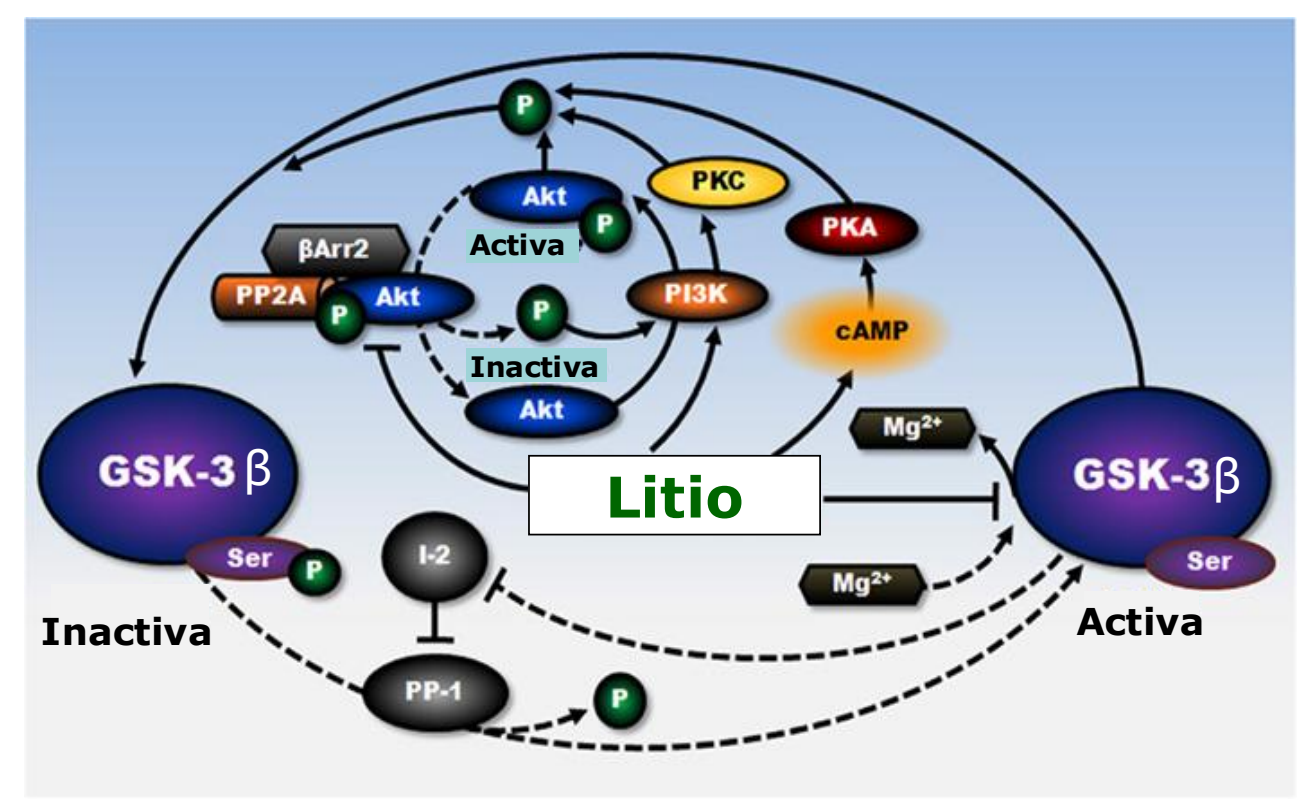

Figura 13: Estados activo e inactivo de GSK-3ß y Akt. Acción del Litio

El litio (Li) ha sido usado en la clínica por más de 60 años y todavía es una de las drogas primarias empleadas en el tratamiento de desórdenes bipolares (Altamura y col., 2011). Diversos trabajos muestran que el tratamiento con $\mathrm{Li}$ disminuye el daño cerebral postisquémico (Li y col., 2011; Xu y col., 2003). Si bien el mecanismo protector contra la injuria por reperfusión ejercido por el Li no está completamente dilucidado, dicha droga parece poseer dos funciones inhibitorias: una es la inhibición directa de la actividad de GSK$3 \beta$ por inhibición competitiva con el $\mathrm{Mg}^{2+} \mathrm{y}$ la otra es la inhibición indirecta de la GSK-3 $\beta$ a través de favorecer su fosforilación (Jope, 2003) (Figura 13). El tratamiento con Cloruro de Li $y$ otros inhibidores de GSK-3 $\beta$ también resultaron ser beneficiosos en modelos de isquemiareperfusión miocárdica realizados en corazones de ratas hiperlipidémicas (Yadav y col., 2010) y de ratas normotensas (Faghihi y col., 2008). 
Estudios previos realizados en corazones aislados muestran que el tratamiento con ciclosporina A (CsA, ver Figura 3), un inhibidor de la formación del poro, mejora la función miocárdica postisquémica y disminuye el tamaño del infarto (Griffiths y Halestrap, 1993).

\section{La rata hipertensa espontánea (SHR) como modelo de hipertensión}

La cepa SHR es usada como modelo experimental de hipertensión esencial (Folkow y col., 1970). La línea fue desarrollada en la década del 60 en la Universidad de Kyoto (Japón) a partir de un grupo de ratas exocriadas de la cepa Wistar seleccionando aquellos animales de PAS mayor a $150 \mathrm{~mm} \mathrm{Hg}$ (Okamoto y col., 1963). En forma similar a lo que se observa en los humanos, los machos de la línea SHR desarrollan la enfermedad en forma más severa y prematura y por lo tanto son el modelo de elección más adecuado. Esta cepa ha sido utilizada por más de 30 años para la prueba de nuevos fármacos anti-hipertensivos (Frohlich, 1986; Dickhout y Lee, 1998).

En un trabajo previo realizado en nuestro laboratorio se demostró que las SHR desarrollan hipertensión arterial a partir de los 40 días de edad y la hipertrofia cardíaca es significativa a partir de los 4 meses (Alvarez y col., 2008). En este trabajo también se puso de manifiesto la presencia de un daño oxidativo importante en esta cepa de ratas.

La respuesta hipertrófica o remodelamiento hipertrófico, es el resultado de la estimulación de múltiples vías de señalización intracelular que alteran la transcripción génica (Frey y col., 2004 a; Frey y col, 2004 a) promoviendo modificaciones a nivel celular y molecular que se manifiestan mediante una serie de cambios morfológicos y funcionales. Trabajos previos describen que la respuesta hipertrófica lleva a la alteración de genes que codifican proteínas involucradas en la homeostasis del $\mathrm{Ca}^{2+}$ y del $\mathrm{Na}^{+}$(Feldman y col., 1993; Johnatty y col., 2000).

Los animales hipertróficos presentan distinto comportamiento frente a la isquemiareperfusión dependiendo del diseño experimental usado y especialmente de la edad de los animales. Los animales seniles muestran una susceptibilidad al daño por isquemia y/o reperfusión aumentada (Allard y col., 1994; Snoeckx y col., 1993). Sin embargo, cuando se usan animales adultos jóvenes, con moderada hipertrofia cardíaca, los resultados no son tan concluyentes. Existen datos previos que muestran que los animales presentan en algunos casos una disminuída (Grover y col., 1996; Haneda y col., 1986) y en otros una similar 
(Hoffmeister y col., 1998) recuperación postisquémica con respecto a corazones de ratas normales. En un trabajo reciente realizado en nuestro laboratorio demostramos que la tolerancia a la isquemia-reperfusión de las SHR adultas jóvenes es menor y la muerte celular es mayor que en las ratas normotensas cuando el período de isquemia es más prolongado (Fantinelli y col., 2013).

En cuanto al PI, en una investigación previa se describe la pérdida de esta protección en condiciones patológicas, una de las cuales es la hipertensión arterial (Balakumar y col., 2009). Existen también otros trabajos que muestran los efectos beneficiosos del PI en el miocardio hipertrófico (Pantos y col., 1996; Boutros y Wang, 1995; Nakagawa y col., 1997). Sin embargo, los mediadores responsables de dicha protección no han sido totalmente identificados. En el estudio reciente realizado por Fantinelli y col. (2013) se pone en evidencia la participación del NO y de los mitoKATP en el PI.

Con respecto a los efectos del PCI en SHR existen datos recientes contradictorios: un trabajo demuestra la acción beneficiosa de esta intervención (Penna y col., 2010) mientras que otro no la encuentra (Wagner y col., 2013).

Analizando la participación de GSK-3 $\beta$ y Akt en los procesos de isquemia-reperfusión en animales hipertróficos la documentación es escasa. Al respecto Barillas y col. (2007) demuestra en conejos hipertensos que la presencia de la forma fosforilada de ambas quinasas aumenta la tolerancia a la isquemia-reperfusión, no existiendo datos respecto a su participación en el PI y en el PCI.

Si bien la participación del PPTM en la isquemia-reperfusión, como así también en el PI y PCI ha sido previamente documentada en animales normotensos, no está clara esta información en animales hipertensos y específicamente en la cepa SHR. 


\section{Hipótesis}

En el miocardio hipertrófico de las ratas hipertensas espontáneas (SHR), la formación y/ó apertura del poro de permeabilidad transitoria de la mitocondria (PPTM) inducida por la isquemia-reperfusión es atenuada por las intervenciones pre y postacondicionamiento isquémicos y el tratamiento con inhibidores de la GSK-3 $\beta$.

\section{Objetivos}

\section{Objetivo general}

Estudiar la participación del PPTM en la respuesta a la isquemia y reperfusión miocárdica en SHR

\section{Objetivos específicos}

1.-Estudiar los efectos de la isquemia-reperfusión sobre la muerte celular, la función miocárdica y el daño oxidativo en el corazón aislado y perfundido según la técnica de Langendorff.

2.- Evaluar los efectos de las intervenciones, preacondicionamiento isquémico (PI) y postacondicionamiento isquémico (PCI)

3.- Examinar la participación de GSK-3 $\beta$ en el PI y PCI

4.- Estudiar los efectos del tratamiento con inhibidores de GSK-3 $\beta$.

5.- Determinar la participación de PI3K/Akt en las intervenciones y tratamientos.

6.- Evaluar parámetros estructurales y funcionales de mitocondrias aisladas de corazones sometidos a las distintas intervenciones y tratamientos. 


\section{MATERIALES Y MÉTODOS}




\section{Animales}

Se utilizaron ratas machos hipertensas espontáneas (SHR) de 5 a 6 meses de edad obtenidas del bioterio de la Facultad de Ciencias Médicas, de la Universidad Nacional de La Plata. Todos los experimentos fueron realizados de acuerdo con la guía para el cuidado y uso de animales de laboratorio publicado por el Instituto Nacional de la Salud (NIH) de Estados Unidos (publicación nro. 85-23, revisada en el año 1996).

\section{Obtención del corazón aislado}

Los animales fueron anestesiados con pentobarbital sódico (6o mg/kg i.p.) Se les abrió rápidamente el tórax, se aisló la aorta, y se cortaron las conexiones cardíacas liberando al corazón de tejido conectivo y adiposo, sacándolo del animal. La aorta se ligó con hilo de lino a una cánula colocada en un sistema de perfusión según la técnica de Langendorff (Fig.14). Estas maniobras se realizaron en un tiempo no mayor de 50 seg para evitar el deterioro del preparado. La composición del Ringer fue: $\mathrm{NaCl} 120 \mathrm{mM}, \mathrm{CaCl}_{2} 1.35 \mathrm{mM}, \mathrm{KCl} 4.7 \mathrm{mM}, \mathrm{MgSO}_{4}$ $1.2 \mathrm{mM}, \mathrm{NaCO}_{3} \mathrm{H} 20 \mathrm{mM}$ y dextrosa $11.1 \mathrm{mM}$, el cual fue termostatizado a $37^{\circ} \mathrm{C}$ y equilibrado con una mezcla gaseosa de $95 \% \mathrm{O}_{2}-5 \% \mathrm{CO}_{2}$, para obtener un valor de $\mathrm{pH}$ de aproximadamente 7.40 .

\section{Perfusión de corazones aislados de rata}

Luego de un breve período de estabilización, se produjo el bloqueo aurículo-ventricular dañando con una fina aguja el tejido conductivo del septum auricular. La estimulación eléctrica se realizó a través de dos electrodos que fueron suturados a la pared ventricular derecha para mantener la frecuencia cardíaca constante en un valor de $280 \pm 10$ lat $/ \mathrm{min}$. Para evaluar la actividad mecánica de los corazones se colocó un balón de látex atado a un tubo de polietileno en el ventrículo izquierdo a través de la válvula mitral. El extremo opuesto del tubo fue conectado a un transductor de presión (AD Instruments), que permitió medir la presión del ventrículo izquierdo (PVI). El globo de látex y el tubo de polietileno se llenaron con un volumen de agua suficiente para lograr una presión diastólica final (PDF) de entre 8-12 mmHg, volumen que se mantuvo constante durante todo el experimento. La presión de 
perfusión coronaria fue monitoreada en el punto de canulación de la aorta y ajustada a aproximadamente entre 60-70 $\mathrm{mmHg}$. El flujo coronario, controlado por una bomba peristáltica fue de aproximadamente entre 10-12 $\mathrm{ml} / \mathrm{min}$ en todos los grupos experimentales. La PVI fue adquirida usando un conversor analógico-digital y el programa de adquisición Chart V4.2.3 (AD Instruments). A través de esta señal se obtuvieron los parámetros mecánicos necesarios para evaluar la función miocárdica.
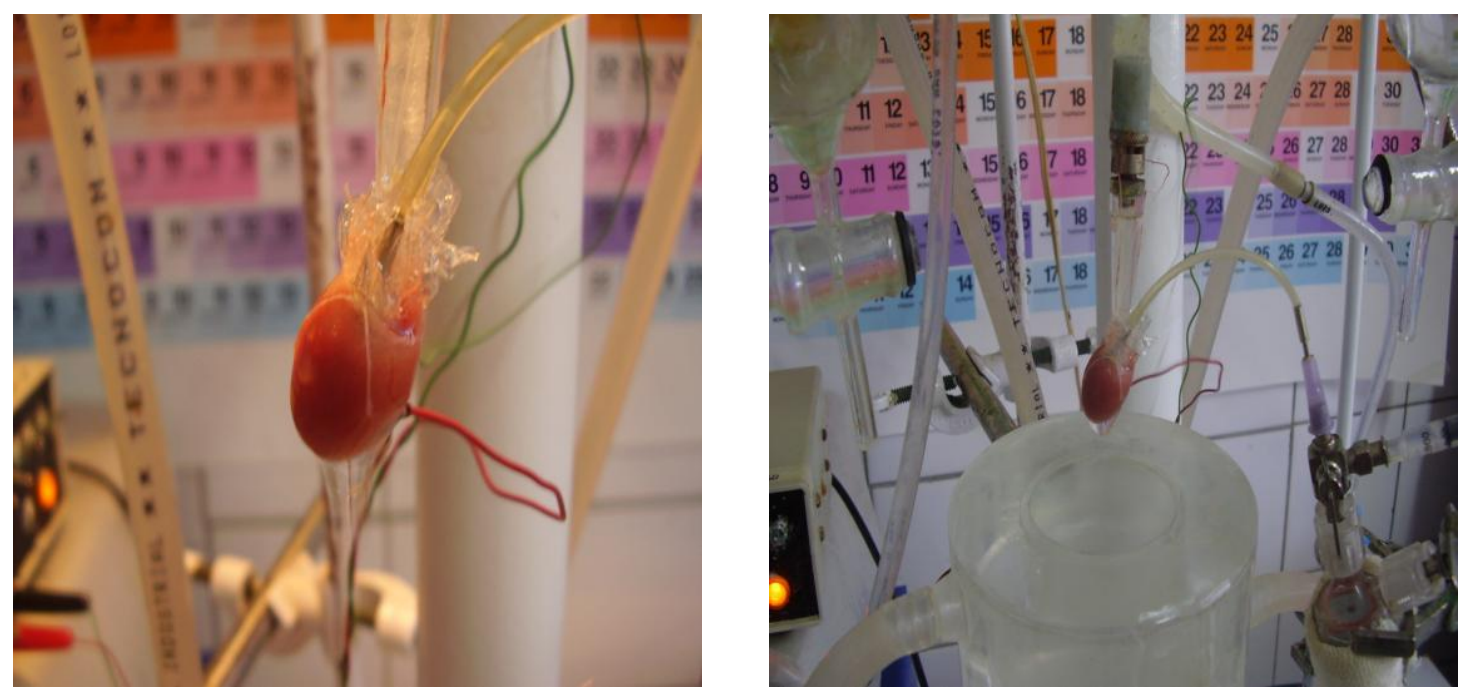

Figura 14: Imagenes de un corazón aislado y perfundido según la técnica de Langendorff

\section{PROTOCOLOS EXPERIMENTALES (Figura 15)}

\section{1 - Control (C)}

Perfusión durante 140 min.

\section{2 - Control Isquémico (CI)}
a) Estabilización (E): $35 \mathrm{~min}$
b) Isquemia global normotérmica (I): $45 \mathrm{~min}$.
c) Reperfusión (R): 60 min. 


\section{3 - Preacondicionamiento Isquémico (PI)}
a) Estabilización (E): 20 min.
b) 1 ciclo de I-R: 5 min I / 10 min $R$
c) Isquemia global normotérmica (I): $45 \mathrm{~min}$.
d) Reperfusión (R): 60 min.

4 - Postacondicionamiento isquémico (PCI)
a) Estabilización (E):35 min
b) Isquemia global normotérmica (I): $45 \mathrm{~min}$.
c) 3 ciclos de I-R: 30 seg. I / 30 seg. R
d) Reperfusión (R): 60 min.

5 - Tratamiento con Cloruro de Litio -3mM- (inhibidor no específico de GSK-3 $\beta$ previamente a la isquemia (ClLi Pre)
a) Estabilización (E): 25 min
b) $\mathrm{Cl} \mathrm{Li:} 10 \mathrm{~min}$
c) Isquemia global normotérmica (I): $45 \mathrm{~min}$.
d) Reperfusión (R): 60 min.

6 - Tratamiento con Cloruro de Litio -3mM- en el inicio de la reperfusión (ClLi Post)
a) Estabilización (E): 35 min
b) Isquemia global normotérmica (I): $45 \mathrm{~min}$
c) ClLi: $3 \mathrm{~min}$
d) Reperfusión (R): 60 min

7 - Tratamiento con 5-Yodo-Indirubin-3-Monoxime (IMI) -1 $\mu \mathrm{M}$ - , inhibidor específico de GSK-3 $\beta$, previamente a la isquemia (IMI Pre)
a) Estabilización (E): 25 min
b) IMI: $10 \mathrm{~min}$
c) Isquemia global normotérmica (I): $45 \mathrm{~min}$. 
d) Reperfusión (R): 60 min.

8 - Tratamiento con 5-Yodo-Indirubin-3-Monoxime (IMI) -1 $\mu M-$, al inicio de la reperfusión (IMI Post)
a) Estabilización (E): 35 min
b) Isquemia global normotérmica (I): 45 min.
c) IMI: 3 min
d) Reperfusión (R): 60 min.

9 - Preacondicionamiento Isquémico en presencia de Wortmanina -10o nM- (PI + Wortm)
a) Estabilización (E): 5 min.
b) 15 min Wortmanina
c) 1 ciclo de I-R: 5 min. I /10 min. $\mathrm{R}$
d) Isquemia global normotérmica (I): $45 \mathrm{~min}$
e) Reperfusión (R): 60 min

10 - Postacondicionamiento Isquémico en presencia de Wortmanina -10o nM(PCI + Wortm)
a) Estabilización (E): 20 min.
b) 15 min Wortmanina
c) Isquemia global normotérmica (I): $45 \mathrm{~min}$
d) 3 ciclos de I-R: 30 seg. I / 30 seg. $R$
e) Reperfusión (R): 60 min.

Estos protocolos experimentales se realizaron por triplicado. Una serie fue utilizada para la determinación del tamaño del infarto. Otra fue procesada para medir parámetros bioquímicos. La tercera serie fue utilizada para el aislamiento de mitocondrias. 


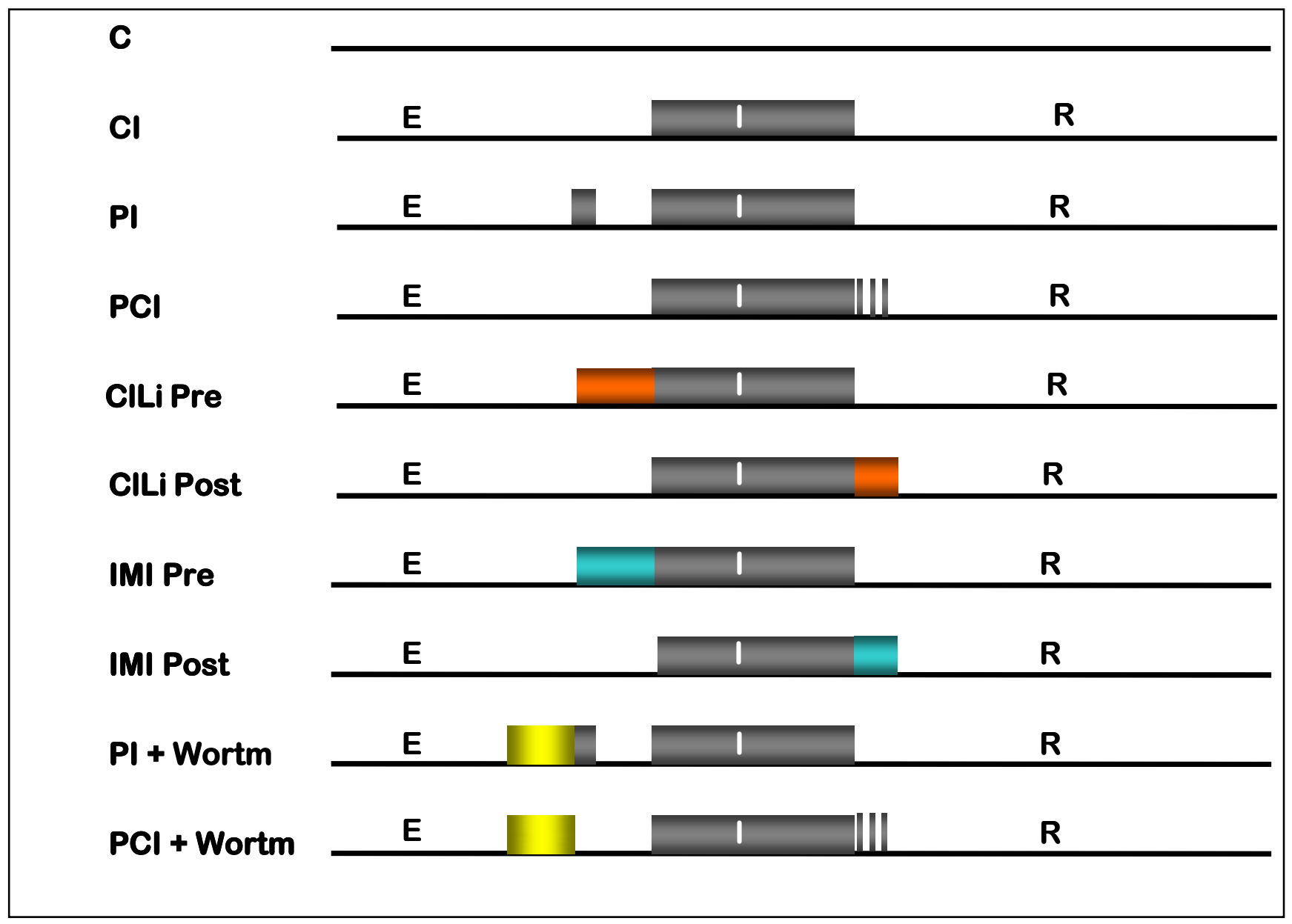

Figura 15: Protocolos experimentales

\section{PARÁMETROS MEDIdOS}

Presión arterial sistólica

Este parámetro se controló semanalmente en la cola de las ratas en forma indirecta usando el método pletismográfico (Byrom y Wilson, 1938) y siguiendo las modificaciones detalladas en el trabajo realizado por Fritz y Rinaldi (2007).

Índice de Hipertrofia

El índice de hipertrofia (IH) fue calculado como el cociente entre la masa del ventrículo izquierdo (MVI, expresada en mg) y la masa corporal (MC, expresada en g) de las ratas. 


\section{Determinación del tamaño del infarto}

Al término del período de reperfusión el corazón fue retirado del sistema de Langendorff y el ventrículo izquierdo (VI), una vez pesado, se congeló a -20 ${ }^{\circ} \mathrm{C}$ por una hora. $\mathrm{Al}$ cabo de este tiempo el VI fue cortado en trozos de $2 \mathrm{~mm}$ de espesor a lo largo del eje mayor desde la punta a la base, los cuales fueron pesados y sumergidos en una solución al $1 \%$ de cloruro de trifeniltetrazolio (TTC) durante $14 \mathrm{~min}$. El colorante ingresa a las células y al ser reducido queda atrapado en su interior tiñéndolas de color rojo. Sólo las células que conservan actividad deshidrogenasa, pueden retener este colorante. En consecuencia, las células que se encuentran vivas, quedarán teñidas de color rojo, mientras que las células muertas no se teñirán, permitiendo así la diferenciación del tejido infartado (Figura 16). Los trozos de corazón fueron guardados en formalina al 10\% por 24 horas luego de lo cual se escanearon y, usando un programa de análisis de imágenes (Scion Image 1.62), se determinaron las áreas de infarto y las áreas de riesgo. El área total de infarto pesada se calculó como (A1 x P1) + (A2 x $\left.\mathrm{P}_{2}\right)+\left(\mathrm{A}_{3} \times \mathrm{P}_{3}\right)+\left(\mathrm{A}_{4} \times \mathrm{P}_{4}\right)+\left(\mathrm{A}_{5} \times \mathrm{P}_{5}\right)+(\mathrm{A} 6 \times \mathrm{P} 6)$, donde Ai es el área de infarto de cada trozo y Pi es la masa respectiva. Como en esta preparación el corazón entero constituye el área de riesgo (AR), el área total de riesgo pesada fue calculada de la misma forma que el área total de infarto pero teniendo en cuenta el área total de cada trozo. El tamaño del infarto se expresó como porcentaje de AR.

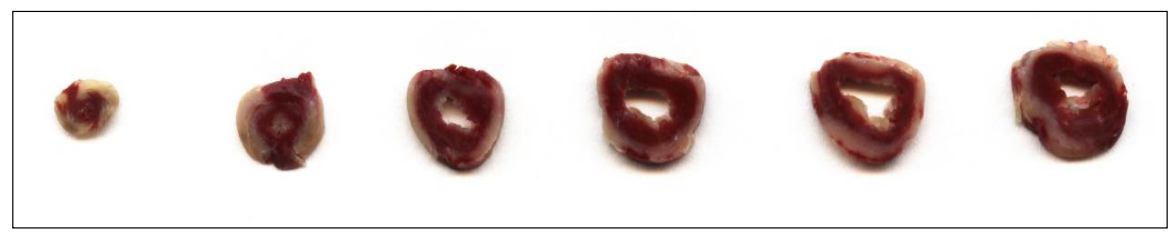

Figura 16: Trozos de VI teñidos con TTC

Función miocárdica sistólica y diastólica

La función sistólica fue evaluada a través de la presión desarrollada del VI (PD) y la máxima velocidad de desarrollo de la presión del VI $\left(+\mathrm{dP} / \mathrm{dt}_{\max }\right)$. La PD se calculó restando a la presión pico la PDF. La $+\mathrm{dPdt}_{\max }$ fue el máximo valor positivo de la primera derivada de la PVI en función del tiempo. La función diastólica fue evaluada a través de la PDF. La 
resistencia coronaria (RC)se evaluó a través del cociente presión de perfusión (PP) y flujo coronario (FC).

\section{DETERMINACIONES BIOQUÍMICAS}

Preparación del homogenato del tejido cardíaco

Al final de la reperfusión, luego de finalizado cada uno de los protocolos experimentales, los corazones se retiraron del sistema de Langendorff. Una porción del ventrículo izquierdo (VI) fue homogeneizada en la proporción de $1 \mathrm{~g}$ de tejido en $5 \mathrm{ml}$ de buffer compuesto por $\mathrm{KPO}_{4} \mathrm{H}_{2}$ $25 \mathrm{mM}$ y ClK $140 \mathrm{mM}$ a pH $=7.4$. El tejido fue homogeneizado durante $1 \mathrm{~min}$. a temperatura entre $0-2{ }^{\circ} \mathrm{C}$ con el homogenizador Polytron. Una alícuota del homogenato fue centrifugado 10 min. a $3000 \mathrm{rpm}$ y el sobrenadante fue utilizado para la determinación de la concentración de sustancias reactivas al ácido tiobarbitúrico (TBARS). Otra alícuota fue usada para medir el contenido de glutatión reducido (GSH). El homogenato remanente fue centrifugado a $12000 \mathrm{x}$ g por 5 min a $4^{\circ} \mathrm{C}$ y el sobrenadante se guardó a $-70{ }^{\circ} \mathrm{C}$ para la determinación de la actividad citosólica de superóxido dismutasa dependiente de Mn (MnSOD). Para realizar estas determinaciones los distintos grupos experimentales fueron repetidos, ya que no se pueden utilizar los corazones usados para medir el tamaño del infarto.

\section{1.- Evaluación del daño oxidativo y sistema de defensa antioxidante}

- Sustancias reactivas al ácido tiobarbitúrico (TBARS) (Buege y Aust, 1978)

Para la estimación de la peroxidación lipídica se utilizó la determinación de TBARS. El ensayo consistió en lo siguiente: a $0.5 \mathrm{ml}$ del sobrenadante se le agregó $1.5 \mathrm{ml}$ de ácido tricloroacético (TCA) al 10\%, $1.0 \mathrm{ml}$ de ácido tiobarbitúrico al $0.67 \%$ y $0.5 \mathrm{ml}$ de agua bidestilada. La preparación se agitó $10 \mathrm{seg}$ y se incubó a $100{ }^{\circ} \mathrm{C}$ durante $15 \mathrm{~min}$. Al término de este período se observó la formación de un producto de color rosado. Las muestras fueron enfriadas y centrifugadas 10 min a $2500 \mathrm{rpm}$. En el sobrenadante obtenido se leyó la absorbancia a 535 $\mathrm{nm}$ contra un blanco con mezcla de reacción y sin muestra. Los resultados fueron expresados como nmoles por mg de proteína (nmoles/ mg de prot.), utilizando el coeficiente de extinción de $1.56 \times 10^{5} \mathrm{M}^{-1} \mathrm{~cm}^{-1}$. 
- Contenido de glutatión reducido (GSH) (Sedlak y Lindsay, 1958)

Para la determinación del contenido de GSH se midieron los grupos sulfhidrilos no unidos a proteínas. El fundamento de la reacción consiste en que el 5,5'-ditiobis-2-ácido nitrobenzoico (DTNB) es reducido por los grupos sulfhidrilos a 2-nitro-5 mercaptobenzoico, que es de color amarillo intenso. El ensayo consistió en lo siguiente: a una alícuota $(820 \mu \mathrm{l})$ del homogenato se agregó $180 \mu \mathrm{l}$ de TCA al 28 \%. Las muestras se agitaron y luego se centrifugaron 10 min a $7.000 \mathrm{rpm}$. A $250 \mu \mathrm{l}$ del sobrenadante se le agregaron $250 \mu \mathrm{l}$ de TCA al $5 \%, 1 \mathrm{ml}$ de Tris $\mathrm{HCl}$ a una concentración de $0.4 \mathrm{M}(\mathrm{pH}=8.9)$ y $25 \mu \mathrm{l}$ del colorante DTNB preparado en metanol a una concentración final de $10 \mathrm{mM}$. Se midió la absorbancia a $414 \mathrm{~nm}$ dentro de los 5 min de agregado el DTNB contra un blanco con la mezcla de reacción sin muestra. Se realizó una curva de calibración usando distintas concentraciones de GSH. Los resultados obtenidos se expresaron como $\mu \mathrm{g}$ por mg de proteína ( $\mu \mathrm{g} / \mathrm{mg}$ proteína).

- Actividad citosólica de la enzima Superóxido Dismutasa (SOD) (Beuchamp y Fridovich, 1971)

La actividad de SOD se determinó utilizando el sistema hipoxantina - xantina - azul de tetrazolio (NBT) a través de la inhibición de la producción del formazán a una temperatura de $25{ }^{\circ} \mathrm{C}$ y $\mathrm{pH}=10.2$. La mezcla de reacción contiene $10 \mu \mathrm{l}$ del sobrenadante, $780 \mu \mathrm{l}$ de buffer $\mathrm{KH}_{2} \mathrm{PO}_{4}-\mathrm{KOH}(50 \mathrm{mM}), 100 \mu \mathrm{l}$ de EDTA $(10 \mathrm{mM}), 10 \mu \mathrm{l}$ de hipoxantina $(10 \mathrm{mM})$ y $100 \mu \mathrm{l}$ NBT ( $1 \mathrm{mM})$ en ausencia o presencia de CNK ( $5 \mathrm{mM})$. Las muestras se incubaron $30 \mathrm{~min}$ a temperatura ambiente. Luego de este período se inició la reacción con el agregado de $100 \mu \mathrm{l}$ de xantina oxidasa $(0.66 \mathrm{U} / \mathrm{ml})$. Las muestras se incubaron 30 minutos a $25{ }^{\circ} \mathrm{C}$. Luego de este período, y para finalizar la reacción, se agregaron $300 \mu \mathrm{l}$ de $\mathrm{CuCl}_{2}$ en una concentración $1 \mathrm{mM}$. Se leyó la absorbancia a $560 \mathrm{~nm}$ cada 30 segundos durante 5 minutos y los resultados obtenidos se expresaron como porcentaje de inhibición por mg de proteína (\% inh/mg prot.). Para medir la actividad citosólica de MnSOD se realizó el ensayo descripto anteriormente después de tratar a la muestra con $5 \mathrm{mM}$ de $\mathrm{KCN}$ para inhibir a la enzima $\mathrm{Cu}-\mathrm{Zn}$ SOD. 


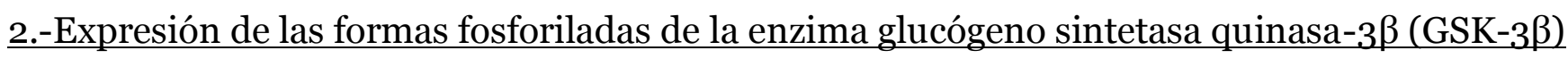
y de la proteína quinasa específica de Serina/Treonina (Akt ó PKB) por Western Blot

Otra porción del VI fue homogeneizada en frío en un buffer para el ensayo de radioinmunoprecipitación (RIPA) compuesto por $300 \mathrm{mM}$ sacarosa, 1 mM DTT, 4 mM EGTA, $20 \mathrm{mM}$ TRIS $\mathrm{pH}$ 7.4, 1\% Triton $\mathrm{X}, 10 \%$ protease cocktail, $25 \mu \mathrm{M}$ FNa, $1 \mu \mathrm{M}$ Ortovanadate. Luego la muestra fue centrifugada a $1000 \mathrm{x}$ g por $15 \mathrm{~min}$ a $4{ }^{\circ} \mathrm{C}$ para remover núcleos y restos celulares. El sobrenadante fue seguidamente centrifugado a $10000 \mathrm{x} \mathrm{g}$ por $30 \mathrm{~min}$ y luego a 100 ooo x g por 1 hora. $60 \mu \mathrm{g}$ de proteínas de la fracción obtenida fueron sembradas en un gel de poliacrilamida con dodecilsulfato sódico para la corrida electroforética (SDS-PAGE) y transferidas a una membrana de polifluoruro de vinilideno (PVDF) durante 2 horas. El teñido con Ponceau S confirmó el uso de la misma cantidad de proteína en todas las muestras sembradas en el gel. Luego las membranas fueron bloqueadas con $5 \%$ de leche descremada en solución salina conteniendo TRIS ( $\mathrm{pH} 7.5$ ) y 0.1 \% Tween (TBS-T) e incubadas toda la noche a $4^{\circ} \mathrm{C}$ con anticuerpos anti-pSerg GSK-3 $\beta$ (1:100o, Santa Cruz Biotechnology) y anti-Akt (1:100o, Santa Cruz Biotechnology). Luego las membranas fueron lavadas 4 veces por $10 \mathrm{~min}$ en una solución salina con buffer TRIS y Tween 20 (TBS-T) antes del agregado del anticuerpo secundario policlonal de conejo (1:500o, Santa Cruz Biotechnology). Las bandas fueron analizadas por un sistema de quimioluminiscencia (ECL Plus; Amersham Biosciences). La señal de gliceraldehído 3-fosfato deshidrogenada (GAPDH) usando el anticuerpo específico (anti-GAPDH) fue usada como control.

3.- Expresión de citocromo c en las fracciones citosólica y mitocondrial por Western Blot El sobrenadante resultante de la centrifugación de $10000 \mathrm{x}$ g, correspondió a la fracción citosólica y el residuo a la fracción mitocondrial. Este residuo fue re-suspendido y otra vez centrifugado a $10000 \mathrm{x}$ g por $30 \mathrm{~min}$ (Baines y col., 2003). Las mitocondrias lavadas fueron entonces resuspendidas. $100 \mu \mathrm{g}$ de proteína mitocondrial y $60 \mu \mathrm{g}$ de la citosólica fueron sembradas en un gel de poliacrilamida con dodecilsulfato sódico para la corrida electroforética (SDS-PAGE), y se siguió el protocolo descripto anteriormente. Se usó el anticuerpo anti-citocromo C (1:100o, Invitrogen). Las señales de GAPDH y canales aniónicos dependientes de voltaje (VDAC) usando los anticuerpos específicos (anti-GAPDH y anti- 
VDAC) fueron usadas como control de las fracciones citosólica y mitocondrial, respectivamente.

\section{4.- Concentración de proteínas}

La concentración de proteínas fue evaluada por el método de Bradford (Bradford, 1976) usando la albúmina de suero bovino como estándar.

\section{Aislamiento de mitocondrias}

$\mathrm{Al}$ término de la reperfusión el VI fue utilizado para el aislamiento de las mitocondrias por centrifugación diferencial (Mela y Seitz, 1979). El VI fue inicialmente lavado en una solución fría de aislamiento (SA) compuesta por $75 \mathrm{mM}$ sacarosa, $225 \mathrm{mM}$ manitol y $0.01 \mathrm{mM}$ EGTA neutralizada con el buffer Trizma a pH 7.4. Luego se lo trozó, se descartó la solución de lavado y se reemplazó por SA nueva $(5 \mathrm{ml})$, transfiriendo esta suspensión a un homogeneizador de mano. Antes de comenzar el proceso de homogeneización se agregó o.8 mg de una proteasa (bacterial, tipo XXIV, Sigma, llamada primeramente Nagarse). El proceso de homogeneización total no llevó más de 14 min realizado en 2 etapas de 7 min cada una (con el agregado de $5 \mathrm{ml}$ de SA fresca cada vez). El homogenato fue cuidadosamente transferido después de cada etapa a un tubo de centrífuga de policarbonato. Después de una centrifugación de $5 \mathrm{~min}$ a $480 \mathrm{xg}$ para descartar tejido no roto y restos celulares el sobrenadante fue centrifugado a $7700 \times \mathrm{g}$ por $10 \mathrm{~min}$ para sedimentar a las mitocondrias. Este sedimento fue lavado 2 veces con SA y un último enjuague con SA sin EGTA centrifugando cada vez a $7700 \times$ g por 5 min.

1- Determinación de la sensibilidad del poro de permeabilidad transitoria de la mitocondria (PPTM) al $\mathrm{Ca}^{2+}$

La habilidad de la mitocondria para resistir el hinchamiento fue evaluada incubando mitocondrias aisladas en una solución conteniendo (en $\mathrm{mM}$ ): $120 \mathrm{KCl}, 20 \mathrm{MOPS}, 10$ Tris- $\mathrm{HCl}$ y $5 \mathrm{KH}_{2} \mathrm{PO}_{4}$ ajustada a $\mathrm{pH}=7.4$ (Baines y $\mathrm{Col}$ 2003). Aproximadamente $0.3 \mathrm{mg}$ de la suspensión mitocondrial energizada con $6 \mathrm{mM}$ de succinato, fueron incubados durante $5 \mathrm{~min}$ y luego tratados con $200 \mu \mathrm{M}$ de $\mathrm{CaCl}_{2}$. Si el poro de permeabilidad transitoria de la mitocondria se abre en presencia de $\mathrm{Ca}^{2+}$ los solutos entran libremente a la matriz mitocondrial provocando la hinchazón de la organela. Este cambio es observado como 
disminución de la dispersión de luz y fue seguido usando un espectrofluorómetro Hitachi F4500 con control de temperatura y agitación continua a $520 \mathrm{~nm}$ como longitud de onda de excitación y emisión. La disminución de la dispersión de la luz fue calculada para cada muestra como la diferencia entre la observada antes y después del agregado de $\mathrm{CaCl}_{2}$.

\section{2- Ultraestructura mitocondrial}

Una muestra de la suspensión mitocondrial fue usada para examen de la ultraestructura de la mitocondria usando un microscopio electrónico de transmisión H-6oo.

\section{ANÁliSiS ESTADÍSTICo}

Los resultados se expresaron como la media \pm error estándar. Para comparar los datos entre dos grupos experimentales se utilizó la prueba de t-Student. Para la comparación de más de dos grupos se utilizó análisis de varianza (ANOVA) de una vía seguido del test de StudentNewman-Keuls. En todos los casos el valor de 0,05 se consideró como el límite de significación estadística. 
RESULTADOS 
La Tabla 2 muestra los datos de peso corporal (PC), peso del corazón (PCo), relación PCo/PC, presión arterial sistólica (PAS), y los valores basales de la presión diastólica final (PDF) y la presión desarrollada del ventrículo izquierdo (PDVI) en los grupos: Control (C), control isquémico $(\mathrm{CI})$, preacondicionamiento isquémico (PI), postacondicionamiento isquémico (PCI) y en los tratados con ClLi, IMI y wortmanina.

Tabla 2

\begin{tabular}{|c|c|c|c|c|c|c|}
\hline GRUPO & PC (g) & PCo (g) & PCo/PC & $\begin{array}{c}\text { PAS } \\
(\mathbf{m m H g})\end{array}$ & $\begin{array}{c}\text { PDF } \\
(\mathbf{m m H g})\end{array}$ & $\begin{array}{c}\text { PDVI } \\
(\mathbf{m m H g})\end{array}$ \\
\hline C & $336 \pm 12$ & $1.50 \pm 0.04$ & $4.5 \pm 0.1$ & $216 \pm 5$ & $10 \pm 1$ & $91 \pm 1$ \\
\hline CI & $328 \pm 6$ & $1.53 \pm 0.07$ & $4.7 \pm 0.2$ & $210 \pm 8$ & $13 \pm 2$ & $88 \pm 6$ \\
\hline PI & $329 \pm 13$ & $1.43 \pm 0.04$ & $4.4 \pm 0.2$ & $208 \pm 9$ & $12 \pm 1$ & $87 \pm 7$ \\
\hline PCI & $325 \pm 13$ & $1.52 \pm 0.07$ & $4.7 \pm 0.2$ & $213 \pm 4$ & $10 \pm 1$ & $89 \pm 6$ \\
\hline CILi Pre & $328 \pm 5$ & $1.46 \pm 0.05$ & $4.5 \pm 0.2$ & $220 \pm 7$ & $12 \pm 1$ & $87 \pm 4$ \\
\hline CILi Post & $325 \pm 10$ & $1.46 \pm 0.03$ & $4.5 \pm 0.2$ & $217 \pm 6$ & $10 \pm 1$ & $91 \pm 2$ \\
\hline IMI Pre & $330 \pm 3$ & $1.54 \pm 0.03$ & $4.7 \pm 0.1$ & $215 \pm 4$ & $12 \pm 1$ & $90 \pm 1$ \\
\hline IMI Post & $322 \pm 10$ & $1.52 \pm 0.05$ & $4.7 \pm 0.2$ & $209 \pm 7$ & $11 \pm 1$ & $89 \pm 4$ \\
\hline PI + W & $340 \pm 12$ & $1.60 \pm 0.07$ & $4.7 \pm 0.2$ & $218 \pm 6$ & $10 \pm 2$ & $86 \pm 8$ \\
\hline PCI + W & $332 \pm 6$ & $1.52 \pm 0.05$ & $4.6 \pm 0.2$ & $212 \pm 5$ & $11 \pm 1$ & $86 \pm 8$ \\
\hline
\end{tabular}


Como se muestra en la Tabla 2 los pesos corporales de los animales usados, los pesos cardíacos, los niveles de PAS y de IH, así como los datos hemodinámicos de los corazones aislados pertenecientes a todos los grupos experimentales fueron similares, no observándose diferencias significativas entre ellos.

\section{Efectos de la isquemia-reperfusión y del preacondicionamiento y postacondicionamiento isquémicos}

\section{Tamaño del Infarto}

En la Figura 1 se muestran los valores promedio de los tamaños del infarto medidos al final del período de reperfusión de corazones de SHR pertenecientes a los grupos C, CI, PI y PCI. En el grupo $\mathrm{C}$ el valor promedio fue de $\mathbf{1 , 6} \pm \mathbf{0 , 3} \%(\mathrm{n}=7)$. Cuando los corazones fueron sometidos a 45 min de isquemia global y 60 min de reperfusión (grupo CI) el tamaño del infarto fue de $51 \pm 4 \%(n=7)$. La aplicación de los ciclos breves de isquemia antes de la isquemia prolongada (grupo PI) ó al inicio de la reperfusión (grupo PCI) redujeron significativamente el tamaño del infarto, siendo los valores de $34 \pm \mathbf{1} \%(n=7)$ y $36 \pm 4 \%$ $(\mathrm{n}=7)$, respectivamente (Figura 17).

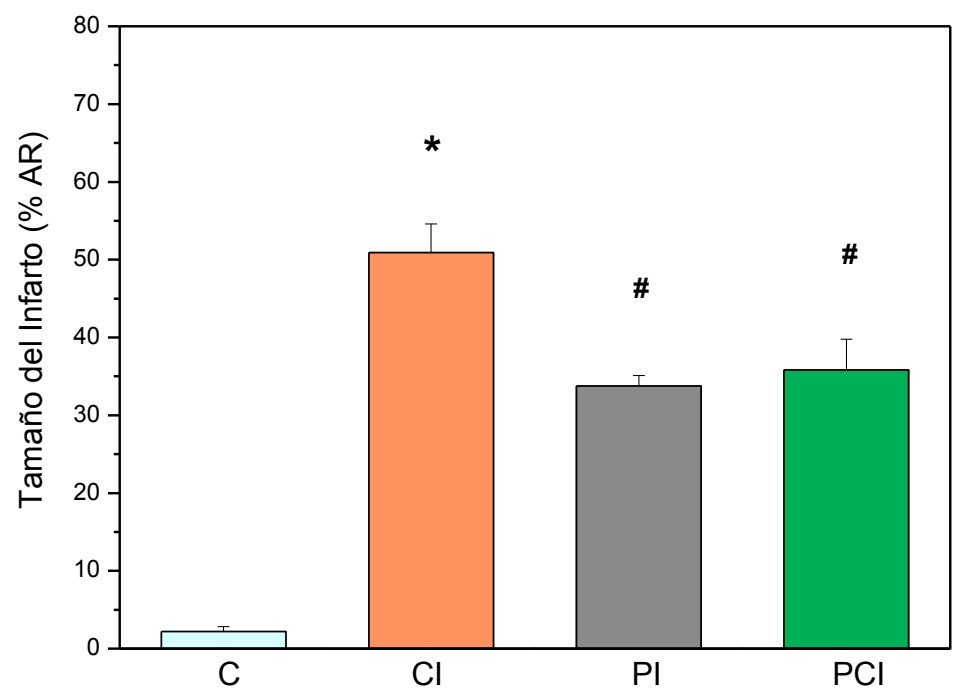

Figura 17: Tamaño del infarto, expresado como porcentaje del área de riesgo (AR), en C: grupo control; CI: grupo control isquémico; PI: Preacondicionamiento Isquémico y PCI: Postacondicionamiento Isquémico. ${ }^{*} \mathrm{p}<0,05$ con respecto a $\mathrm{C} ; \# \mathrm{p}<0,05$ con respecto a $\mathrm{CI}$. 


\section{Función sistólica y diastólica}

La perfusión durante 140 min de los corazones del grupo C no modificó la contractilidad respecto a la observada al final del período de estabilización (20 min). Sin embargo, en los corazones sometidos al protocolo de isquemia-reperfusión la PDVI se recuperó escasamente (aproximadamente 1\%). Similares valores de PDVI fueron observados al final de la reperfusión cuando el PI y PCI fueron aplicados. Es decir, que el deterioro de la contractilidad postisquémica no fue prevenido ni atenuado por ambas intervenciones. La función diastólica, medida a través de la PDF, aumentó significativamente durante la reperfusión en el grupo CI hasta un valor de $86 \pm 8 \mathrm{mmHg}$ al final de dicho período. En los grupos PI y PCI, los valores de PDF al final de la reperfusión no fueron estadísticamente diferentes del obtenido en el grupo CI (106 \pm 7 y $91 \pm 10 \mathrm{mmHg}$ para PI y PCI, respectivamente). La presión de perfusión de los grupos CI, PI y PCI aumentó durante la reperfusión desde aproximadamente 71 a 130 mmHg. Como el flujo coronario se mantuvo constante durante todo el experimento, los cambios de la presión de perfusión se debieron a cambios en la resistencia coronaria. Por lo

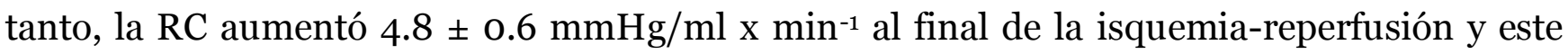
aumento se mantuvo en los corazones pre y postacondicionados.

Evaluación del daño oxidativo y sistema de defensa antioxidante

-Sustancias reactivas al ácido tiobarbitúrico (TBARS):

La peroxidación lipídica fue estimada a partir de la determinación de TBARS. La concentración de TBARS del grupo $\mathrm{C}$ fue de $\mathbf{0 , 2 2} \pm \mathbf{0 , 0 3}$ nmoles $/ \mathrm{mg}$ prot $(\mathrm{n}=7)$ y aumentó significativamente en el grupo CI $(\mathbf{0 , 4 6} \pm \mathbf{0 , 0 4}$ nmoles/mg prot, $n=7)$. Ambas intervenciones cardioprotectoras (PI y PCI) disminuyeron dichos niveles y las TBARS alcanzaron los valores de $\mathbf{0 , 2 6} \pm \mathbf{0 , 0 5}(\mathrm{n}=7)$ y $\mathbf{0 , 2 8} \pm \mathbf{0 , 0 3}$ nmoles $/ \mathrm{mg} \operatorname{prot}(\mathrm{n}=7)$, respectivamente (Figura 18). 


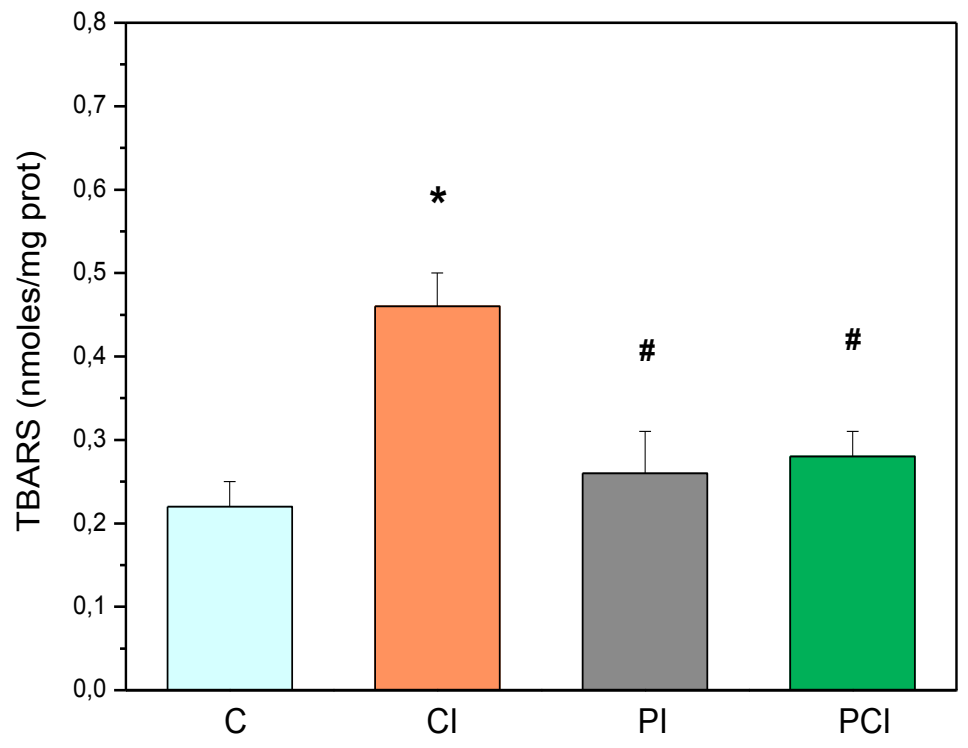

Figura 18: Concentración de TBARS, expresada en nmoles por mg de proteína, en los grupos C, CI, PI y PCI. ${ }^{*} \mathrm{p}<0,05$ con respecto a $\mathrm{C} ; \# \mathrm{p}<0,05$ con respecto a CI.

-Glutatión reducido (GSH):

El contenido de GSH en los corazones del grupo $\mathrm{C}$ fue de $\mathbf{3 , 6 6} \pm \mathbf{0 , 3 7} \mu \mathrm{g} / \mathrm{mg}$ prot $\mathrm{y}$ disminuyó en aquellos sometidos a isquemia-reperfusión (grupo CI) a o,94 \pm o,15 $\mu \mathrm{g} / \mathrm{mg}$ prot. Las intervenciones preservaron parcialmente los niveles de GSH, siendo los valores de $\mathbf{2 , 0 6} \pm \mathbf{0 , 3 1}$ y $\mathbf{1 , 7 7} \pm \mathbf{0 , 1 8} \mu \mathrm{g} / \mathrm{mg}$ prot en los grupos PI y PCI, respectivamente (Figura 19).

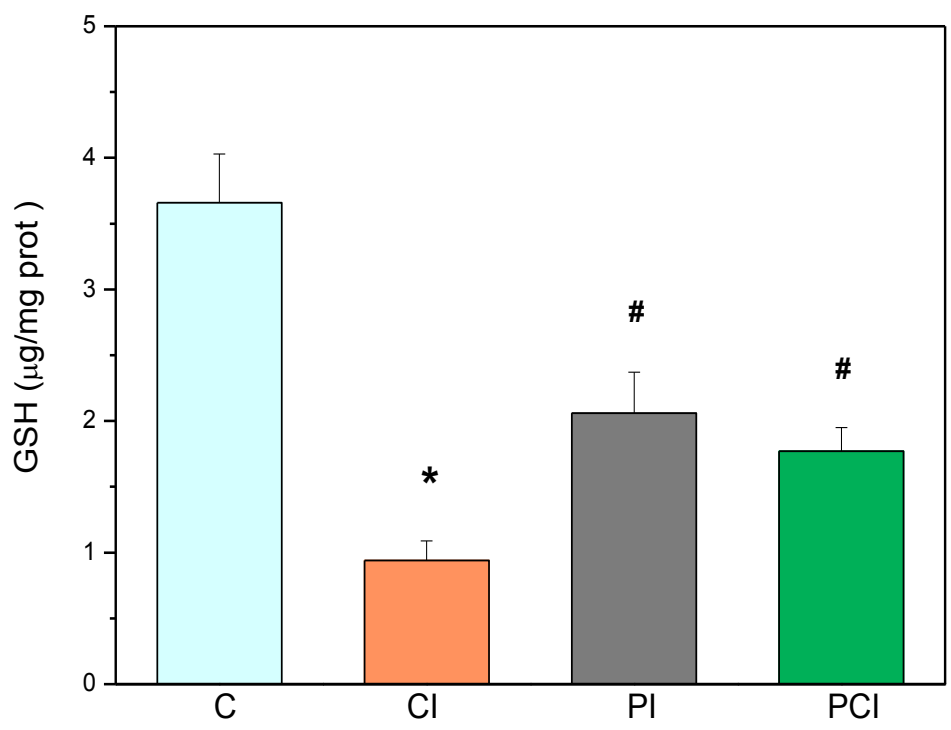

Figura 19: Contenido de glutatión reducido (GSH), expresado en $\mu \mathrm{g} / \mathrm{mg}$ de proteína, en los grupos $\mathrm{C}$, CI, PI y PCI. * $\mathrm{p}<0,05$ con respecto a $\mathrm{C} ; \#$ p $<0,05$ con respecto a CI. 
-Actividad citosólica de Superóxido Dismutasa Total (SOD T):

La actividad citosólica de la SODT fue de $\mathbf{4 , 4 5} \pm \mathbf{0 , 7 5} \%$ inhibición/mg prot en el grupo C y aumentó significativamente en el grupo CI, siendo el valor de 9,54 $\pm \mathbf{0 , 2 2} \%$ inhibición $/ \mathrm{mg}$ prot. Con las intervenciones los valores disminuyeron a $5,78 \pm \mathbf{0 , 7 8} \%$ inhibición $/ \mathrm{mg}$ prot en el grupo PI y 6,45 \pm 0,75 \% inhibición/mg prot en el grupo PCI (Figura 20).

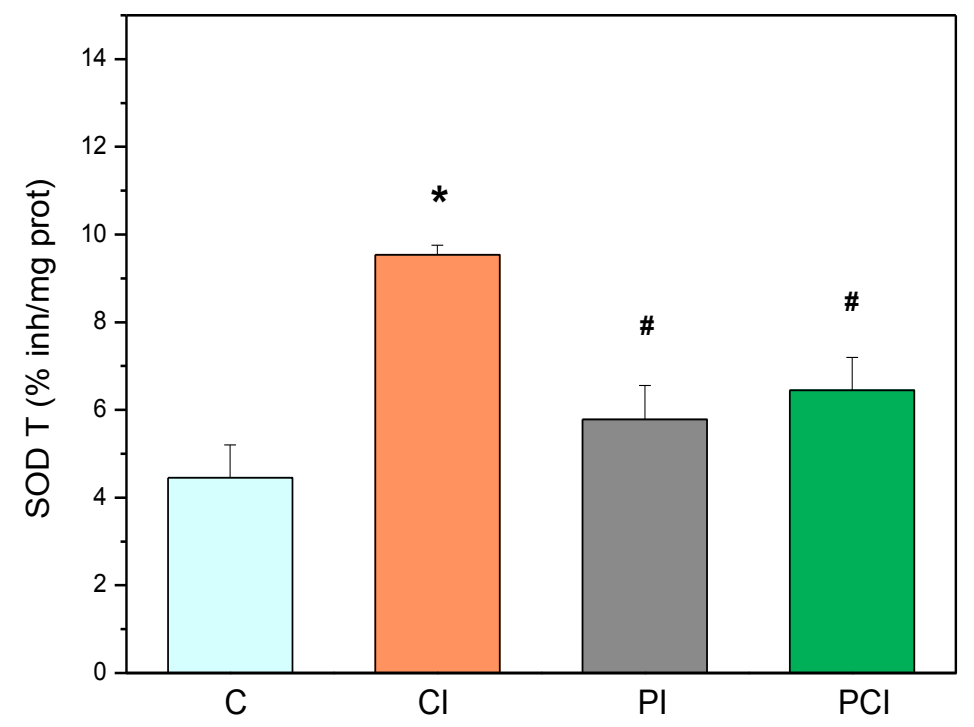

Figura 20: Actividad citosólica de SOD total (SODT), expresada como porcentaje de inhibición por mg de proteína, en corazones de los grupos $\mathrm{C}, \mathrm{CI}, \mathrm{PI}, \mathrm{PCI} .{ }^{*} \mathrm{p}<0,05$ con respecto a C; \# p< 0,05 con respecto a $\mathrm{CI}$.

-Actividad citosólica de Superóxido Dismutasa dependiente de Manganeso (SODMn):

La actividad citosólica de SODMn fue de $4.45 \pm \mathbf{0 . 6 3} \%$ inhibición $/ \mathrm{mg}$ de proteína en el grupo C. Aumentó en el grupo CI a $\mathbf{1 0 . 0 2} \pm \mathbf{0 . 3 8} \%$ inhibición $/ \mathrm{mg}$ prot y este valor disminuyó en los corazones intervenidos, siendo los valores de $6.96 \pm 0.93$ y $7.5 \pm 0.41 \%$ inhibición/mg prot en los grupos PI y PCI, respectivamente (Figura 21). 


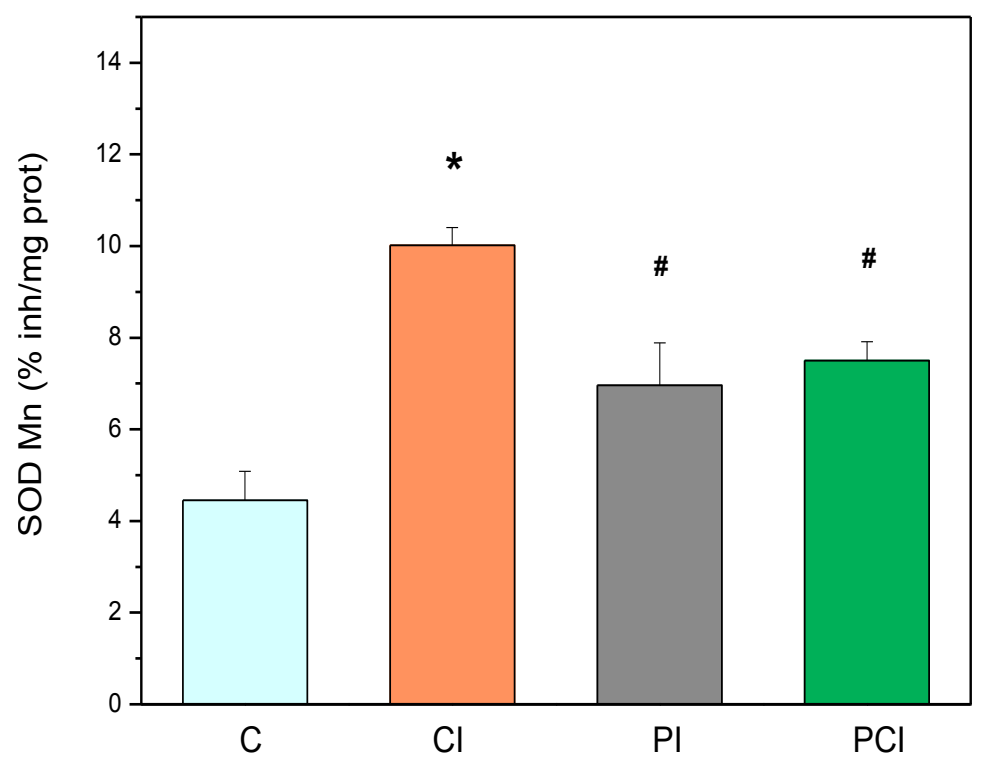

Figura 21: Actividad citosólica de SOD Mn, expresada como porcentaje de inhibición por mg de proteína, en corazones de los grupos C, CI, PI, PCI. * $\mathrm{p}<0,05$ con respecto a $\mathrm{C}$; \# $\mathrm{p}<0,05$ con respecto a $\mathrm{CI}$.

\section{Expresión de P-GSK-3ßy P-Akt}

La expresión de P-GSK-3 $\beta$ disminuyó en el grupo CI (41 $\pm \mathbf{3 \%}$ ) y este valor aumentó en los corazones pre y postacondicionados. Los valores fueron de $63 \pm 1 \%$ y $65 \pm 2 \%$ en los grupos PI y PCI, respectivamente (Figura 22).

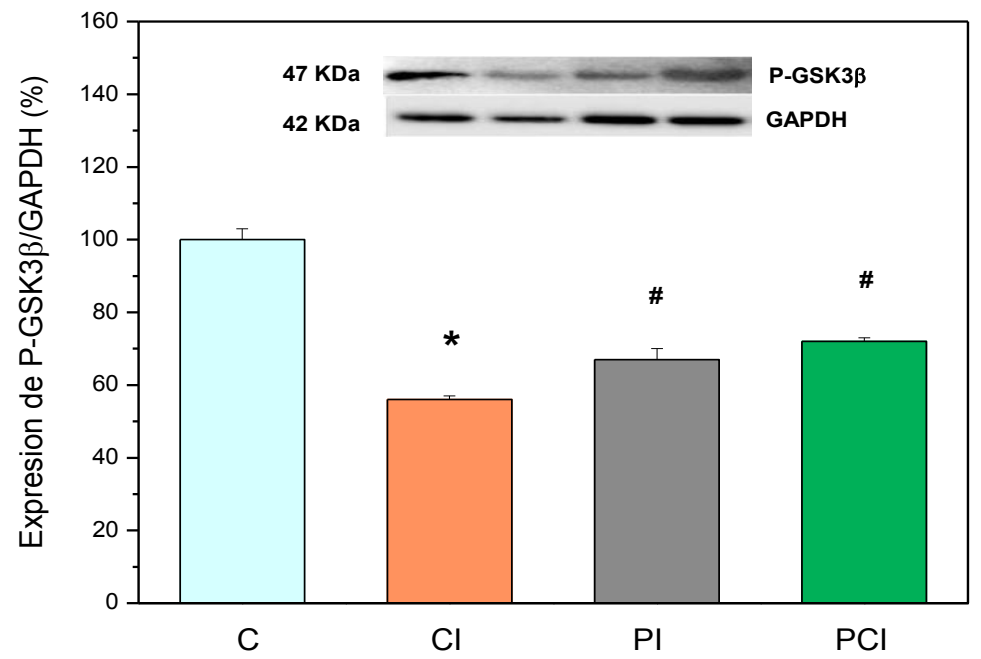

Figura 22: Expresión de P-GSK-3 $\beta /$ GAPDH, expresado como porcentaje del valor obtenido en el grupo $\mathrm{C}(100 \pm 2 \%)$, en los grupos $\mathrm{CI}, \mathrm{PI}, \mathrm{PCI} .{ }^{*} \mathrm{p}<0,05$ con respecto a $\mathrm{C} ; \# \mathrm{p}<0,05$ con respecto a CI. 
La expresión de P-Akt disminuyó en el grupo CI (56 $\pm \mathbf{2 \%})$ con respecto al valor hallado en los corazones controles no isquémicos. Este valor aumentó en los corazones pre y postacondicionados. Los valores fueron de $67 \pm 1 \%$ y $72 \pm 2 \%$ en los grupos PI y PCI, respectivamente (Figura 23).

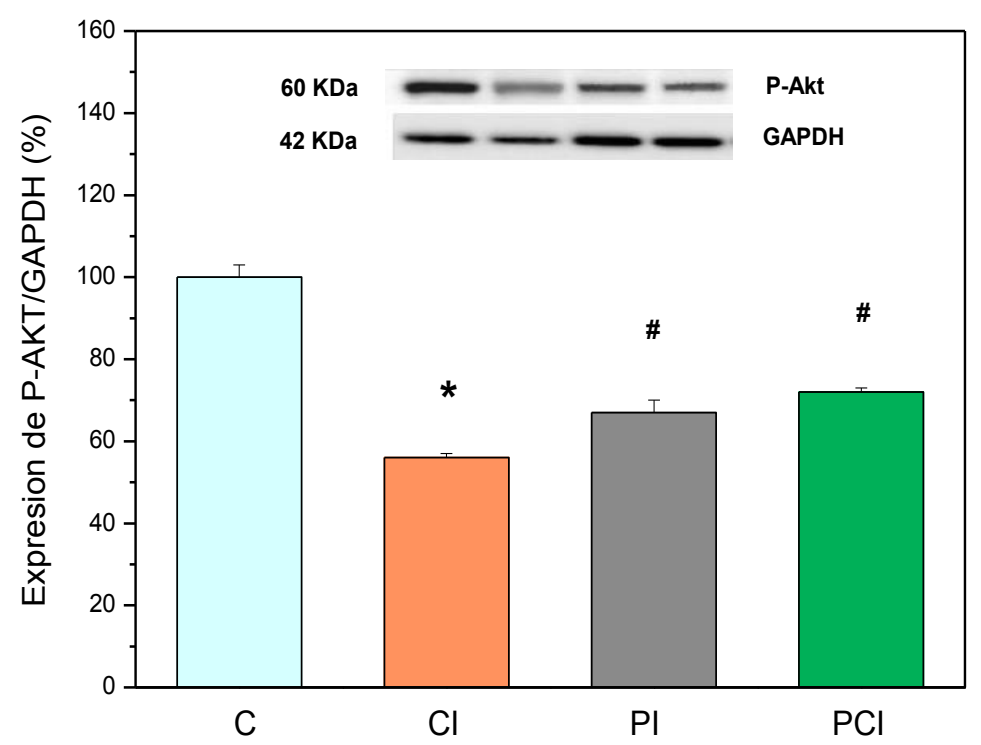

Figura 23: Contenido de P-Akt/GAPDH, expresado como porcentaje del valor obtenido en el grupo C (100 $\pm 2 \%$ ), en los grupos CI, PI, PCI. * $\mathrm{p}<0,05$ con respecto a C; \# $\mathrm{p}<0,05$ con respecto a CI.

\section{$\underline{\text { Sensibilidad del PPTM al } \mathrm{Ca}^{2+} \text { : }}$}

El agregado de $\mathrm{Ca}^{2+}$ a las suspensiones mitocondriales produce dispersión de la luz. El cambio de dispersión de la luz que ocurre entre el tiempo o y los 5 min es una medida de la sensibilidad del PPTM al $\mathrm{Ca}^{2+}$ (Figura 24). Como se observa en la figura a continuación la menor sensibilidad al $\mathrm{Ca}^{2+}$ la poseen las mitocondrias del grupo CI y la mayor las del grupo C. 


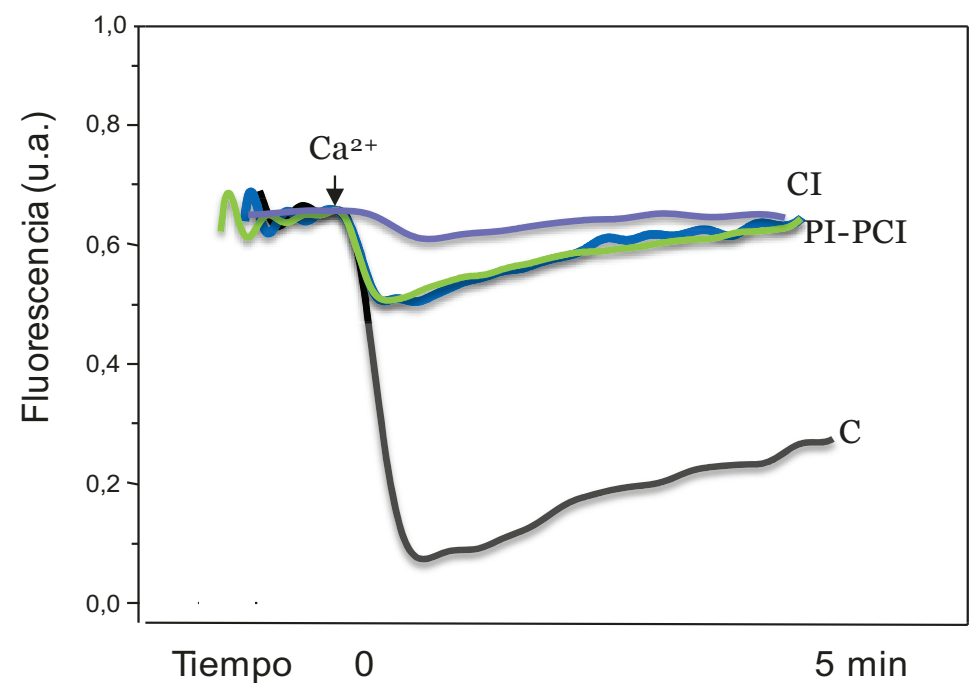

Figura 24: Registros típicos de los cambios de fluorescencia producidos por el agregado de $\mathrm{Ca}^{2+}$ a mitocondrias aisladas de los grupos C, CI, PI y PCI.

Los valores medios se muestran en la Figura 25. Las mitocondrias aisladas de los corazones perfundidos pero no sometidos a isquemia (grupo C) mostraron una disminución de la dispersión de la luz de $\mathbf{0 , 7 4} \pm \mathbf{0 , 0 7}$ unidades arbitrarias (u.a.) (n=6) ante el agregado de $\mathrm{Ca}^{2+}$. La isquemia de 45 min seguida de reperfusión durante 60 min empeoró la respuesta de las mitocondrias al $\mathrm{Ca}^{2+}$ y la dispersión de la luz disminuyó a $\mathbf{0 , 0 6} \pm \mathbf{0 , 0 1}$ u.a. $(\mathrm{n}=6)$. En los corazones pre y postacondicionados la sensibilidad del PPTM al $\mathrm{Ca}^{2+}$ mejoró significativamente, siendo los valores de $\mathbf{0 , 2 3} \pm \mathbf{0 , 0 3}$ u.a. $(\mathrm{n}=6)$ en el grupo PI y de $\mathbf{0 , 2 9} \pm$ o,o3 u.a. $(\mathrm{n}=6)$ en el grupo PCI (Figura 25). 


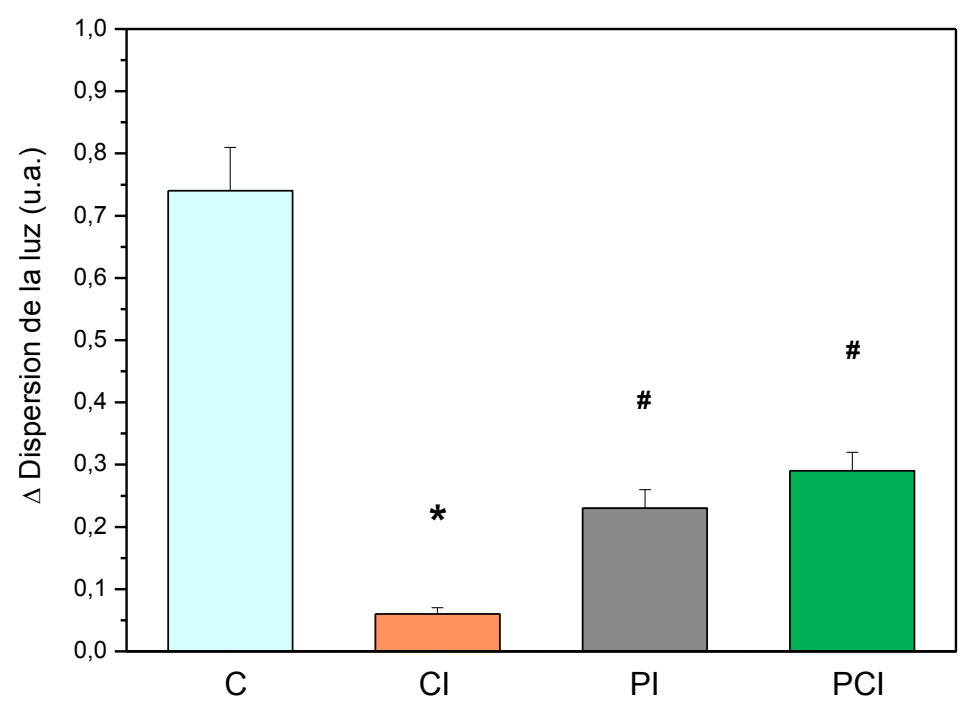

Figura 25: Cambio de la dispersión de la luz, expresado en unidades arbitrarias (u.a.), por el agregado de $200 \mu \mathrm{M}$ de $\mathrm{Cl}_{2} \mathrm{Ca}$, a mitocondrias aisladas de corazones de los grupos $\mathrm{C}, \mathrm{CI}, \mathrm{PI}, \mathrm{PCI}$. ${ }^{*} \mathrm{p}<$ 0,05 con respecto a $\mathrm{C}$; \# $\mathrm{p}<0,05$ con respecto a CI.

\section{Ultraestructura mitocondrial (Figura 26)}

En el grupo control (C) se observan mitocondrias con ultraestructura normal, con escaso edema y preservación de las crestas. La aplicación del protocolo de isquemia-reperfusión provocó muerte celular, acompañada por un elevado grado de edematización y destrucción de las crestas mitocondriales (CI). En los corazones pre y postacondicionados (PI y PCI) se observan algunas mitocondrias con ultraestructura normal, persistiendo la presencia de edema significativo y organelas dañadas. 
C

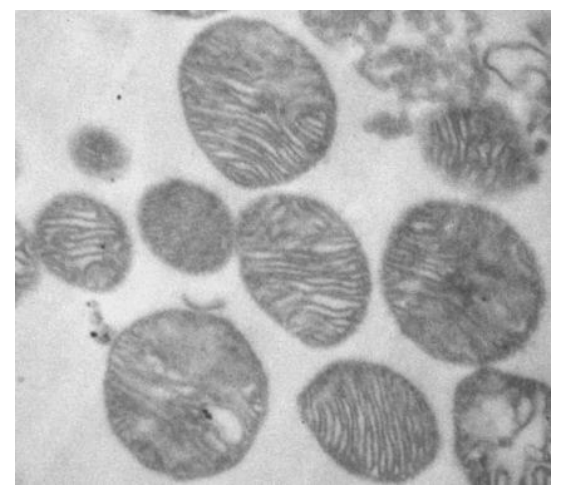

PI

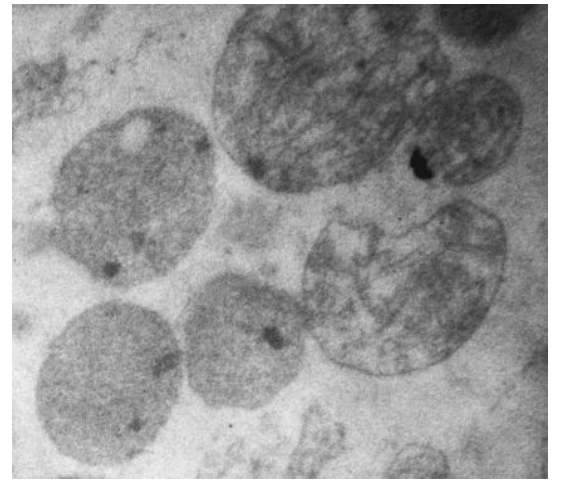

CI

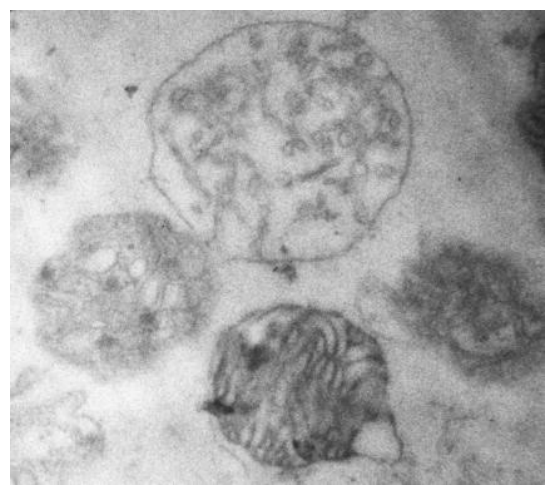

PCI

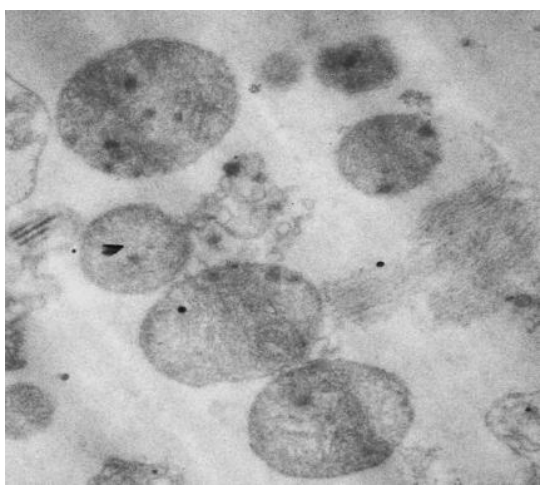

Figura 26: Fotomicrografía de microscopio electrónico ( $x$ 25000) de mitocondrias aisladas pertenecientes a corazones de los grupos control (C), control isquémico (CI), preacondicionado (PI) y postacondicionado (PCI).

La aplicación de $45 \mathrm{~min}$ de isquemia global y 60 min de reperfusión a corazones aislados de SHR, comparado a los controles no-isquémicos, produjo:

1-Aumento del tamaño del infarto

2-Disminución abrupta de la función sistólica miocárdica

3- Aumento de la rigidez diastólica y de la resistencia vascular

4-Aumento del daño oxidativo

5-Disminución de P-GSK-3 $\beta$ y P-Akt

6.-Disminución de la sensibilidad del PPTM al $\mathrm{Ca}^{2+}$.

7-Alteración de la ultraestructura mitocondrial. 


\section{Las intervenciones PI y PCI produjeron:}

1-Disminución del tamaño del infarto

2-No modificaron la recuperación postisquémica de la función miocárdica y vascular

3- Disminución del daño oxidativo evidenciado por:

- Disminución de la peroxidación lipídica.

- Preservación parcial del contenido de GSH.

- Disminución de la actividad de SODT y SODMn.

4- Aumento de la expresión de P-GSK3ß y de P-Akt.

5- Aumento de la sensibilidad del PPTM al $\mathrm{Ca}^{2+}$.

6- Conservación parcial de la ultraestructura mitocondrial.

\section{Participación de la glucógeno sintetasa quinasa $3 \beta$ (GSK-3 $\beta$ ) en isquemia- reperfusión en el PI y PCI.}

Siendo la GSK-3 $\beta$ una enzima clave en las cascadas de protección, los datos que a continuación se detallan son los obtenidos inhibiendo dicha enzima con un inhibidor no específico como el ClLi y otro específico como el 5-Yodo-Indirubin-3-Monoxime (IMI). La administración de dichos inhibidores fue realizada antes de la isquemia de 45 min (grupos ClLi Pre e IMI Pre) y en los primeros 3 min de la reperfusión (grupos ClLi Post e IMI Post).

Tamaño del Infarto

En la Figura 27 se muestran los valores promedio de los tamaños de infarto medidos al final del período de reperfusión en corazones de ratas SHR pertenecientes a los grupos CI, Cl Li Pre, IMI Pre, Cl Li Post e IMI Post. En el grupo CI el valor fue de $5 \mathbf{1} \pm \mathbf{4}$ \%, el cual disminuyó significativamente con el tratamiento con los inhibidores. Los valores fueron de $\mathbf{3 6} \pm \mathbf{2}$ \% $(n=6)$ para el grupo ClLi Pre y de $37 \pm \mathbf{3} \%(n=6)$ para el grupo ClLi Post. Resultados 
similares se obtuvieron con el tratamiento con IMI, obteniéndose valores de $\mathbf{3 3} \pm \mathbf{1} \%$ ( $\mathrm{n}=6)$ para el grupo IMI Pre y $36 \pm \mathbf{2} \%(\mathrm{n}=6)$ para el grupo IMI Post.

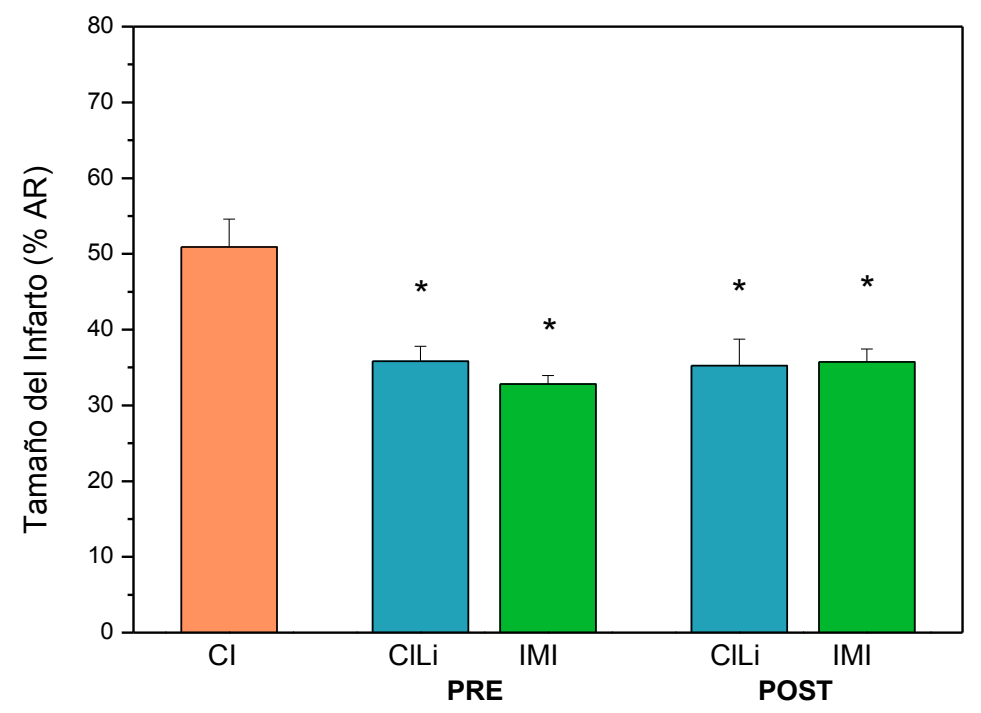

Figura 27: Tamaño del infarto, expresado como porcentaje del área de riesgo (AR), en CI: grupo control isquémico; ClLi e IMI PRE: ClLi e IMI administrados antes de la isquemia; ClLi e IMI POST: administradas al inicio de la reperfusión. * $\mathrm{p}<0,05$ con respecto a CI.

\section{Función sistólica y diastólica}

La recuperación postisquémica de la función miocárdica observada en los corazones tratados con ClLi e IMI fue similar a la obtenida en los corazones CI. Al final del período de reperfusión la PDVI y la $+\mathrm{dP} / \mathrm{dt}_{\max }$ adquirieron valores del orden del 1 al $1.5 \%$ de los valores preisquémicos. La PDF mostró valores de aproximadamente $115 \mathrm{mmHg}$ en todos los grupos tratados, que fueron similares a los observados en el grupo isquémico no tratado. La presión de perfusión de los 4 grupos tratados (ClLi Pre, ClLi Post, IMI Pre e IMI Post) aumentó durante la reperfusión alcanzando valores similares a los obtenidos en el grupo CI (aproximadamente $130 \mathrm{mmHg}$ ). Al término de la reperfusión (60 $\mathrm{min}$ ) la resistencia coronaria aumentó y adquirió valores similares a los del grupo CI (aproximadamente 5 $\mathrm{mmHg} / \mathrm{ml} \mathrm{x} \mathrm{min}^{-1}$ ). 
Evaluación del daño oxidativo y sistema de defensa antioxidante

-Sustancias reactivas al ácido tiobarbitúrico (TBARS)

La concentración de TBARS obtenida en los corazones pertenecientes al grupo control isquémico $(\mathbf{0 , 5 7} \pm \mathbf{0 , 0 4} \mathrm{nmol} / \mathrm{mg}$ prot$)$ fue significativamente disminuída por la administración antes ó después de la isquemia de ambos inhibidores de GSK-3 $\beta$ (Figura 28). Los valores fueron de $\mathbf{0 , 3 7} \pm \mathbf{0 , 0 5} \mathrm{nmol} / \mathrm{mg}$ prot en el grupo ClLi Pre (n=6), $\mathbf{0 , 2 9} \pm \mathbf{0 , 0 5}$ $\mathrm{nmol} / \mathrm{mg}$ prot en el grupo IMI Pre $(\mathrm{n}=6), \mathbf{0 , 3 8} \pm \mathbf{0 , 0 4} \mathrm{nmol} / \mathrm{mg}$ prot en el grupo ClLi Post $(\mathrm{n}=6)$ y $\mathbf{0 , 2 9} \pm \mathbf{0 , 0 6} \mathrm{nmo} / \mathrm{mg}$ prot en IMI Post $(\mathrm{n}=6)$. No se observaron diferencias estadísticamente significativas entre los grupos tratados con ClLi e IMI.

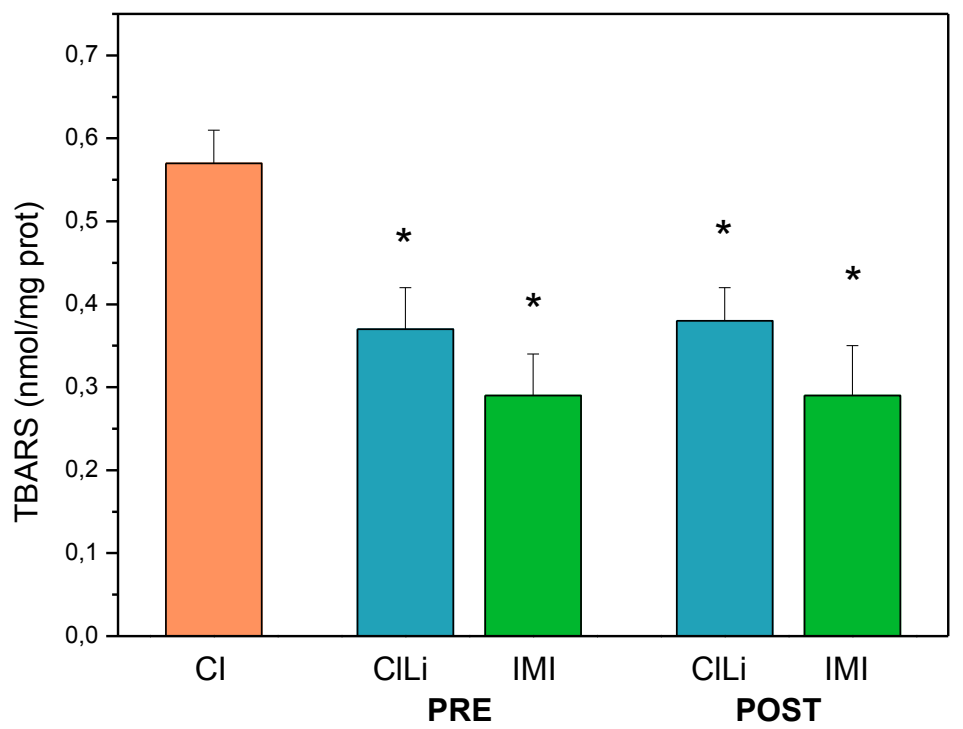

Figura 28: Concentración de TBARS, expresada en nmoles por mg de proteína, en los grupos CI, ClLi (PRE y POST) e IMI (PRE y POST). * $\mathrm{p}<0,05$ con respecto a CI.

-Glutatión reducido (GSH)

El contenido de GSH obtenido en los corazones del grupo CI $(\mathbf{0 , 9 4} \pm \mathbf{0 , 1 5} \mu \mathrm{mol} / \mathrm{mg}$ prot $)$ aumentó significativamente en los grupos tratados con ClLi e IMI. Los valores hallados fueron de: 1,55 $\pm \mathbf{0 , 1 7}, \mathbf{2 , 0 7} \pm \mathbf{0 , 1 6}, \mathbf{2 , 1 2} \pm \mathbf{0 , 7}$ y $\mathbf{2 , 2 5} \pm \mathbf{0 , 3 3} \mu \mathrm{mol} / \mathrm{mg}$ prot para los grupos ClLi Pre, IMI Pre, ClLi Post e IMI Post, respectivamente (Figura 29). 


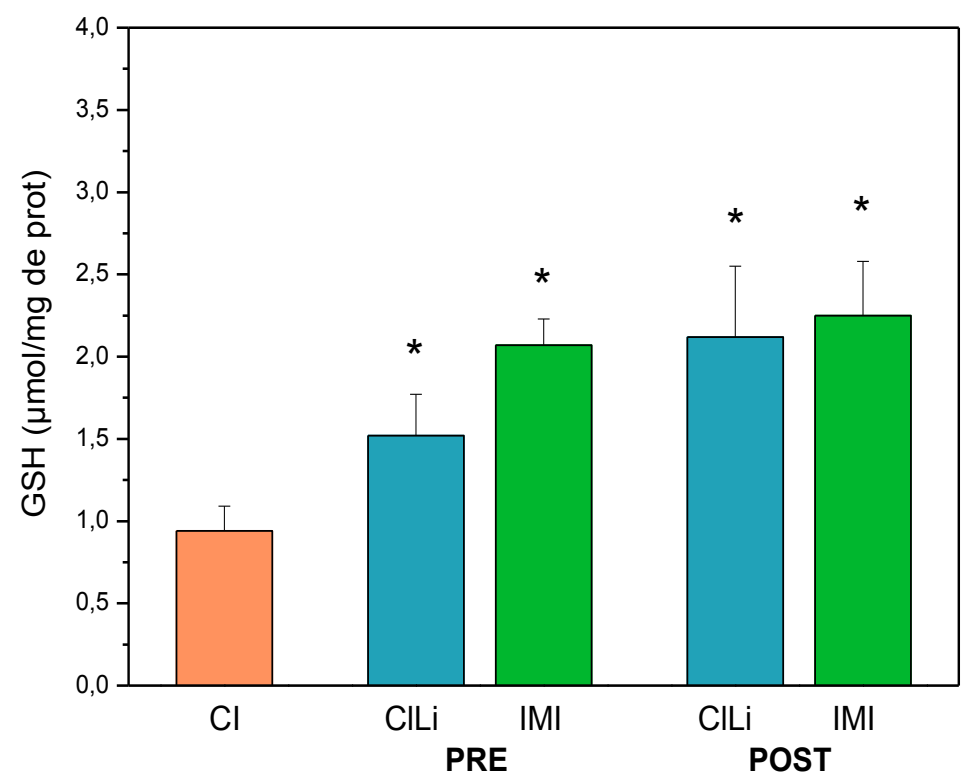

Figura 29: Contenido de glutatión reducido (GSH), expresado en $\mu$ g por mg de proteína, en los grupos CI, ClLi (PRE y POST) e IMI (PRE y POST).* p < 0,05 con respecto a CI.

-Actividad citosólica de Superóxido Dismutasa Total (SOD T):

La actividad citosólica de la SOD total (SOD T) disminuyó significativamente en los grupos tratados con ambos inhibidores de la GSK-3 $\beta$ con respecto al valor observado en el grupo CI (Figura 30).

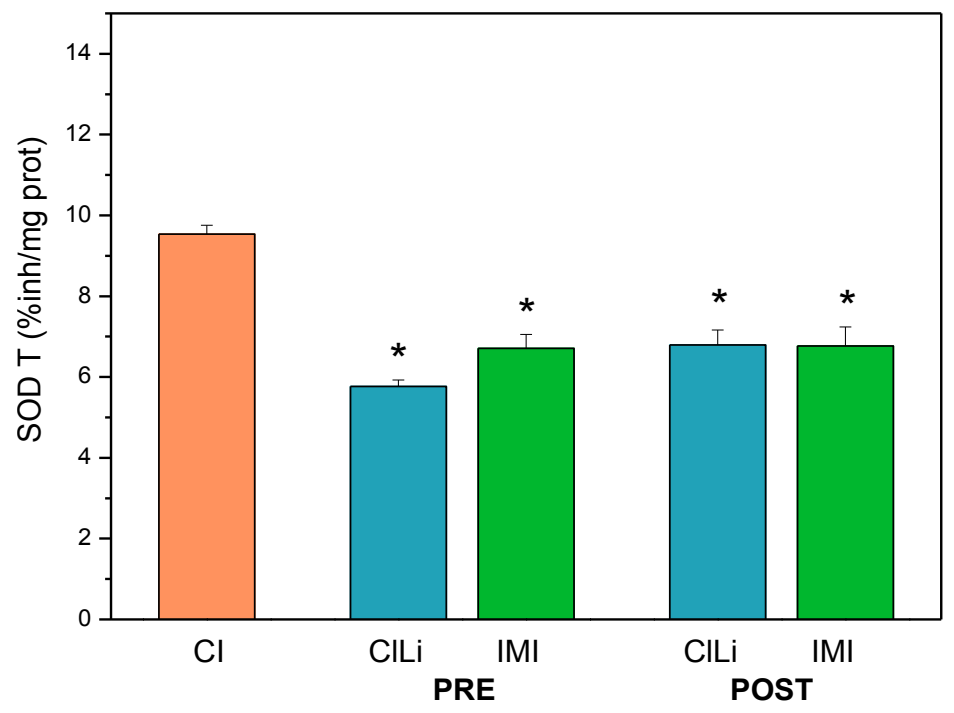

Figura 30: Actividad citosólica de SOD total (SOD T), expresada en porcentaje de inhibición por mg de proteína, en los grupos CI, ClLi (PRE y POST) e IMI (PRE y POST). * $\mathrm{p}<0,05$ con respecto a CI. 
Los valores obtenidos fueron de $\mathbf{9 , 5 4} \pm \mathbf{0 , 2 2} \%$ inhibición/mg prot para el grupo CI, 5,77 \pm o,16 y 6,71 \pm 0,34 \% inhibición/mg prot para los grupos ClLi Pre e IMI Pre. En los corazones pertenecientes a los grupos ClLi Post e IMI Post los valores fueron de $\mathbf{6 , 7 9} \pm \mathbf{0 , 3 7}$ y $6,77 \pm \mathbf{0 , 4 7} \%$ inhibición/mg prot, respectivamente.

-Actividad citosólica de Superóxido Dismutasa dependiente de Manganeso (SODMn):

La actividad citosólica de SODMn disminuyó significativamente con los tratamientos con ClLi e IMI. En el grupo CI el valor fue de $\mathbf{1 0 , 0 2} \pm \mathbf{0 , 3 8} \%$ inhibición/mg prot. En los corazones tratados los valores fueron: $6,58 \pm \mathbf{0 , 3 0}$ y $6,95 \pm \mathbf{0 , 3 4} \%$ inhibición $/ \mathrm{mg}$ prot en los grupos ClLi Pre y ClLi Post respectivamente, y 6,97 \pm o,36 y 7,o8 \pm o,62 en IMI Pre e IMI Post respectivamente (Figura 31).

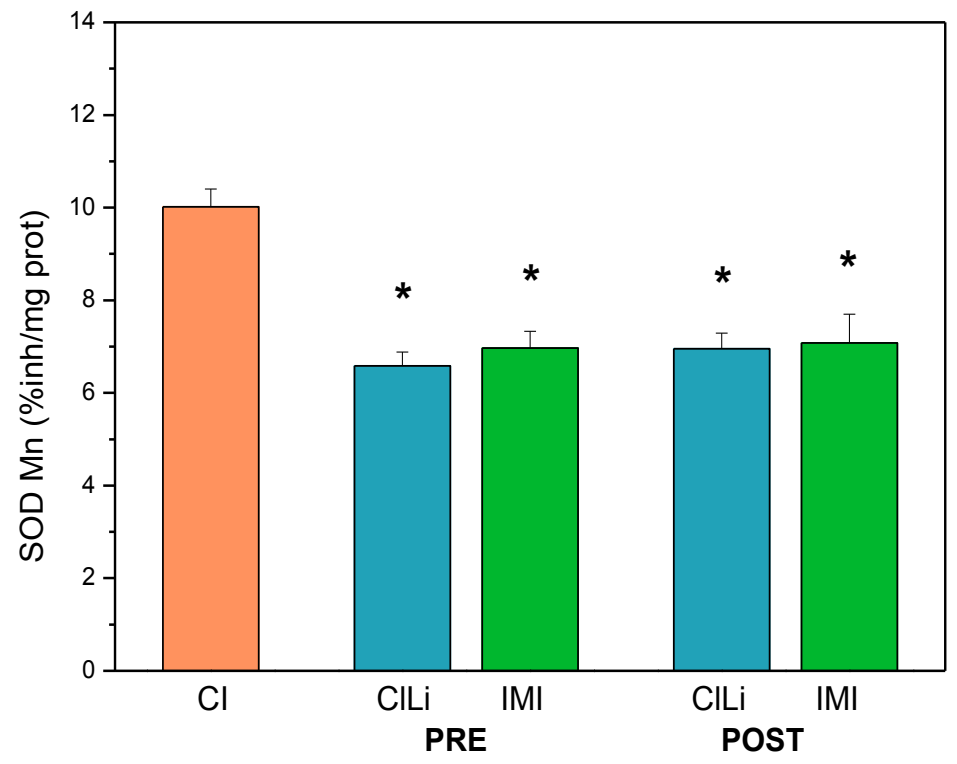

Figura 31: Actividad citosólica de SOD Mn, expresadas como porcentaje de inhibición por mg de proteína, en corazones de los grupos CI, ClLi (PRE y POST) e IMI (PRE y POST). * p < 0,05 con respecto a $\mathrm{CI}$

\section{Expresión de P-GSK-3ß y P-Akt}

La expresión de P-GSK-3 $\beta$ disminuyó en el grupo CI $(\mathbf{4 1} \pm \mathbf{3} \%)$ y este valor aumentó significativamente en los corazones tratados con ClLi e IMI. Los valores fueron de $\mathbf{8 4} \pm \mathbf{2} \%$ y 
$84 \pm 1 \%$ en los grupos en los cuales las drogas fueron administradas previamente a la isquemia y de $85 \pm 3 \%$ y $82 \pm \mathbf{1} \%$ en aquellos en los que la infusión de ambos bloqueantes de GSK-3 $\beta$ fue realizada al comienzo de la reperfusión (Figura 32).

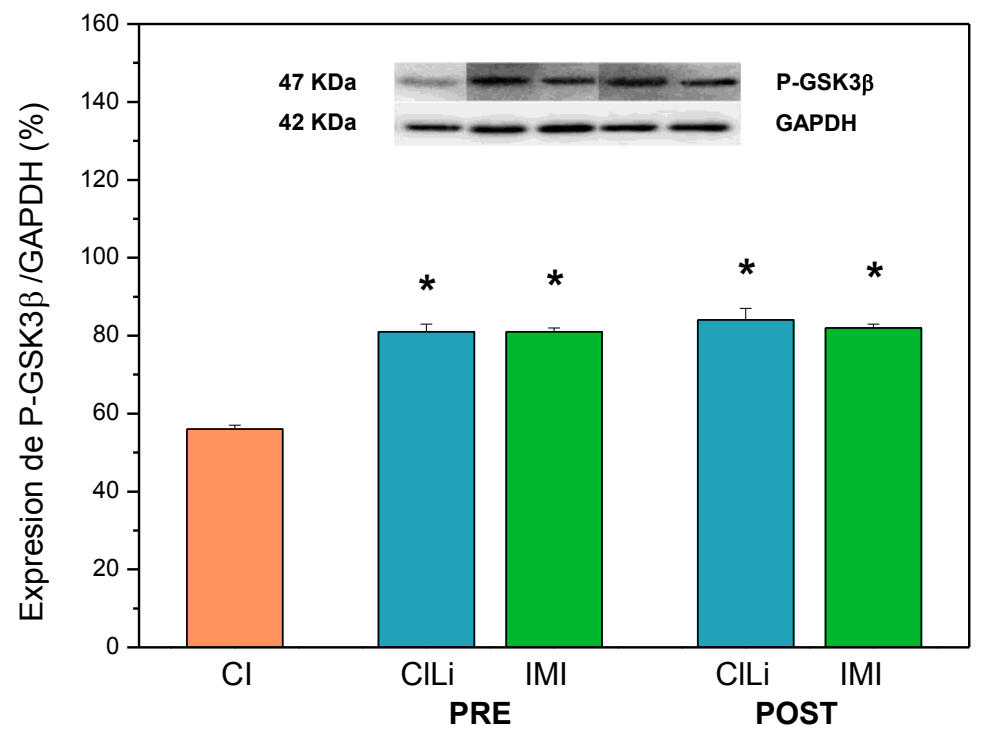

Figura 32: Expresión de P-GSK-3 $\beta /$ GAPDH, expresada como porcentaje del valor obtenido en el grupo C (100 $\pm 2 \%)$, en los grupos CI, ClLi e IMI PRE y ClLi e IMI POST. * $\mathrm{p}<0,05$ con respecto a CI

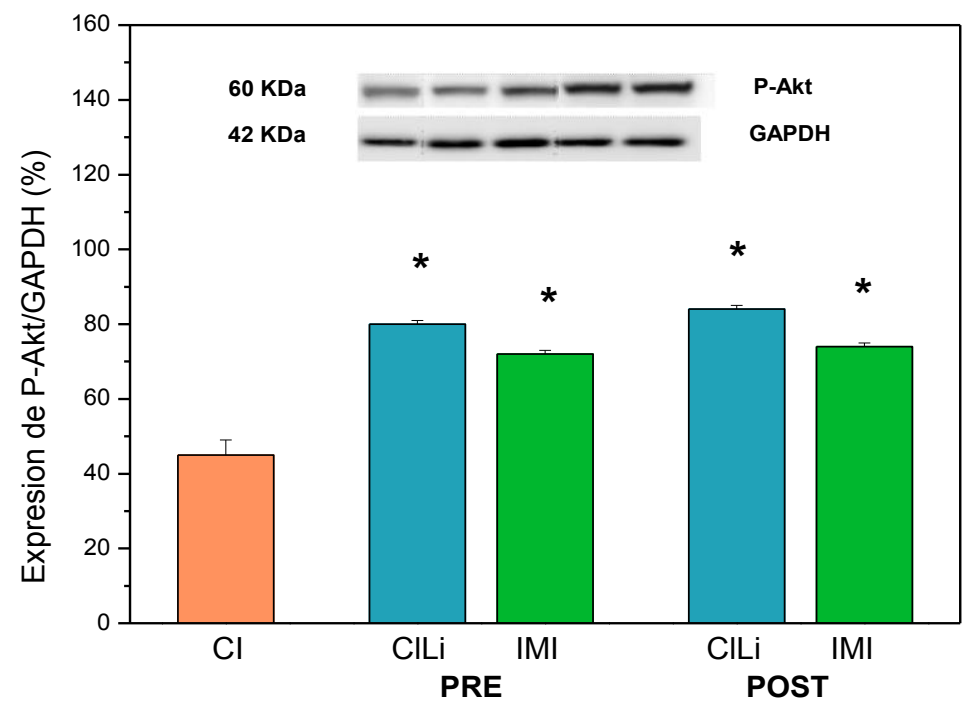

Figura 33: Expresión de P-Akt/GAPDH, expresada como porcentaje del valor obtenido en el grupo C (100 $\pm 3 \%$ ), en los grupos CI, ClLi e IMI PRE y ClLi e IMI POST. * $\mathrm{p}<0,05$ con respecto a CI 
La expresión de P-Akt disminuyó en el grupo CI (56 $\pm \mathbf{2}$ \%) con respecto al valor hallado en los corazones controles no isquémicos. En los corazones tratados previamente a la isquemia ó al inicio de la reperfusión con ClLi e IMI la expresión de P-Akt aumentó. Los valores fueron de $82 \pm 1 \%$ y $80 \pm 1 \%$ para los grupos PRE y de $85 \pm 1 \%$ y $78 \pm 1 \%$ para los grupos POST (Figura 33).

\section{Sensibilidad del PPTM al $\mathrm{Ca}^{2+}$ :}

En las mitocondrias de corazones tratados con cualquiera de los dos inhibidores de GSK- $3 \beta$ se observó un aumento significativo en la sensibilidad del PPTM al $\mathrm{Ca}^{2+}$. El grupo CI exhibió un decaimiento de la dispersión de la luz de $\mathbf{0 , 0 6} \pm \mathbf{0 , 0 1}$ u.a. En los grupos tratados los valores fueron de $\mathbf{0 , 3 5} \pm \mathbf{0 , 0 5}$ y $\mathbf{0 . 2 4} \pm \mathbf{0 . 0 3}$ u.a. en los grupos ClLi e IMI PRE y de $\mathbf{0 , 2 7} \pm \mathbf{0 , 0 4}$ y $\mathbf{0 , 1 8} \pm \mathbf{0 , 0 4}$ u.a. para los grupos ClLi e IMI POST, respectivamente (Figura 34).

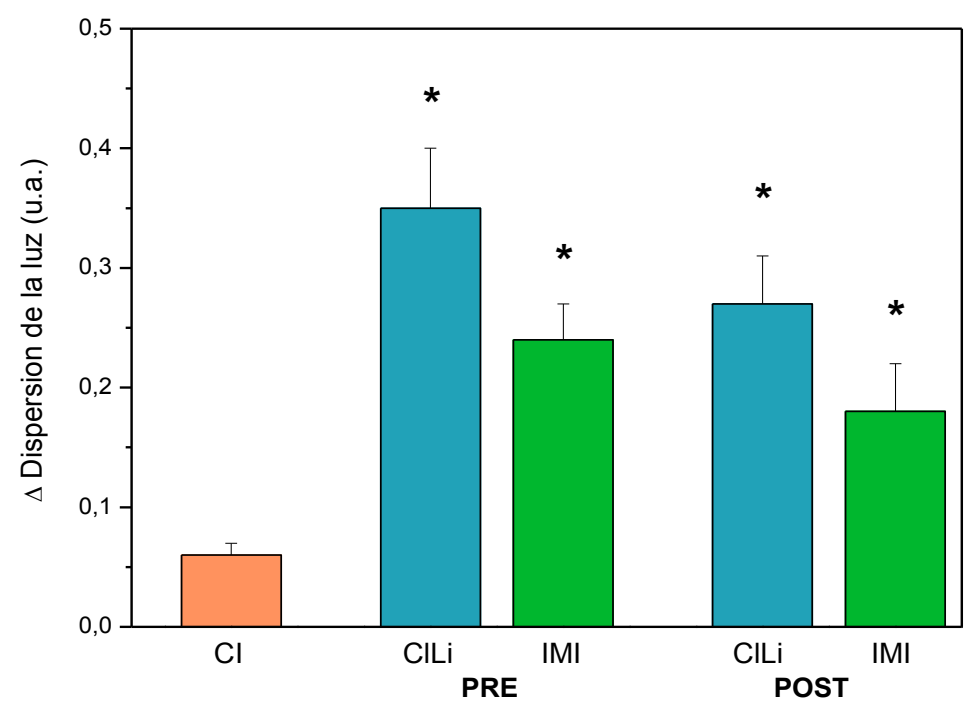

Figura 34: Cambio de la dispersión de la luz, expresado en unidades arbitrarias (u.a.), por el agregado de $200 \mu \mathrm{M} \mathrm{de} \mathrm{Cl}_{2} \mathrm{Ca}$, en corazones de los grupos CI, ClLi (PRE y POST) e IMI (PRE y POST). ${ }^{*} \mathrm{p}<0,05$ con respecto a $\mathrm{CI}$.

Ultraestructura mitocondrial:

En la Figura 35 se observa el efecto de los tratamientos con ClLi e IMI Pre y Post sobre la ultraestructura de las mitocondrias aisladas de dichos grupos experimentales. Como se muestra en dicha figura ambos inhibidores de GSK- $3 \beta$ mejoraron el aspecto morfológico de las mitocondrias respecto de lo observado en los corazones isquémicos sin tratamiento, detectándose mitocondrias con ultraestructura normal. 


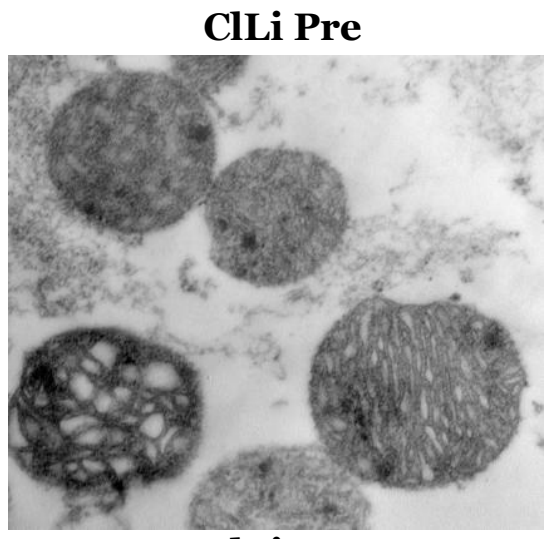

ClLi Post

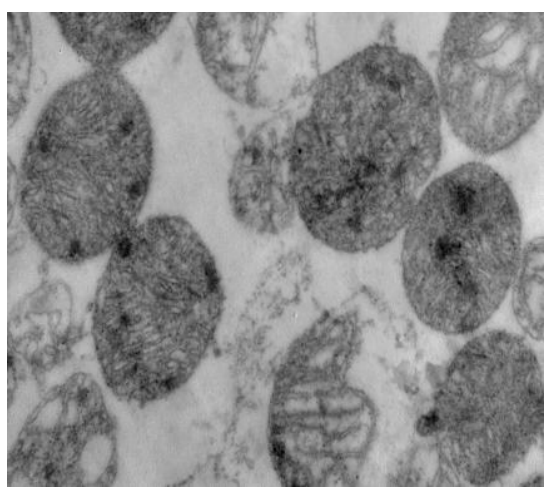

IMI Pre

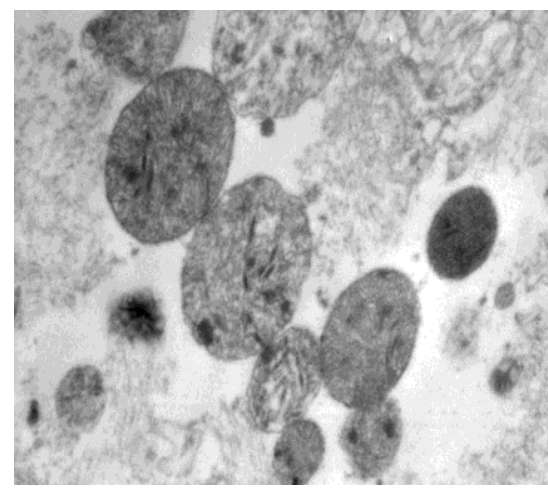

IMI Post

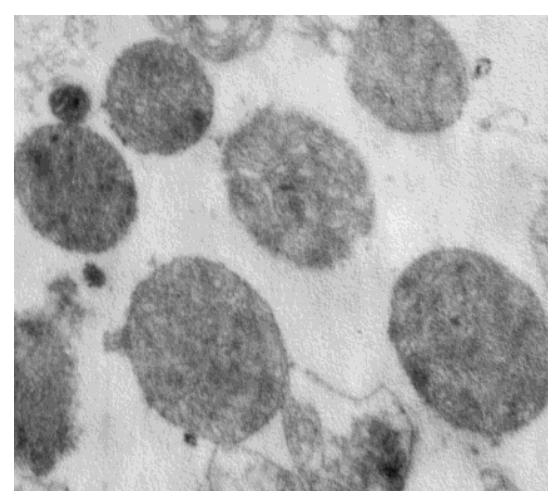

Figura 35: Fotomicrografía de microscopio electrónico ( $x$ 2500o) de mitocondrias aisladas pertenecientes a corazones de los grupos tratados con ClLi e IMI previamente a la isquemia (ClLi e IMI Pre) ó al comienzo de la reperfusión (ClLi e IMI Post).

Nuestros resultados muestran que, el tratamiento previo a la isquemia (Pre) ó al inicio de la reperfusión (Post) con los inhibidores de GSK-3ß, ClLi e IMI, produjo:

1-Disminución del tamaño del infarto

2-No modificó la recuperación postisquémica de la función miocárdica y vascular

3- Disminución del daño oxidativo evidenciado por:

- Disminución de la peroxidación lipídica

- Preservación parcial del contenido de GSH

- Disminución de la actividad de SODT y SODMn4- Aumento de la expresión de P-GSK3 $\beta$ y de P-Akt

5- Aumento de la sensibilidad del PPTM al $\mathrm{Ca}^{2+}$

6- Conservación parcial de la ultraestructura mitocondrial 


\section{Papel de PI3K/Akt en isquemia-reperfusión $y$ en el pre $y$ postacondicionamiento isquémicos (PI y PCI)}

Tamaño del Infarto

En la Figura 36 se muestran los valores correspondientes a los tamaños de infarto para el grupo CI y para los grupos pre y postacondicionados, en presencia y ausencia de wortmanina, inhibidor de PI3K/Akt. En el grupo CI el valor promedio fue de $51 \pm 4 \%$ y este valor disminuyó significativamente en los grupos PI: $34 \pm \mathbf{1} \%$ y PCI: $36 \pm 4 \%$. El tratamiento con wortmanina (W) anuló el efecto cardioprotector del PI y PCI, obteniéndose tamaños de infarto similares a los observados en los corazones controles isquémicos. Estos valores fueron: $\mathbf{5 8} \pm \mathbf{7}$ \% en el grupo PI + W (n=6), y de $49 \pm \mathbf{1} \%(n=6)$ en el grupo PCI $+W$. El agregado de W a corazones del grupo $\mathrm{CI}(\mathrm{n}=6)$ no modificó el tamaño del infarto (49 $\pm 2 \%)$.

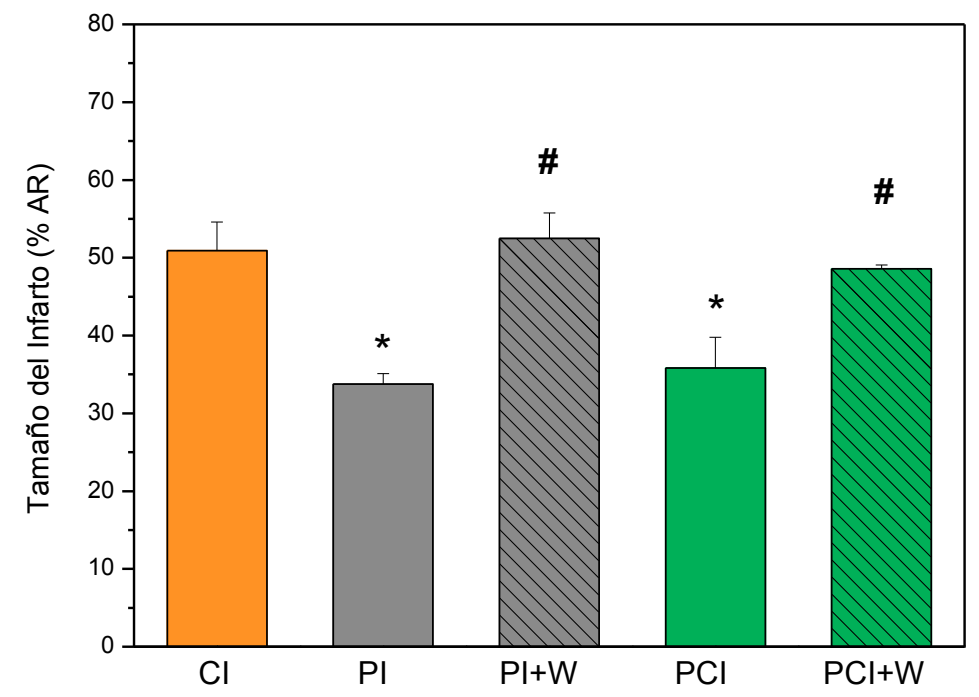

Figura 36: Tamaño del infarto, expresado como porcentaje del área de riesgo (AR), en los grupos CI, $\mathrm{PI}, \mathrm{PI}+\mathrm{W}$, PCI y PCI + $\mathrm{W}^{*} \mathrm{p}<0,05$ con respecto a C; \# $\mathrm{p}<0,05$ con respecto a CI.

Función sistólica y diastólica

La recuperación postisquémica de la función miocárdica observada en los corazones tratados con W fue similar a la obtenida en los grupos PI y PCI. Al final del período de reperfusión la 
PDVI y la $+\mathrm{dP} / \mathrm{dt}_{\max }$ adquirieron valores del orden del $1 \%$ de los valores preisquémicos. La PDF mostró valores de aproximadamente $110 \mathrm{mmHg}$ en todos los grupos tratados. La presión de perfusión de los grupos $\mathrm{PI}+\mathrm{W}$ y $\mathrm{PCI}+\mathrm{W}$ aumentó durante la reperfusión alcanzando valores similares a los obtenidos en el grupo CI (aproximadamente $130-140 \mathrm{mmHg}$ ). Al final de la reperfusión la resistencia coronaria aumentó y adquirió valores de aproximadamente 5 $\mathrm{mmHg} / \mathrm{ml} \times \mathrm{min}^{-1}$. El agregado de $\mathrm{W}$ a corazones del grupo CI no modificó la respuesta contráctil y vascular.

\section{Evaluación del daño oxidativo y sistema de defensa antioxidante}

-Sustancias reactivas al ácido tiobarbitúrico (TBARS)

En la Figura 37 se muestra que la concentración de TBARS aumentó cuando los corazones fueron tratados con W, anulando el efecto protector del PI y PCI sobre la peroxidación lipídica. Los valores fueron: $\mathbf{0 , 6 9} \pm \mathbf{0 , 0 5} \mathrm{nmol} / \mathrm{mg}$ prot en el grupo PI $+\mathrm{W}$ y $\mathbf{0 , 6 5} \pm \mathbf{0 , 0 3}$ $\mathrm{nmol} / \mathrm{mg}$ prot en el grupo PCI $+\mathrm{W}$, que fueron significativamente mayores que los obtenidos en los grupos PI y PCI, respectivamente.

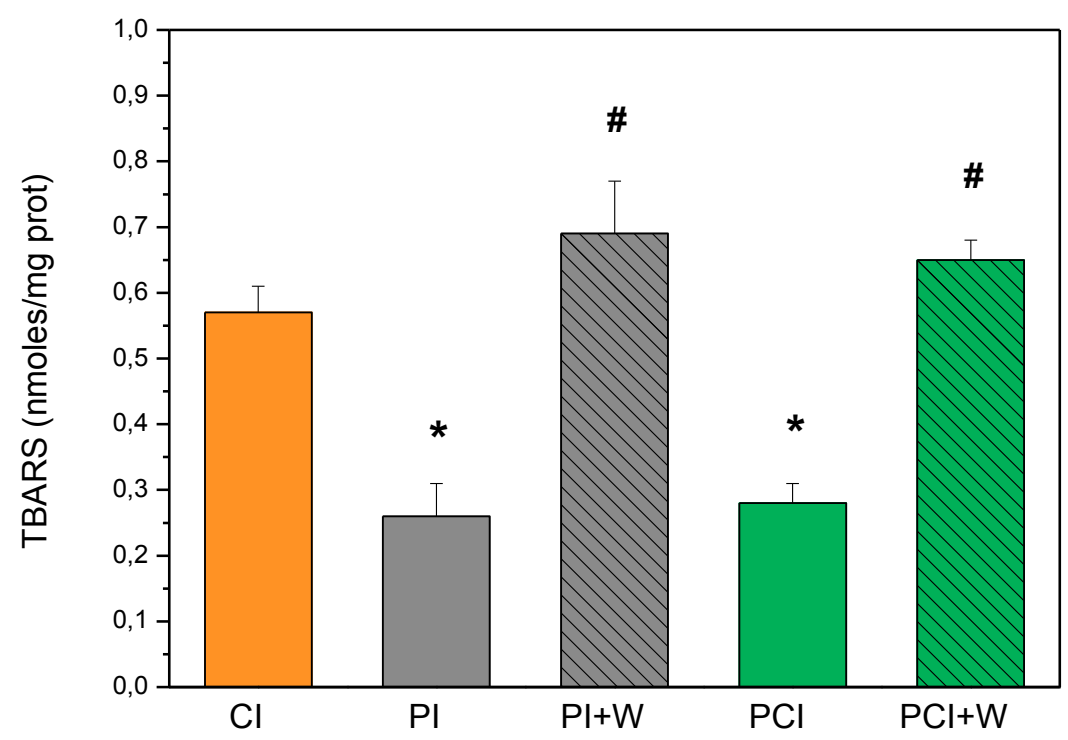

Figura 37: Concentración de TBARS, expresada en nmoles por mg de proteína, en los grupos CI, PI, $\mathrm{PI}+\mathrm{W}, \mathrm{PCI}$, y PCI $+\mathrm{W}$. ${ }^{*} \mathrm{p}<0,05$ con respecto a CI; \# p $<0.05$ con respecto a PI y PCI. 


\section{-Glutatión reducido (GSH):}

Como mostramos anteriormente el PI y el PCI preservaron parcialmente los niveles de GSH con respecto al observado en el grupo CI. Cuando estas intervenciones fueron realizadas en presencia del inhibidor de PI3K/Akt, los contenidos de GSH fueron similares a los del grupo CI (Figura 38).

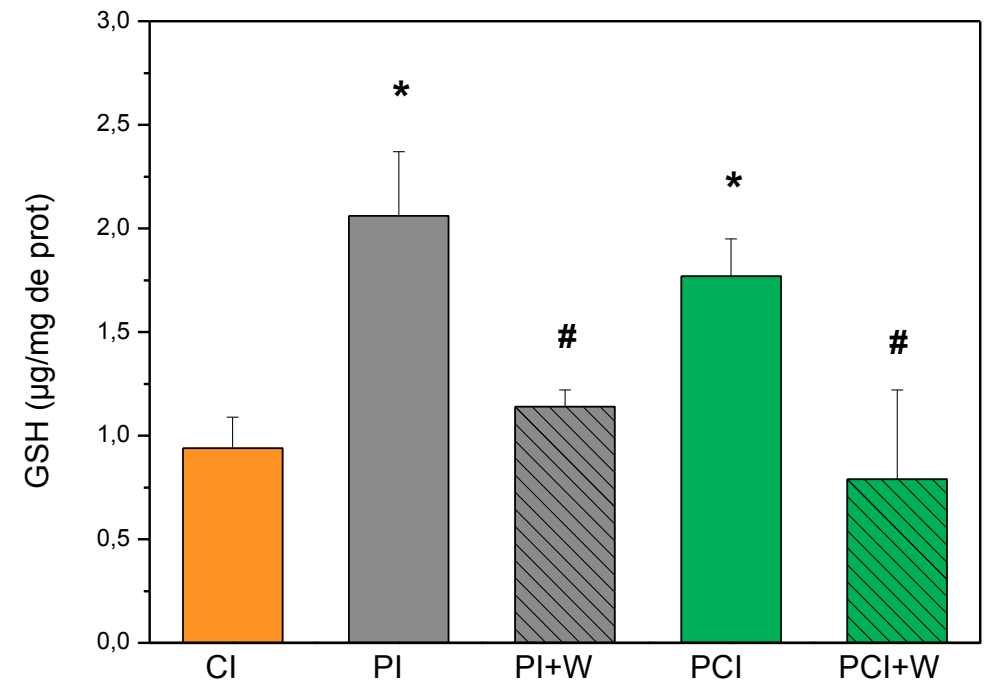

Figura 38: Contenido de glutatión reducido (GSH), expresado en $\mu$ g por mg de proteína, en los grupos CI, PI, PI + W, PCI y PCI + W. * p $<0,05$ con respecto a CI; \# p< 0.05 con respecto a PI y PCI.

-Actividad citosólica de Superóxido Dismutasa Total (SOD T):

La actividad citosólica de la SOD Total (SODT) disminuyó en los grupos PI y PCI con respecto a lo observado en el grupo CI $\mathbf{( 5 , 7 8} \pm \mathbf{0 , 7 8}$ y $\mathbf{6 , 4 5} \pm \mathbf{0 , 7 5}$, respectivamente vs. 9,54 $\pm \mathbf{0 , 2 2}$ \% inhibición/mg prot). El tratamiento con $\mathrm{W}$ previo a la aplicación de ambos protocolos cardioprotectores produjo un aumento de la actividad de SODT. Los valores fueron de: 10.05 $\pm \mathbf{0 . 5 7}$ y de $\mathbf{1 0 . 1 7} \pm \mathbf{0 . 5 5} \%$ inhibición/mg prot para los grupos PI + W y PCI + W, respectivamente (Figura 39). 


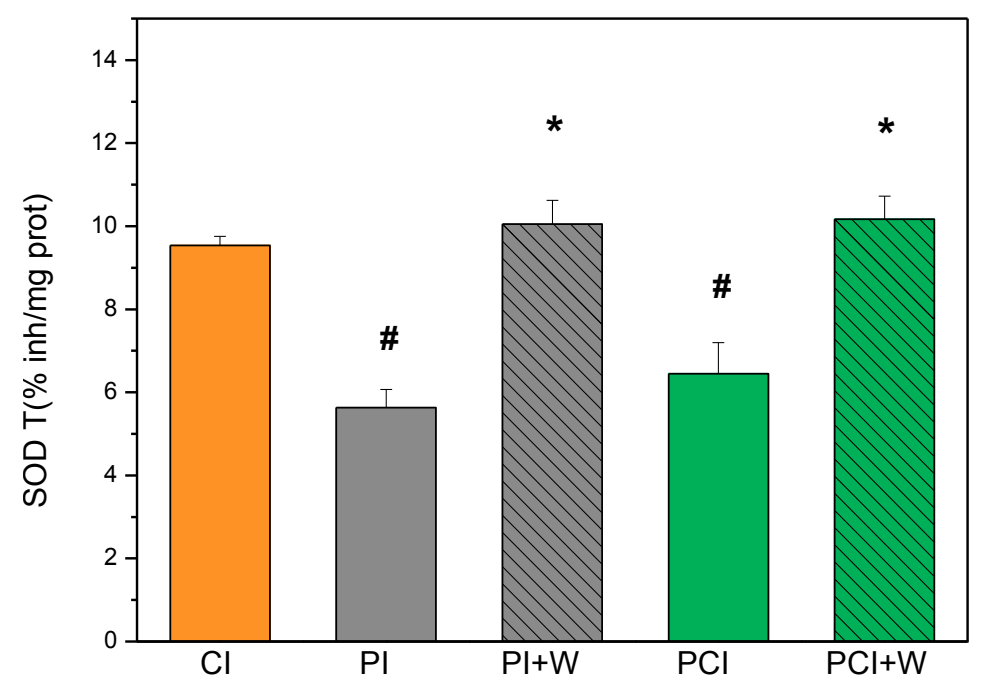

Figura 39: Actividad citosólica de SOD total (SODT), expresada como porcentaje de inhibición por mg de proteína, en corazones de los grupos CI, PI, PI + W, PCI y PCI + W. * p < 0,05 con respecto a CI; \# $\mathrm{p}<0.05$ con respecto a PI y PCI.

-Actividad citosólica de Superóxido Dismutasa dependiente de Manganeso (SODMn):

El aumento de la actividad citosólica de SODMn obtenido en los corazones controles isquémicos (grupo CI) disminuyó significativamente con los protocolos de PI y PCI.

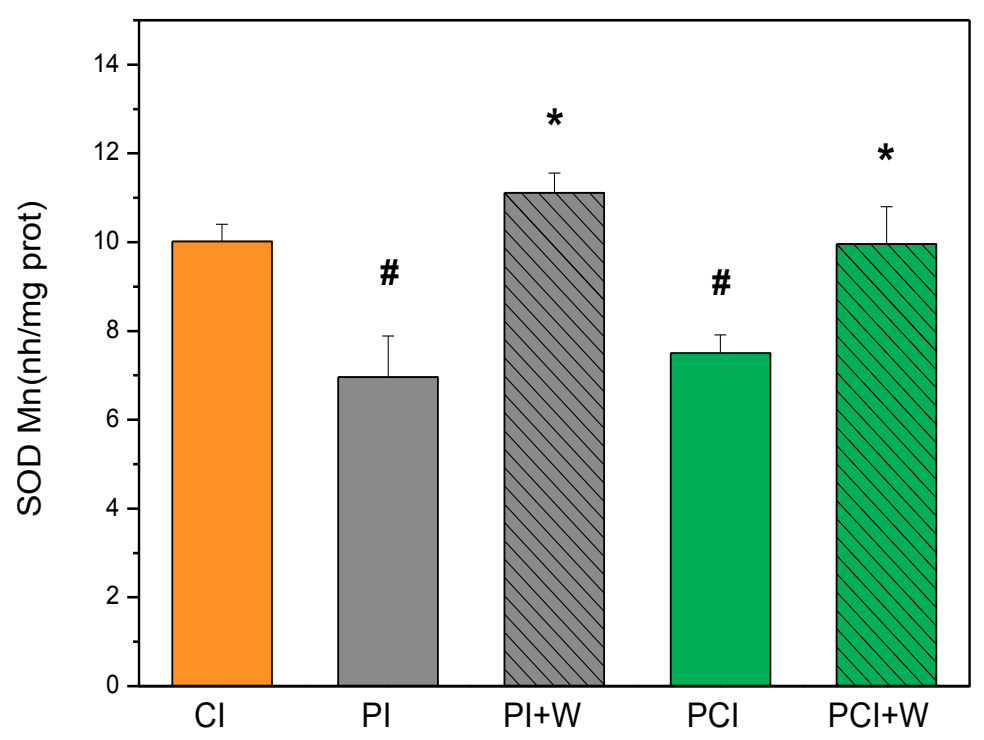

Figura 40: Actividad citosólica de SODMn, expresada como porcentaje de inhibición por mg de proteína, en corazones de los grupos CI, PI, PI + W, PCI y PCI + W. * p $<0,05$ con respecto a CI; \# p $<$ 0.05 con respecto a PI y PCI. 
Cuando ambas intervenciones fueron realizadas en presencia de la inhibición de $\mathrm{PI}_{3} \mathrm{~K} / \mathrm{Akt}$ con W la actividad de SODMn retornó a niveles similares a los observados en el grupo CI. Los valores fueron de: $\mathbf{1 1 . 1 1} \pm \mathbf{0 . 4 5}$ y $\mathbf{9 . 9 6} \pm \mathbf{0 . 8 4} \%$ inhibición $/ \mathrm{mg}$ prot para los grupos PI $+\mathrm{W}$ y PCI + W, respectivamente (Figura 40).

\section{Expresión de P-GSK-3ßy P-Akt}

La expresión de P-GSK-3 $\beta$ aumentó significativamente en los corazones sometidos a los protocolos de PI y PCI. Cuando estas intervenciones fueron realizadas en presencia de wortmanina, los niveles de P-GSK- $3 \beta$ alcanzaron valores similares a los obtenidos en el grupo CI. Los valores fueron de: $\mathbf{4 3} \pm \mathbf{2} \%$ y $\mathbf{4 1} \pm \mathbf{2} \%$ para los grupos PI + W y PCI + W, respectivamente (Figura 41).

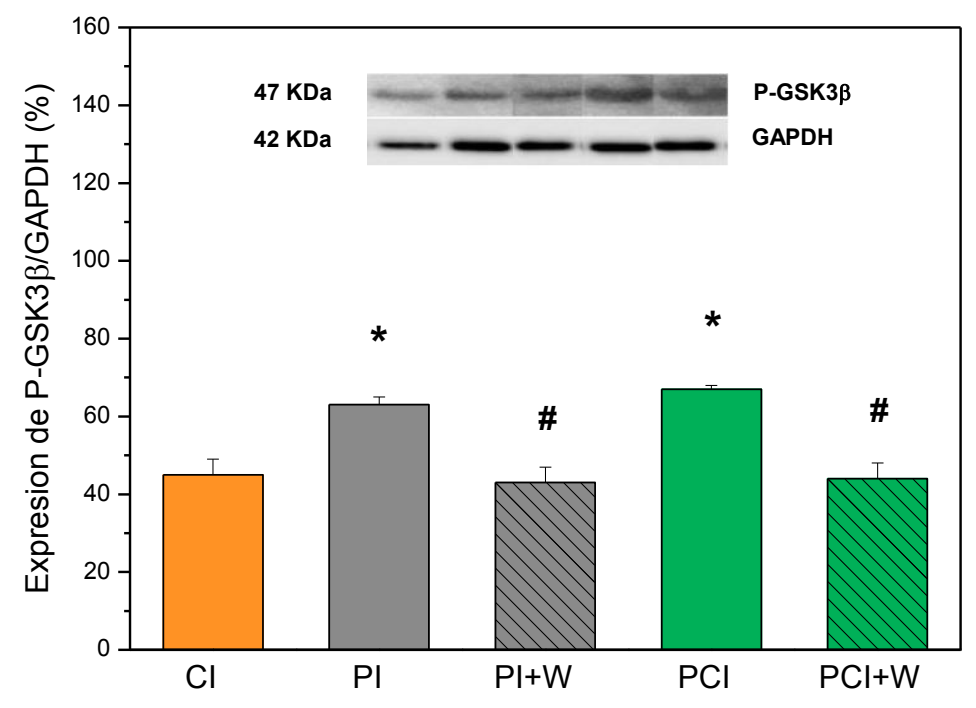

Figura 41: Expresión de P-GSK-3 $\beta /$ GAPDH, como porcentaje del valor obtenido en el grupo C (100 \pm $2 \%$ ), en los grupos $\mathrm{CI}, \mathrm{PI}, \mathrm{PI}+\mathrm{W}$, PCI y $\mathrm{PCI}+\mathrm{W} .{ }^{*} \mathrm{p}<0,05$ con respecto a $\mathrm{C} ; \# \mathrm{p}<0,05$ con respecto a PI ó PCI.

La expresión de P-Akt aumentó en los grupos PI y PCI con respecto a lo hallado en el grupo CI. El tratamiento con W previo a la aplicación de los protocolos de PI y PCI disminuyó la expresión de P-Akt. Los valores fueron de: $9 \pm \mathbf{1} \%$ y $12 \pm \mathbf{2} \%$ para los grupos PI + W y PCI + $\mathrm{W}$, respectivamente (Figura 42). 


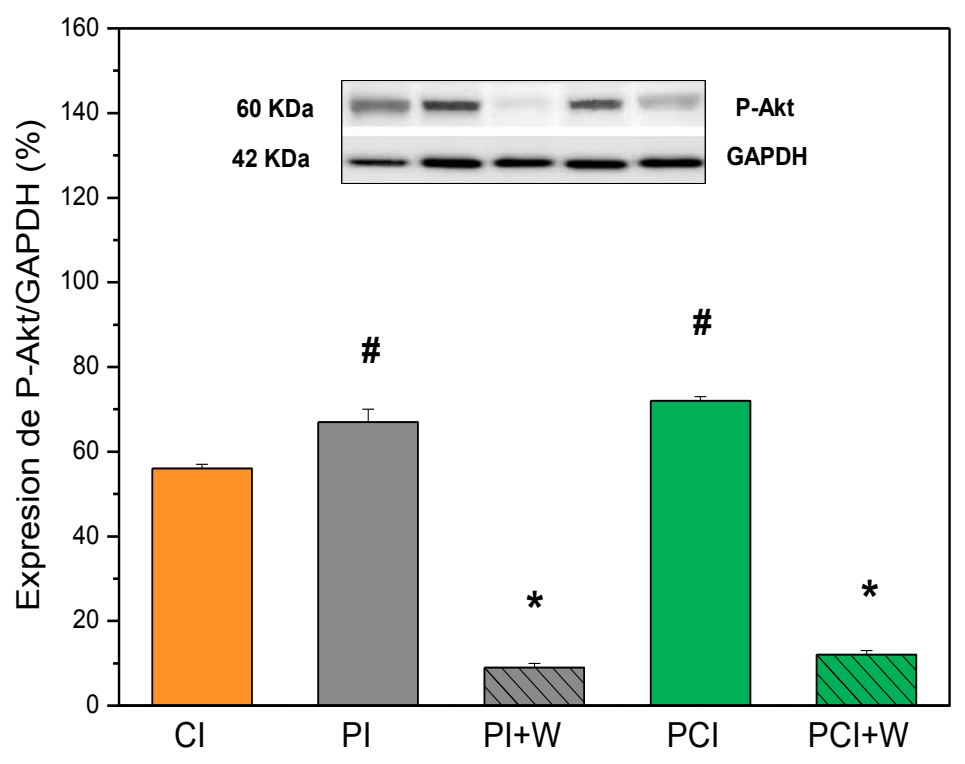

Figura 42: Expresión de P-Akt/GAPDH, expresado como porcentaje del valor obtenido en el grupo C (100 $\pm 3 \%$ ), en los grupos CI, ClLi e IMI PRE y ClLi e IMI POST. * $\mathrm{p}<0,05$ con respecto a CI; \# $\mathrm{p}<$ o,05 con respecto a PI ó PCI.

\section{$\underline{\text { Sensibilidad del PPTM al } \mathrm{Ca}^{2+} \text { : }}$}

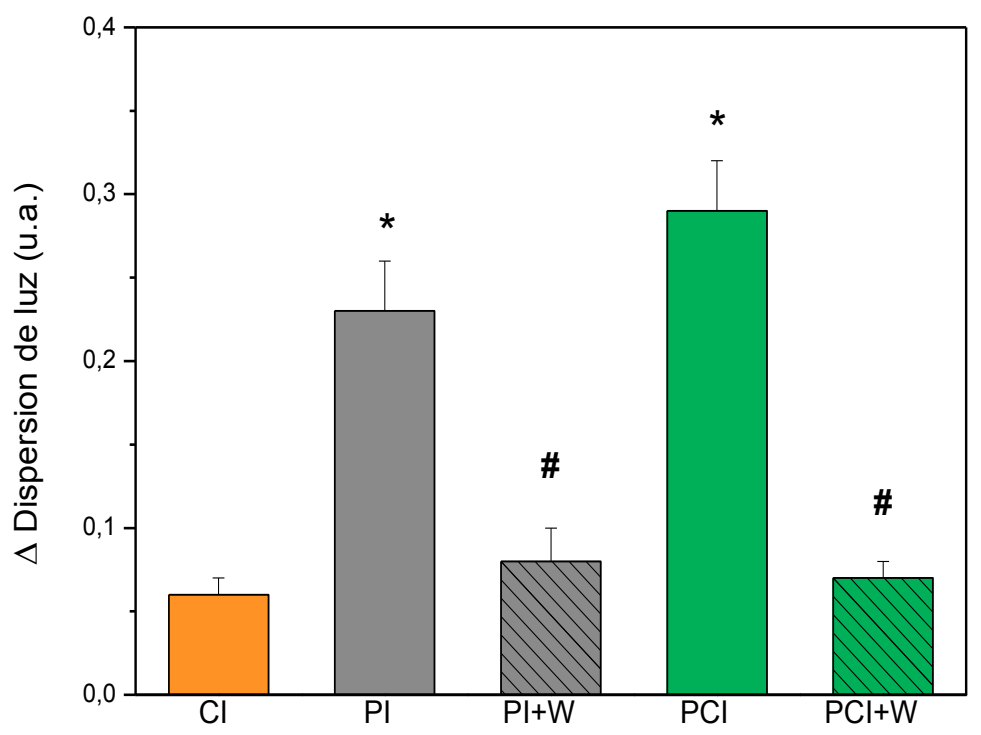

Figura 43: Cambio de la dispersión de la luz, expresado en unidades arbitrarias (u.a.), por el agregado de $200 \mu \mathrm{M}$ de $\mathrm{Cl}_{2} \mathrm{Ca}$, en corazones de los grupos CI, PI, PI+W, PCI y PCI+W. * $\mathrm{p}<0,05$ con respecto a CI. \# $\mathrm{p}<0,05$ con respecto a PI ó $\mathrm{PCI} \# \mathrm{p}<0,05$ con respecto a PI ó PCI 
En las mitocondrias de corazones tratados con W previo a la aplicación de los protocolos de PI y PCI se observó una disminución significativa de la sensibilidad del PPTM al $\mathrm{Ca}^{2+}$ (Figura 43). El decaimiento de la dispersión de la luz fue de $0.08 \pm 0.02$ y $0.07 \pm 0.01$ u.a. para los grupos PI + W y PCI + W, respectivamente.

\section{Ultraestructura mitocondrial}

En la Figura 44 se observa el efecto del tratamiento con W. La inhibición de PI3K/Akt anuló los efectos beneficiosos del PI y PCI observándose, de manera similar a lo obtenido en el grupo CI, la presencia de edema mitocondrial, la destrucción de las crestas y pérdida de la integridad de dicha organela.
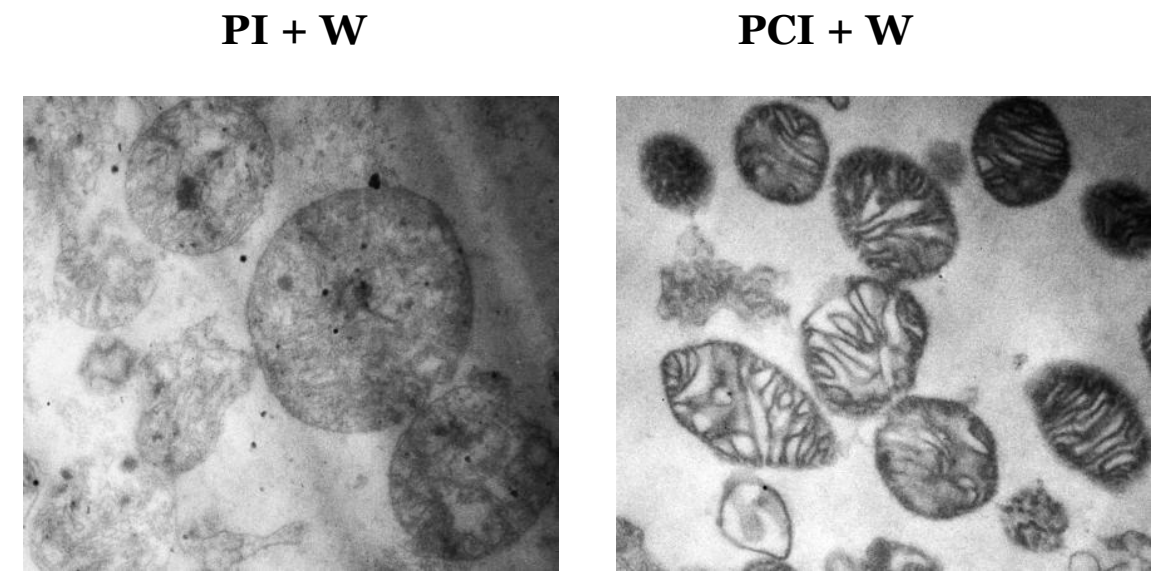

Figura 44: Fotomicrografía de microscopio electrónico de mitocondrias aisladas pertenecientes a corazones de los grupos PI + W (x 25000) y PCI + W (x 20000). 
Nuestros resultados muestran que, el tratamiento con wortmanina (inhibidor de PI3K/Akt) previo a los protocolos de PI y PCI, anula el efecto cardioprotector de estas intervenciones, observándose:

1-Aumento del tamaño del infarto

2-No produjo cambios en la recuperación postisquémica de la función miocárdica y vascular

3- Aumento del daño oxidativo evidenciado por:

- Aumento de la peroxidación lipídica

4. Disminución del contenido de GSH

- Aumento de la actividad de SODT y SODMn

4- Disminución de la expresión de P-GSK3 $\beta$ y de P-Akt.

5- Disminución de la sensibilidad del PPTM al $\mathrm{Ca}^{2+}$.

6- Alteración de la ultraestructura mitocondrial

Medida del contenido de citocromo en las fracciones citosólica y mitocondrial

Como se muestra en la Figura 45 el contenido de citocromo c en la fracción citosólica aumentó en el grupo de corazones controles isquémicos, siendo el valor de $\mathbf{1 3 7} \pm \mathbf{1} \%$ comparado con lo obtenido en el grupo C (100 $\pm \mathbf{2}$ \%). Todas las intervenciones disminuyeron significativamente la liberación de citocromo c. Los valores fueron de: $118 \pm 4 \%, 122 \pm 3 \%$, $116 \pm 3 \%, 117 \pm 4 \%, 120 \pm 2 \%$ y $122 \pm \mathbf{2} \%$ para los grupos PI, PCI, ClLi Pre y Poste IMI Pre y Post, respectivamente. El tratamiento con W aumentó la liberación de citocromo c hasta valores similares a los observados en el grupo CI (142 \pm 2 \% y $145 \pm 2 \%$ para los grupos $\mathrm{PI}+\mathrm{W}$ y $\mathrm{PCI}+\mathrm{W}$, respectivamente). 


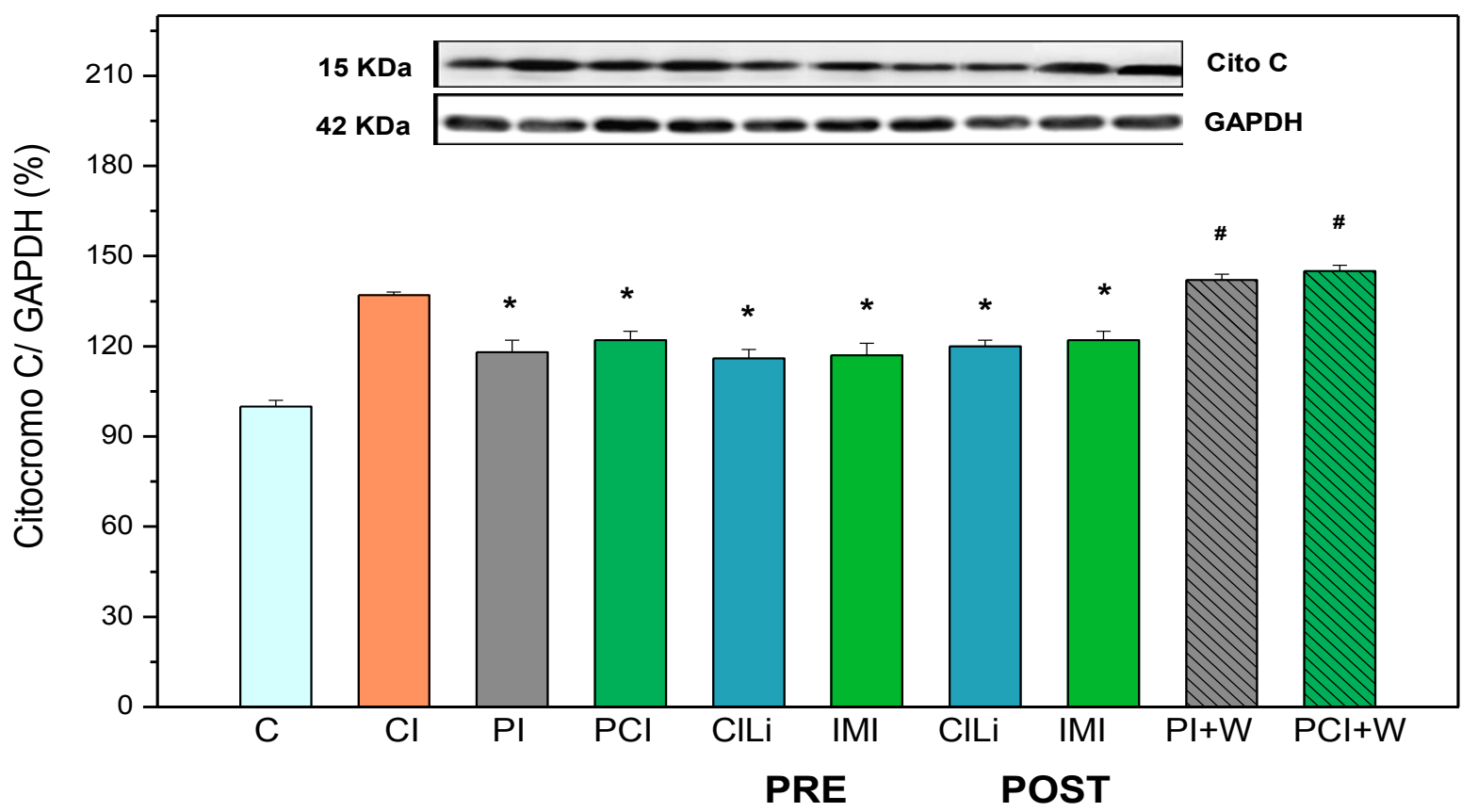

Figura 45: Expresión de citocromo c/GAPDH en la fracción citosólica, como porcentaje del valor obtenido en el grupo C, en los grupos C, CI, PI, PCI, ClLi e IMI Pre, ClLi e IMI Post, PI+W y PCI+W. * $\mathrm{p}<0,05$ con respecto a $\mathrm{CI} ; \# \mathrm{p}<0,05$ con respecto a PI ó PCI. $(\mathrm{n}=4)$

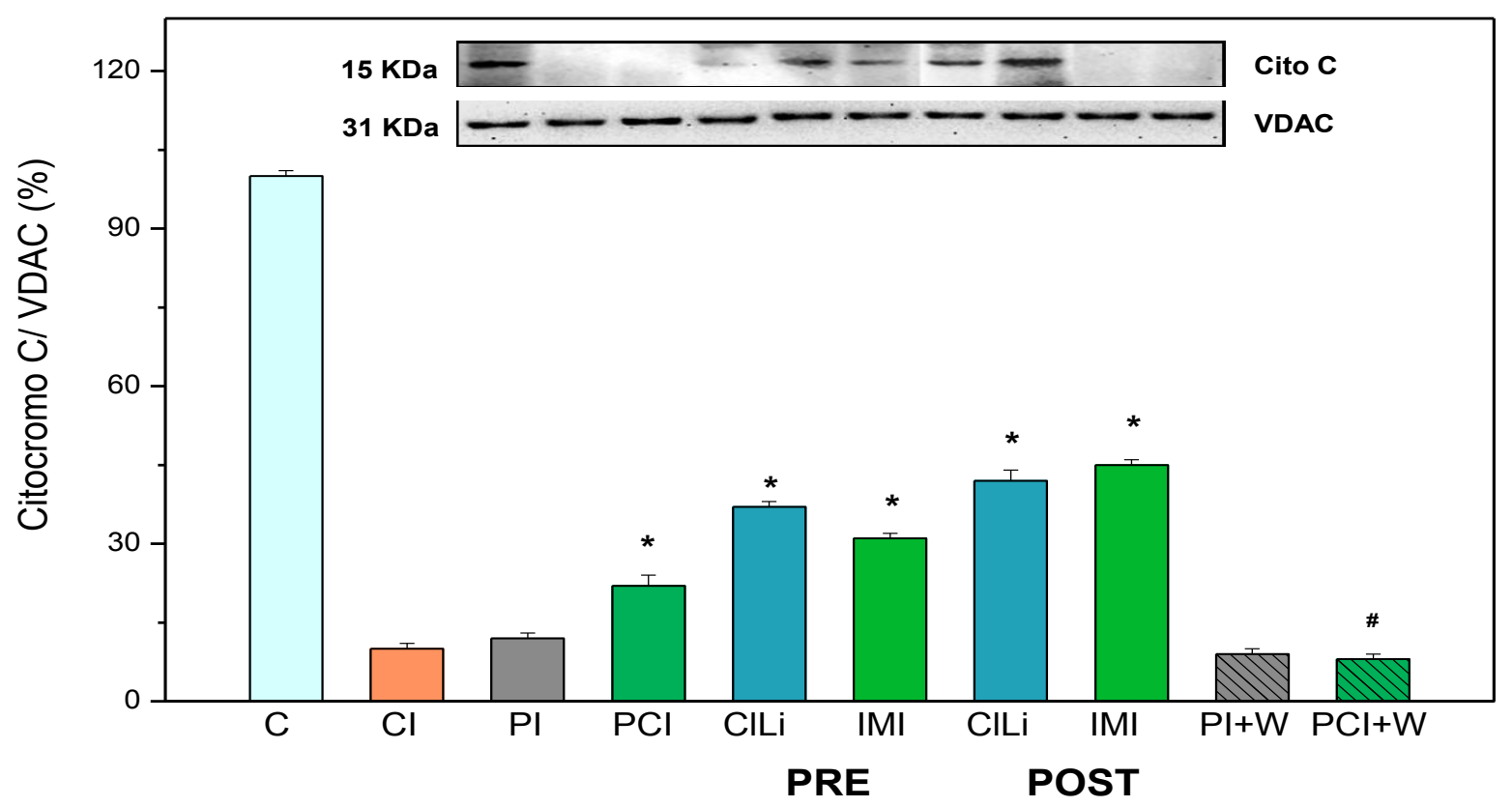

Figura 46: Expresión de citocromo c/VDAC en fracción mitocondrial, como porcentaje del valor obtenido en el grupo C, en los grupos C, CI, PI, PCI, ClLi e IMI Pre, ClLi e IMI Post, PI+W y PCI+W. * $\mathrm{p}<0,05$ con respecto a CI; \# $\mathrm{p}<0,05$ con respecto a PI ó PCI. $(\mathrm{n}=4)$ 
El contenido de citocromo $\mathrm{c}$ en la fracción mitocondrial mostró una disminución muy marcada en el grupo CI (10 $\pm \mathbf{1} \%)$ (Figura 46). Aumentó en todos los grupos intervenidos excepto en el grupo PI. Los valores fueron de: $22 \pm 2 \%, 37 \pm 1 \%, 31 \pm 1 \%, 42 \pm 2 \%$ y 45 $\pm 1 \%$ para PCI, ClLiPre, ClLiPost, IMIPre e IMIPost, respectivamente. La inhibición de PI3K/Akt en el grupo PCI retornó los niveles de citocromo c a un valor similar al obtenido en el grupo CI $(\mathbf{8} \pm \mathbf{1} \%)$.

\section{Relaciones entre variables en las distintas intervenciones}

El análisis de los datos mostró la presencia de correlaciones positivas (Tamaño del Infarto vs. TBARS) y negativas (Tamaño del Infarto vs. GSH y Sensibilidad del PPTM al $\mathrm{Ca}^{2+}$ vs. Tamaño del Infarto y TBARS) estadísticamente significativas.

\section{- Tamaño del Infarto vs. TBARS}

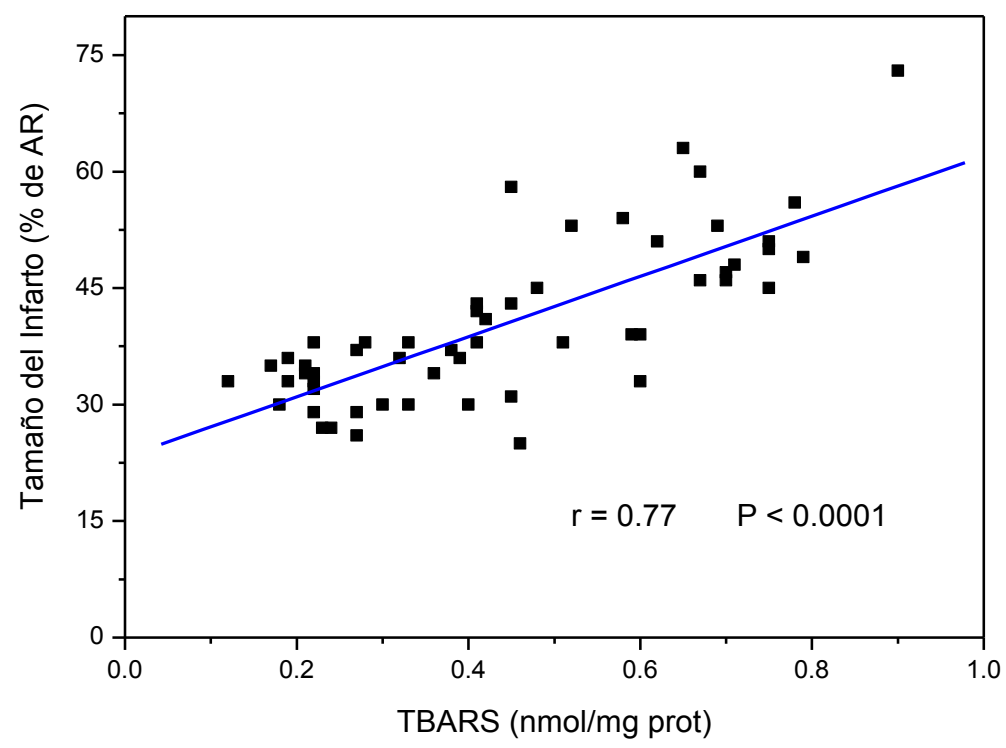

Esta recta $(\mathrm{r}=0.77)$ demuestra la existencia de una dependencia entre ambos parámetros e indica que cuando la peroxidación lipídica aumenta es posible obtener un mayor tamaño de infarto. 


\section{- Tamaño del Infarto vs. GSH}

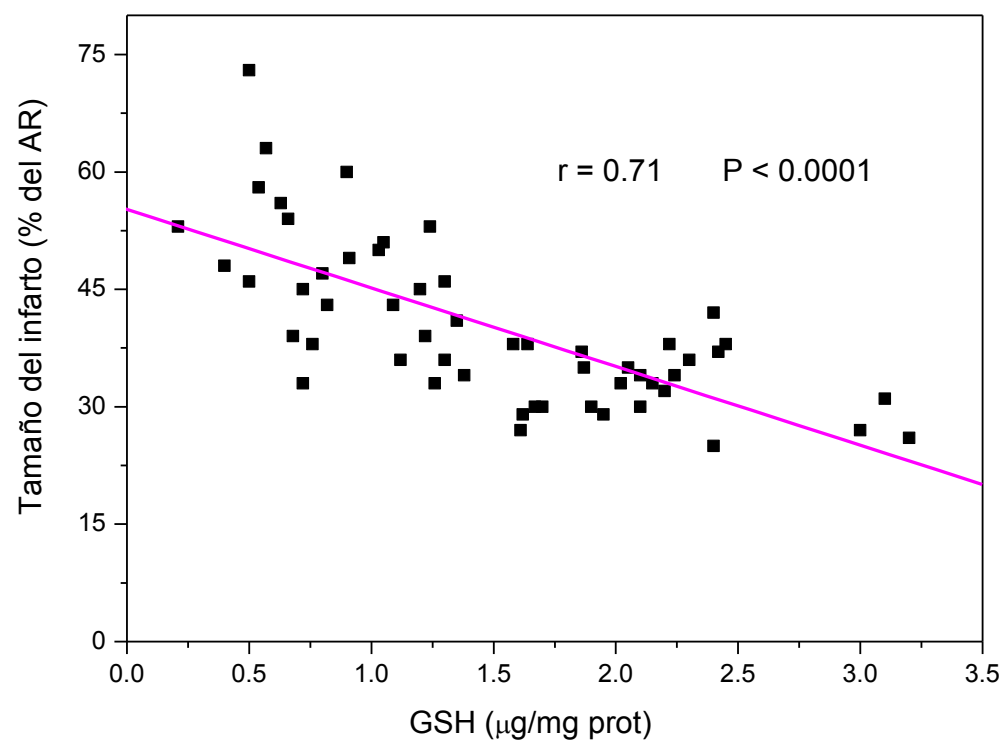

Esta recta ( $\mathrm{r}=0.71)$ muestra que el tamaño del infarto es menor cuando el antioxidante GSH se preserva y posee niveles mayores.

Del análisis de las 2 relaciones (Tamaño del Infarto vs. TBARS y GSH) surge que la muerte celular producida por isquemia-reperfusión depende del daño oxidativo y que la atenuación de la misma está en relación directa con las modificaciones de dichos parámetros. 


\section{- Sensibilidad del PPTM al Ca ${ }^{2+}$ vs Tamaño del infarto}

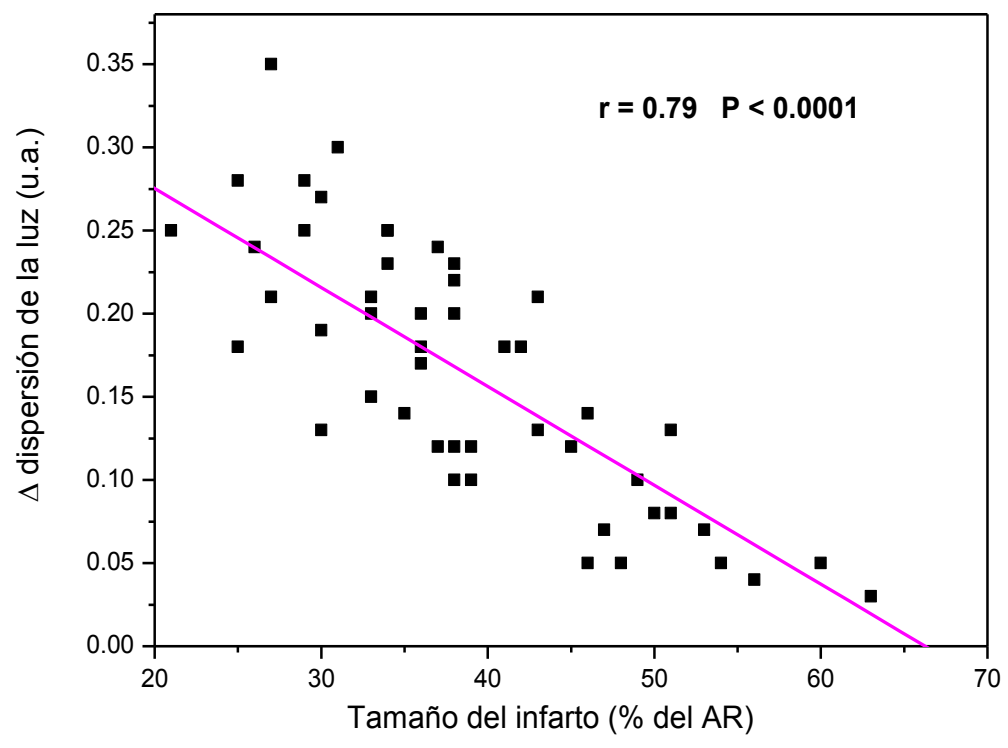

- Sensibilidad del PPTM al $\mathrm{Ca}^{2+}$ vs. TBARS

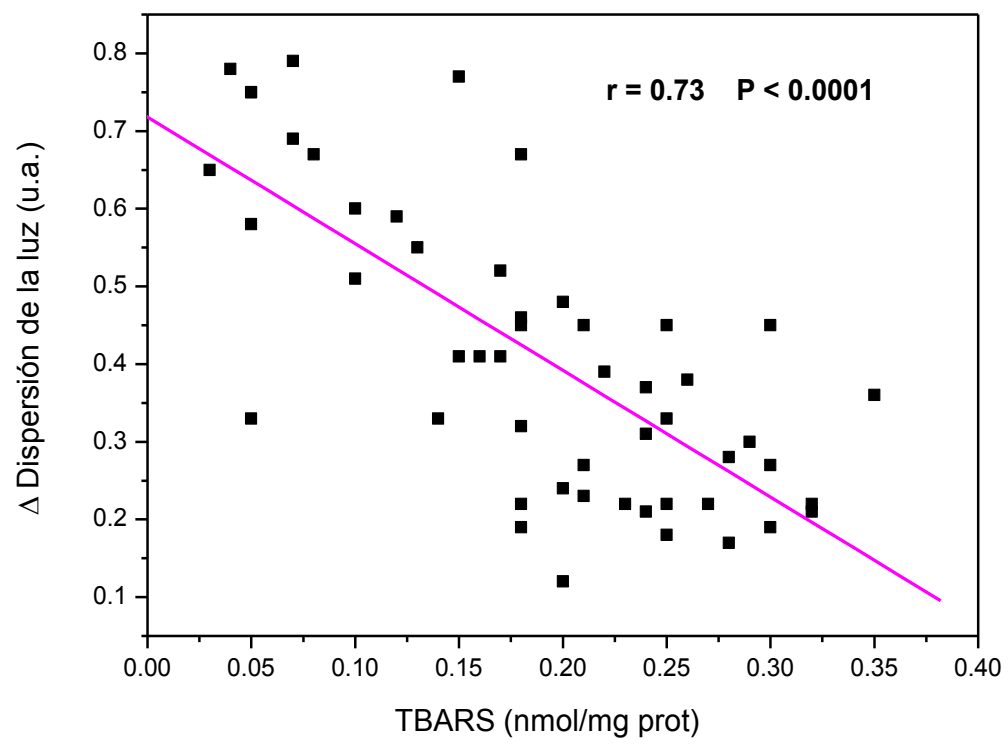

Las 2 últimas relaciones establecen que la respuesta de las suspensiones mitocondriales depende del tamaño del infarto y de la peroxidación lipídica. Es decir, que la sensibilidad del PPTM al $\mathrm{Ca}^{2+}$ disminuye cuando ambas variables aumentan. En otras palabras, cuando la 
muerte celular y el daño oxidativo son mayores, las mitocondrias responden escasamente a los estímulos aplicados, en este caso al $\mathrm{Ca}^{2+}$. 
Los resultados de este trabajo de tesis muestran que, en corazones aislados de ratas hipertensas espontáneas (SHR), el pre y postacondicionamiento isquémicos (PI y PCI) disminuyen el tamaño del infarto y el daño oxidativo producido por $45 \mathrm{~min}$ de isquemia global y $60 \mathrm{~min}$ de reperfusión. Efectos beneficiosos similares fueron obtenidos mediante el tratamiento con los inhibidores de la GSK-3 $\beta$. Según nuestros datos la cardioprotección dada por todas las intervenciones aparece asociada a la menor liberación de citocromo c al citosol. Este evento indica que la atenuación de la formación y/ó apertura del poro de permeabilidad transitoria de la mitocondria (PPTM) desempeña un papel importante en la disminución del daño irreversible producido por la isquemia-reperfusión.

Numerosos trabajos utilizando animales normotensos muestran que el efecto cardioprotector del PI y PCI ocurre como resultado de la activación, a partir de receptores de superficie, de diferentes cascadas de señalización que incluyen el grupo de quinasas de salvataje (RISK, Hausenloy y Yellon, 2007) y de factores activadores de sobrevida (SAFE, Lecour, 2009). Estas vías convergen en la mitocondria, organela que cumple un rol central en la cardioprotección endógena que resulta de ambas intervenciones (Perrelli y col., 2011). La mitocondria no sólo participa en la traducción de señales producidas por las ROS, sino que también es efectora de la protección, la que se manifiesta como una reducida probabilidad de apertura del PPTM durante la reperfusión (Juhaszova y col., 2004; Davidson y col., 2006; Bopassa y col., 2006; Obame y col., 2008; Argaud y col., 2005; Smith y col., 2006; Feng y col., 2005; Pagel y col., 2006; Hausenloy y col., 2009). En este sentido, un trabajo reciente realizado por Ruiz-Meana y col. (2014) demuestra el papel clave de la mitocondria y menciona el mecanismo de "preacondicionamiento mitocondrial" contra el daño oxidativo y el deterioro de la función energética de dicha organela que se producen en la isquemia-reperfusión (Ruiz-meana y col., 2014). En animales hipertensos la efectividad del PI y PCI ha sido cuestionada. Resultados recientes muestran en un modelo experimental utilizando corazones hipertróficos de SHR que el PCI no ejerció acción beneficiosa (Wagner y col., 2013).

Investigaciones previas realizadas en animales normotensos muestran que la inhibición de la GSK-3 $\beta$ mediante la fosforilación en el residuo Serina 9 juega un papel importante en diferentes intervenciones cardioprotectoras (Nishino y col., 2008; Miura y Miki, 2009). Esta importancia podría atribuirse al hecho de que GSK- $3 \beta$ es sustrato de varias quinasas y, por lo tanto, en ella convergen múltiples vías de señalización. Trabajos previos realizados en corazones de ratas hiperlipidémicas (Yadav y col., 2010) y en corazones de ratas normotensas 
utilizando diversos modelos de isquemia-reperfusión, muestran que la inhibición de GSK-3 $\beta$ es beneficiosa (Faghihi y col., 2008; Gross y col., 2004; Obame y col., 2008). Entre los efectos beneficiosos de la fosforilación de GSK- $3 \beta$ está la elevación del umbral de la apertura del PPTM (Juhaszova y col., 2009), que según estudios previos se abre en los primeros minutos de la reperfusión. En nuestro modelo experimental, y utilizando los corazones hipertróficos de SHR, el PI y PCI, así como el tratamiento con ambos inhibidores de GSK-3 $\beta$ (ClLi e IMI), administrados antes de la isquemia ó al inicio de la reperfusión- produjeron al final de los 60 min de reperfusión un aumento de los niveles de P-GSK-3 $\beta$ comparado al hallado en los corazones controles isquémicos (CI). Es decir, que en nuestras condiciones, la inactivación de GSK-3 $\beta$ ejerce un efecto "pre y postacondicionante", produciendo una disminución del tamaño del infarto similar al obtenido con el PI y PCI. Por lo tanto, la atenuación de la muerte celular observada en los corazones pre y postacondicionados isquémicos y en aquellos tratados con ClLi e IMI es mediada por un mecanismo dependiente de P-GSK-3 $\beta$. En estos datos es interesante destacar las acciones beneficiosas logradas con el ClLi lo que convierten a esta droga en una herramienta promisoria para atenuar el daño por isquemia-reperfusión en animales hipertensos.

La necrosis está marcada por distintos cambios morfológicos, que incluyen hinchazón celular y mitocondrial, daño de la membrana plasmática y pérdida de ATP. La pérdida de la integridad celular y liberación del contenido celular produce una segunda reacción inflamatoria con potenciales consecuencias patológicas (Whelan y col., 2010). Inicialmente la necrosis era considerada una muerte pasiva y accidental. Evidencias recientes sugieren que dicho proceso está regulado por una serie de eventos que suceden en forma controlada. Es por ello que varios términos han sido introducidos para describir esta forma de necrosis, tales como necrosis programada, necroptosis y muerte celular independiente de caspasas (Russell y col., 2004). Una serie de mecanismos han sido propuestos en la iniciación y ejecución de la necrosis, incluyendo receptores de muerte, sobrecarga de $\mathrm{Ca}^{2+} \mathrm{y}$ apertura del PPTM (Vanlangenakker y col., 2008; Kroemer y col., 2007). Este último hecho también ha sido implicado en la redistribución citosol/espacio intermembrana mitocondrial de citocromo c durante la isquemia-reperfusión (Kim y col., 2003; Loor y col., 2011). El análisis de la ultraestructura mitocondrial por microscopía electrónica evidenció que la mayor parte de las mitocondrias procedentes de los corazones controles isquémicos poseían la membrana dañada, estaban edematizadas y tenían sus crestas destruídas. Esto se correspondió con la 
escasa respuesta del PPTM al $\mathrm{Ca}^{2+}$ y el aumento de la liberación del citocromo $\mathrm{c}$ al citosol y la disminución marcada de dicha sustancia en la fracción mitocondrial. Estos cambios fueron atenuados en los corazones pre y postacondicionados y de manera similar, en los corazones tratados con ClLi e IMI. Así, en las muestras obtenidas de estos corazones al final de los 60 min de reperfusión, se observaron algunas mitocondrias con ultraestructura normal, una parcial recuperación de la sensibilidad del PPTM al $\mathrm{Ca}^{2+}$, una disminución del contenido de citocromo $\mathrm{c}$ en el citosol y un aumento simultáneo de dicha sustancia en la fracción mitocondrial.

Si bien se ha descripto que las modificaciones del PPTM ocurren al inicio de la reperfusión, nuestros datos muestran que estos cambios se extienden hasta el final del período de reperfusión. Estos resultados, sumados a los anteriormente mencionados, también obtenidos a los 60 min de reperfusión, sugieren que niveles elevados de P-GSK- $3 \beta$ estarían asociados a la preservación parcial de la integridad mitocondrial, atenuando la formación del PPTM. Esta conclusión estaría avalada por una investigación previa, realizada por Zhai y col. (2011), quienes mostraron que el estado de fosforilación de GSK-3 $\beta$ persiste desde los 30 min hasta las 4 horas de reperfusión. Por lo tanto, el nivel de P-GSK- $3 \beta$ hallado al final de la reperfusión estaría implicado en la disminución del PPTM a ese tiempo y a la consecuente liberación de citocromo c. Entonces, ambos eventos estarían vinculados a la limitación del tamaño del infarto observado en los corazones intervenidos.

Entre las quinasas capaces de activar a GSK-3 $\beta$ está la PI3K/Akt (Pap y Cooper, 1998), que participa de la cardioprotección contra la injuria por reperfusión (Zhu y col., 2006). Un aumento en la actividad de Akt lleva a la fosforilación/inactivación de GSK-3 $\beta$, mientras que una disminución conduce a la desfosforilación y activación de GSK-3 $\beta$. En los corazones controles isquémicos el nivel de P-Akt disminuyó y la expresión de P-GSK-3 $\beta$ disminuyó mientras que en aquellos corazones intervenidos y/ó tratados se observó la situación inversa. El tratamiento con wortmanina anuló la protección del PI y PCI, indicando la participación de PI3K/Akt en la disminución de la muerte celular observada en los corazones intervenidos. También mostramos que la inhibición de dicha quinasa disminuyó el nivel de P-Akt y el de PGSK-3 $\beta$. Por lo tanto, estos datos destacan el papel importante de la vía Akt/GSK-3 $\beta$ en isquemia-reperfusión en SHR y están de acuerdo con estudios previos realizados en conejos hipertensos (Barillas y col., 2007) y en ratas hipertensas con accidente cerebrovascular (SHRSP, Yano y col., 2011). La inhibición de PI3K/Akt aumentó la liberación de citocromo c al 
citosol, disminuyendo su contenido en la fracción mitocondrial. Si consideramos que esta liberación tiene lugar por la apertura del PPTM, como ha sido descripto previamente, nuestros datos sugieren que Akt participa en la disminución de la muerte celular a través de la inhibición de la formación y/ó apertura del PPTM, reteniendo el citocromo c dentro del espacio intermembranoso mitocondrial. Esta conclusión tiene relación con lo obtenido en la respuesta de las mitocondrias aisladas al $\mathrm{Ca}^{2+}$. En los experimentos en los cuales Akt fue inhibida la sensibilidad del PPTM al $\mathrm{Ca}^{2+}$ disminuyó, alcanzando valores similares a los observados en corazones controles isquémicos. Esto fue asociado al hallazgo de mitocondrias con ultraestructura alterada en las fotos de microscopia electrónica.

El estrés oxidativo ha sido involucrado en la isquemia-reperfusión (Griendling y FitzGerald, 2003; Papaharalambus y Griendling, 2007; Ravingerová y col., 1999; Kalaycioglu y col., 1999) y también en el origen de la hipertensión (Newaz y Nawal, 1999; Vaziri y Sica, 2004). Trabajos previos (Leichtweis y Ji, 2001; Slodzinski y col., 2008) muestran que la producción abrupta de ROS que ocurre tempranamente durante la reperfusión está directamente relacionada con la disminución de la reserva de GSH intracelular. El glutatión representa el antioxidante de menor peso molecular que actúa reciclando los grupos tiol en las células de los mamíferos y de esta manera, desempeña un papel central en la defensa celular contra el daño oxidativo. Otros sistemas antioxidantes como SOD también están contribuyendo a lograr la disminución en los niveles de ROS. En los corazones controles isquémicos, se obtuvo un aumento de la peroxidación lipídica -aumento de TBARS- que se correlacionó con una disminución del contenido de GSH y de la actividad de SOD (SODT y SODMn). En los corazones pre y postacondicionados y en aquellos tratados con ambos inhibidores de GSK-3 $\beta$ la lipoperoxidación disminuyó mientras que el contenido de GSH y la actividad de SOD fueron parcialmente restauradas. Estos datos indican la presencia de un daño oxidativo en los corazones de SHR sometidos a isquemia-reperfusión, el cual fue atenuado por las intervenciones y los tratamientos aplicados. Además sugieren que una menor producción de ROS podría tener lugar en los corazones de los grupos PI, PCI, ClLi e IMI. Considerando que las ROS pueden causar la apertura del PPTM (Halestrap, 2009) la recuperación parcial de la integridad y de la respuesta al $\mathrm{Ca}^{2+}$ observada en mitocondrias aisladas de corazones intervenidos y tratados apoyan la hipótesis de que, en estas condiciones, se estaría produciendo y/ó liberando una menor cantidad de ROS. Por otro lado, y de acuerdo con lo sugerido por un trabajo previo (Jin y col, 2005), la detección de actividad de SODMn en el 
citosol estaría indicando un aumento de la permeabilidad de la membrana mitocondrial. Es decir, que la disminución de la actividad de dicha enzima observada en los grupos intervenidos (PI, PCI, ClLi e IMI) es otra demostración de la acción beneficiosa de los mismos a nivel mitocondrial y refuerza la hipótesis planteada. Recientemente (Martindale y Metzer, 2014) se demostró que durante la reperfusión, además del estrés oxidativo, se produce inestabilidad de la membrana e hinchamiento mitocondrial, eventos que inducen la entrada de $\mathrm{Ca}^{2+}$ a la mitocondria y la despolarización de la membrana mitocondrial. Una menor concentración de $\mathrm{Ca}^{2+}$ mitocondrial podría también explicar los efectos beneficiosos observados en los corazones intervenidos. Sin embargo, nuestros datos no nos permiten descartar esta posibilidad.

La asociación entre estrés oxidativo y muerte celular está avalada por las correlaciones anteriormente descriptas. Una de ellas establece la correlación positiva entre el tamaño del infarto y la concentración de TBARS - parámetro usado como índice de la peroxidación lipídica - , indicando que cuando el daño oxidativo es mayor se obtiene un mayor infarto. Simultáneamente, hallamos una correlación inversa (ó negativa) entre el contenido de GSH y el tamaño del infarto, que muestra que elevados niveles de GSH están asociados a menores infartos. Es decir, ambas variables (TBARS y GSH) presentaron cambios opuestos debidos posiblemente a una relación causa-efecto. Además esto sugiere que cuando la intervención y/ó tratamiento es capaz de disminuir la producción de ROS, el daño oxidativo sería menor, las defensas antioxidantes se preservarían -tendientes a mantener su concentración normal- y la muerte celular disminuiría. Estos resultados son acompañados por cambios en la actividad de SOD, la cual fue menor en los corazones pre y postacondicionados y en aquellos tratados con los inhibidores de GSK-3 $\beta$. Todos estos datos sugieren que la formación de lipoperóxidos es una de las posibles causas de injuria por isquemia-reperfusión y que la atenuación del estrés oxidativo -mediante una disminución de liberación y/ó producción de ROS y/ó un mantenimiento ó mejoramiento de los antioxidantes endógenos- podría ser uno de los mecanismos implicados en la cardioprotectión obtenida en las intervenciones y tratamientos aplicados a los corazones hipertróficos de SHR. Esta disminución del estrés oxidativo mediada por el PI, el PCI, y los tratamientos con ClLi e IMI, fue acompañada por una menor liberación de citocromo c, sugiriendo la participación del estrés oxidativo en la determinación de la integridad de la mitocondria y de la consecuente muerte celular. El estrés oxidativo también ha sido implicado en los cambios de la morfología mitocondrial. Por lo tanto, la 
disminución del daño oxidativo participa en la atenuación de los desorganización, dispersión y edematización observada en las fotomicrografías de microscopio electrónico de las mitocondrias extraídas de corazones controles isquémicos.

¿Cuál es el mecanismo por el cual la vía Akt/GSK-3 $\beta$ afecta la formación del PPTM? Aunque nuestros datos no nos permiten dilucidar las acciones de estos mediadores cardioprotectores, estudios previos muestran que P-GSK-3 $\beta$ interactúa con ANT (Nishihara y col., 2007; Terashima y col., 2010) y es capaz de fosforilar VDAC conduciendo a la ruptura de la unión de la hexoquinasa II y VDAC (Pastorino y col., 2005; Das y col., 2008; Nishihara y col., 2007). También Akt es capaz de fosforilar directamente a la hexoquinasa II e inducir la unión con VDAC (Miyamoto y col., 2008) y así mantener la integridad mitocondrial y promover la sobrevida celular. 


\section{CONCLUSIONES}


Las principales conclusiones que derivan del presente trabajo de tesis se resumen a continuación:

-La aplicación de 45 min de isquemia global y 60 min de reperfusión a corazones aislados de SHR produjo un tamaño del infarto de aproximadamente 50\% del área en riesgo, y la recuperación de la función sistólica fue del orden del 1\%, con un aumento de la rigidez diastólica y de la resistencia vascular. Estos resultados fueron acompañados por un aumento del daño oxidativo, evidenciado por un aumento de la peroxidación lipídica (TBARS), una disminución marcada del contenido de GSH y un aumento de la actividad de SODT y SODMn. Al mismo tiempo, se observó una disminución en el contenido de las formas fosforiladas de GSK-3 $\beta$ y Akt y de la sensibilidad del poro de permeabilidad transitoria de la mitocondria (PPTM) al $\mathrm{Ca}^{2+}$. También obtuvimos un aumento de la expresión de citocromo c en la fracción citosólica y una disminución en la mitocondrial, indicando liberación de dicho compuesto, lo que se correlacionó con la ultraestructura mitocondrial, observándose la presencia de edema y destrucción de las crestas de dichas organelas.

-Las intervenciones, pre y postacondicionamiento isquémicos (PI y PCI) produjeron una disminución del tamaño del infarto y del daño oxidativo. Este último fue determinado por la disminución de la peroxidación lipídica, la preservación parcial del contenido de GSH y la disminución de la actividad de SODT y SODMn. También se obtuvo un aumento de la expresión de P-GSK3 $\beta$ y de P-Akt y de la sensibilidad del PPTM al $\mathrm{Ca}^{2+}$, una disminución de la liberación de citocromo c y en las fotografías de microscopio electrónico se observaron algunas mitocondrias con ultraestructura conservada.

-Los tratamientos previos a la isquemia ó al inicio de la reperfusión con los inhibidores de GSK- $3 \beta$ produjeron efectos beneficiosos, observándose en los corazones tratados un tamaño de infarto menor comparado con los corazones no tratados. Estos resultados fueron acompañados por una disminución del daño oxidativo, evidenciado por la disminución de la peroxidación lipídica, la preservación parcial del contenido de GSH y la disminución de la actividad de SODT y SODMn. El nivel de expresión de las formas fosforiladas de las enzimas GSK-3 $\beta$ y Akt, así como la sensibilidad del PPTM al $\mathrm{Ca}^{2+}$ aumentaron en presencia de ambos inhibidores de GSK-3 $\beta$. En los corazones tratados se encontraron algunas mitocondrias con ultraestructura normal y menor liberación de citocromo c. 
-El tratamiento con wortmanina (inhibidor de PI3K/Akt) anuló el efecto cardioprotector del PI y PCI, observándose un aumento del tamaño del infarto y del daño oxidativo (aumento de TBARS, disminución de GSH y aumento de la actividad de SODT y SODMn). La sensibilidad del PPTM al $\mathrm{Ca}^{2+}$ disminuyó y no se encontraron mitocondrias con ultraestructura normal, observándose un alto grado de edematización y destrucción de las crestas. Esto fue acompañado por un aumento significativo en el contenido de citocromo c en el citosol.

-De las relaciones Tamaño del Infarto vs. TBARS y GSH y Sensibilidad del PPTM al $\mathrm{Ca}^{2+}$ vs Tamaño del Infarto y TBARS surge que: el Tamaño del Infarto es mayor cuando la peroxidación lipídica aumenta y el contenido de GSH disminuye. En estas condiciones la sensibilidad del PPTM al $\mathrm{Ca}^{2+}$ es menor. La situación opuesta se da en presencia de intervenciones cardioprotectoras. Por lo tanto, en ellas el tamaño del infarto es menor cuando la peroxidación lipídica disminuye y el contenido de GSH aumenta. En estas condiciones la sensibilidad del PPTM al $\mathrm{Ca}^{2+}$ tiende a recuperarse.

En base a los datos obtenidos se concluye que las alteraciones de la formación y/ó apertura del PPTM, participan y determinan la muerte ó la sobrevida celular en el corazón hipertrófico de SHR sometido a isquemia-reperfusión. Así, la disminución del tamaño del infarto obtenida con las intervenciones y/ó tratamientos utilizados fue el resultado de la disminución del daño oxidativo íntimamente asociada a la recuperación parcial de la integridad mitocondrial menor apertura del PPTM- vía P-Akt/P-GSK-3ß (Figura 47).

Otro hallazgo interesante fue que la protección por el tratamiento con ClLi (fármaco ampliamente utilizado en psiquiatría) fue similar a la obtenida con las intervenciones de acondicionamiento isquémico (PI y PCI). Por lo tanto, esta droga podría convertirse en una posible herramienta terapéutica para atenuar las alteraciones cardíacas postisquémicas en animales hipertensos. 


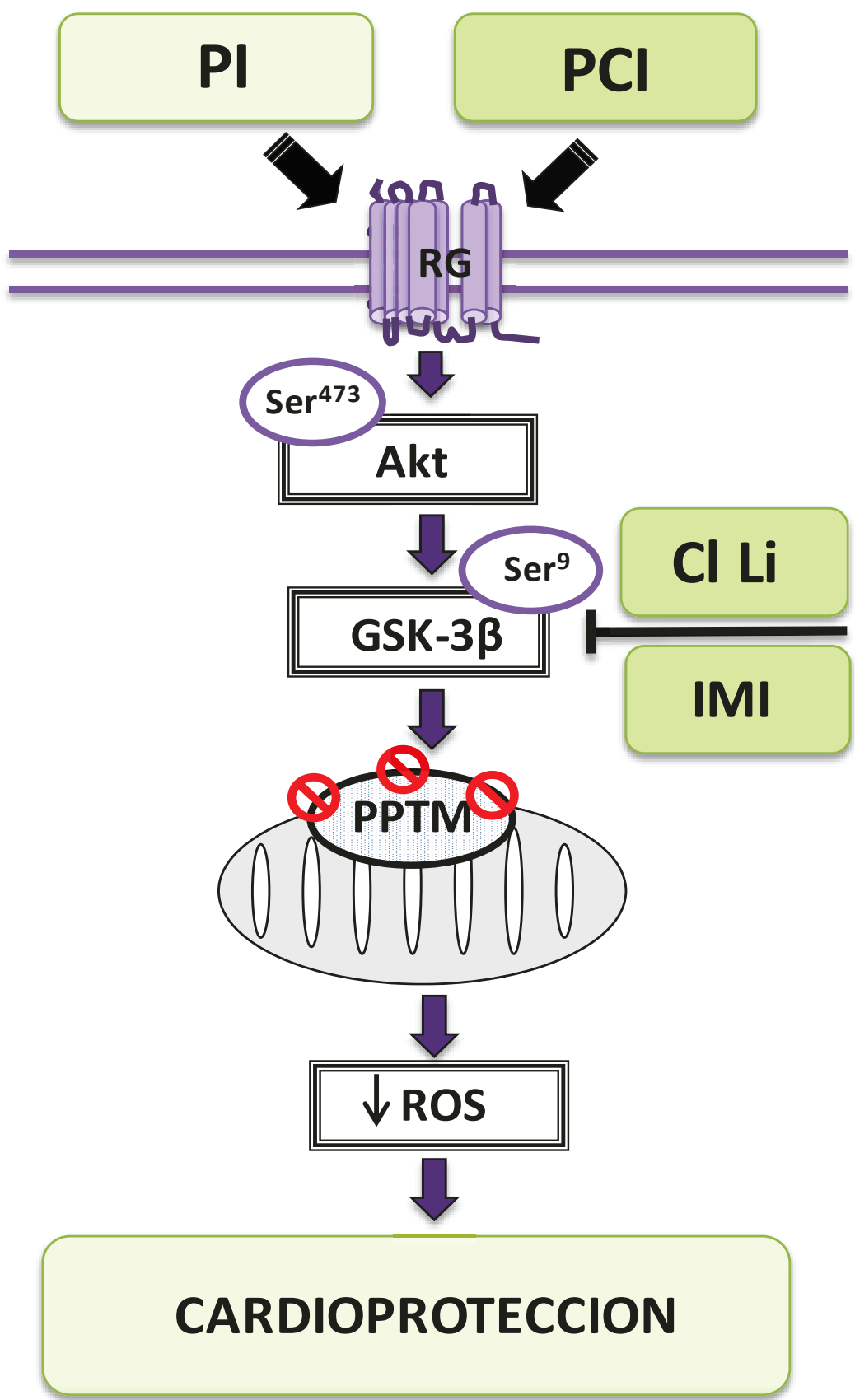

Figura 47: Esquema del mecanismo propuesto para el preacondicionamiento isquémico (PI), el postacondicionamiento isquémico (PCI) y el tratamiento con los inhibidores de GSK-3 $\beta$ (ClLi e IMI). RG: Receptor acoplado a proteína $\mathrm{G}$ 


\section{BIBLIOGRAFÍA}


Allard MF, Flint JD, English JC, Henning SL, Salamanca MC, Kamimura CT, English DR. Calcium overload during reperfusion is accelerated in isolated hypertrophied rat hearts. J Mol Cell Cardiol 1994; 26(12): 1551-1563.

Altamura AC, Lietti L, Dobrea C, Benatti B, Arici C, Dell'Osso B. Mood stabilizers for patients with bipolar disorder: the state of the art. Expert Rev Neurother 2011; 11: 85-99.

Álvarez MC, Caldiz C, Fantinelli JC, Garciarena CD, Console GM, Ciappe de Cingolani GE, Mosca SM. Is cardiac hypertrophy in spontaneously hypertensive rats the cause or the consequence of oxidative stress? Hypertens Res 2008; 31(7): 1465-1476.

Ambrosio G, Flaherty JT, Duilio C, Tritto I, Santoro G, Elia PP, Condorelli M, Chiariello M. Oxygen radicals generated at reflow induce peroxidation of membrane lipids in reperfused hearts. J Clin Invest 1991; 87: 2056-2066.

Andreadou I, Iliodromitis EK, Farmakis D, Kremastinos DT. To prevent, protect and save the ischemic heart: antioxidants revisited. Expert Opin Ther Targets 2009; 13(8): 945956.

Argaud L, Gateau-Roesch O, Raisky O, Loufouat J, Robert D, Ovize M. Postconditioning inhibits mitochondrial permeability transition. Circulation 2005; 111: 194-197.

Baines CP, Song CX, Zheng YT. Protein kinase C epsilon interacts with and inhibits the permeability transition pore in cardiac mitochondria. Circ Res 2003; 92: 873-880.

Balakumar P, Singh H, Singh M, Anand-Srivastava MB. The impairment of preconditioningmediated cardioprotection in pathological conditions. Pharmacol Res 2009(1):18-23.

Barillas R, Friehs I, Cao-Danh H, Martinez JF, del Nido PJ. Inhibition of glycogen synthase kinase- $3 \beta$ improves tolerance to ischemia in hypertrophied hearts. Ann Thorac Surg 2007; 84: 126-133.

Baxter GF, Mocanu MM, Brar BK, Latchman DS, Yellon DM. Cardioprotective effects of transforming growth factor-beta 1 during early reoxygenation or reperfusion are mediated by p42/p44 MAPK. J Cardiovasc Pharmacol 2001; 38(6): 930-939.

Becker LB. New concepts in reactive oxygen species and cardiovascular reperfusion physiology. Cardiovasc Res 2004; 61: 461-470.

Becker LB, Vanden Hoek TL, Shao Z, Li C, Schumacker PT. Generation of superoxide in cardiomyocytes during ischemia before reperfusion. Am J Physiol Heart Circ Physiol 1999; 277: H2240-H2246. 
Bell RM, Yellon DM. Atorvastatin, administered at the onset of reperfusion, and independent of lipid lowering, protects the myocardium by up-regulating a pro-survival pathway. $\mathrm{J}$ Am Coll Cardiol 2003; 41(3):508-515.

Bell RM, Yellon DM. Bradykinin limits infarction when administered as an adjunct to reperfusion in mouse heart: the role of $\mathrm{PI}_{3} \mathrm{~K}$, Akt and eNOS. J Mol Cell Cardiol 2003; 35(2): 185-193.

Beuchamp C, Fridovich I. Superoxide dismutase: improved assays and an assay applicable to acrylamide gels. Anal Biochem 1971; 44(1): 276-287.

Bijur GN, Jope RS. Glycogen synthase kinase-3 beta is highly activated in nuclei and mitochondria. Neuroreport 2003; 14(18):2415-2419.

Bopassa JC, Ferrera R, Gateau-Roesch O. PI 3-kinase regulates the mitochondrial transition pore in controlled reperfusion and postconditioning. Cardiovasc Res 2006; 69: 178185.

Boutros A, Wang J. Ischemic preconditioning, adenosine and bethanechol protect spontaneously hypertensive isolated rat hearts. J Pharmacol Exp Ther 1995; 275(3):1148-1156.

Bradford MM. A rapid and sensitive method for the quantitation of microgram quantitites of protein utilizing the principle of protein-dye binding. Anal Biochem 1976; 72: 248-254.

Brar BK, Stephanou A, Liao Z, O'Leary RM, Pennica D, Yellon DM, Latchman DS. Cardiotrophin-1 can protect cardiac myocytes from injury when added both prior to simulated ischaemia and at reoxygenation. Cardiovasc Res 2001; 51(2): 265-274.

Buege JA y Aust SD. Microsomal lipid peroxidation. Meth Enzymol 1978; 52: 302-309.

Buonocore G, Perrone S, Tataranno ML. Oxygen toxicity: chemistry and biology of reactive oxygen species. Semin Fetal Neonatal Med 2010 15(4): 186-190.

Burwell LS, Brookes PS. Mitochondria as a target for the cardioprotective effects of nitric oxide in ischemiareperfusion injury. Antioxid Redox Signal 2008; 10: 579-599.

Byrom FB, Wilson C. A plethysmographic method for measuring systolic blood pressure in the intact rat. J Physiol 1938 Aug 15;93(3):301-4.

Carmody RJ, Cotter TG. Signalling apoptosis: a radical approach. Redox Rep 2001; 6: 77-90.

Chance B, Sies H, Boveris A. Hydroperoxide metabolism in mammalian organs. Physiol Rev 1979; 59: 527-605. 
Cheeseman K, Slater T. An introduction to free radical biochemistry. Br Med Bull 1993; 49: 481-493.

Chobanian AV, Bakris GL, Black HR, Cushman WC, Green LA, Izzo JL Jr, Jones DW, Materson BJ, Oparil S, Wright JT Jr, Roccella EJ; National Heart, Lung, and Blood Institute Joint National Committee on Prevention, Detection, Evaluation, and Treatment of High Blood Pressure; National High Blood Pressure Education Program Coordinating Committee. The Seventh Report of the Joint National Committee on Prevention, Detection, Evaluation, and Treatment of High Blood Pressure: the JNC 7 report. JAMA. 2003; 289:2560-2572.

Costa AD, Jakob R, Costa CL. The mechanism by which the mitochondrial ATP-sensitive K+ channel opening and $\mathrm{H}_{2} \mathrm{O} 2$ inhibit the mitochondrial permeability transition. J Biol Chem 2006; 281: 20801-20808.

Crow MT, Mani K, Nam YJ, Kitsis RN. The mitochondrial death pathway and cardiac myocyte apoptosis. Circ Res 2004; 95: 957-970.

Davidson SM, Hausenloy D, Duchen MR. Signalling via the reperfusion injury signalling kinase (RISK) pathway links closure of the mitochondrial permeability transition pore to cardioprotection. Int J Biochem Cell Biol 2006; 38: 414-419.

Das S, Wong R, Rajapakse N, Murphy E, and Steenbergen C. Glycogen synthase kinase $3 \beta$ inhibition slows mitochondrial adenine nucleotide transport and regulates voltagedependent anion channel phosphorylation. Circ Res 2008; 103: 983-991.

Dickhout JG, Lee RM. Blood pressure and heart rate development in young spontaneously hypertensive rats. Am J Physiol 1998; 274: H794-H8oo.

Di Lisa F, Canton M, Menabo R, Dodoni G, Bernardi P. Mitochondria and reperfusion injury. The role of permeability transition. Basic Res Cardiol 2003; 98: 235-241.

Downey JM, Davis AM, Cohen MV. Signaling pathways in ischemic preconditioning. Heart Fail Rev 2007; 12(3-4): 181-188.

Droge W. Free radicals in the physiological control of cell function. Physiol Rev 2002; 82(1): 47-95.

Eigel BN, Gursahani H, Hadley RW. ROS are required for rapid reactivation of $\mathrm{Na}+\mathrm{Ca2+}$ exchanger in hypoxic reoxygenated guinea pig ventricular myocytes. Am J Physiol 2004; 286: H955-H963. 
Faghihi M, Mirershadi F, Dehpour AR, Bazargan M. Preconditioning with acute and chronic lithium administration reduces ischemia/reperfusion injury mediated by cyclooxygenase not nitric oxide synthase pathway in isolated rat heart. Eur $\mathrm{J}$ Pharmacol 2008; 597(1-3): 57-63.

Fantinelli JC, González Arbeláez LF, Pérez Núñez IA, Mosca SM. Protective effects of N-(2mercaptopropionyl)-glycine against ischemia-reperfusion injury in hypertrophied hearts. Exp Mol Pathol 2013;94(1):277-284.

Fantinelli JC, Pérez Núñez IA, Gonzalez Arbeláez LF, Schinella GR, Mosca SM. Participation of mitochondrial permeability transition pore in the effects of ischemic preconditioning in hypertrophied hearts: role of NO and mitoK(ATP). Int J Cardiol 2013; 166: 173-180.

Feldman AM, Weinberg EO, Ray PE, Lorell BH. Selective_changes_in cardiac gene expression during compensated hypertrophy_and the transition to cardiac decompensation in rats with chronic aortic banding. Circ Res. 1993; 73(1):184-92.

Feng J, Lucchinetti E, Ahuja P, Pasch T, Perriard JC, Zaugg M. Isoflurane postconditioning prevents opening of the mitochondrial permeability transition pore through inhibition of glycogen synthase kinase 3 $\beta$. Anesthesiology 2005; 103:987-995.

Fleet WF, Johnson TA, Graebner CA, Gettes LS. Effect of serial brief ischemic episodes on extracellular $\mathrm{K}+, \mathrm{pH}$ and activation in the pig. Circulation 1985; 72: 922-932.

Folkow B, Hallback M, Lundgren Y, Weiss L. Background of increased flow resistance and vascular reactivity in spontaneously hypertensive rats. Acta Physiol Scand 1970; 80: 93-106.

Frame S, Cohen P. GSK-3 takes centre stage more than 20 years after its discovery. Biochem J 2001; 359:1-16.

Frey N, Barrientos T, Shelton JM, Frank D, Rutten H, Gehring D, Kuhn C, Lutz M, Rothermel B, Bassel-Duby R, Richardson JA, Katus HA, Hill JA, Olson EN. Mice lacking calsarcin1 are sensitized to calcineurin signaling and show accelerated cardiomyopathy in response to pathological biomechanical stress. Nat Med 2004; 10(12): 1336-1343.

Frey N, Katus HA, Olson EN, Hill JA. Hypertrophy of the heart: a new therapeutic target? Circulation 2004; 109(13): 1580-1589.

Fritz M, Rinaldi G. Influence of nitric oxide-mediated vasodilation on the blood pressure measured with the tail-cuff method in the rat. J Biomed Sci 2007; 6:757-765. 
Frohlich ED. Is the spontaneously hypertensive rat a model for human hypertension? J Hypertens Suppl 1986; 4: S15-S9.

Garcia-Echeverria C, Sellers WR. Drug discovery approaches targeting the PI3K/Akt pathway in cancer.Oncogene 2008; 27(41): 5511-5526.

Garlid KD, Paucek P, Yarov-Yarovoy V, Murray HN, Darbenzio RB, D'Alonzo AJ, Lodge NJ, Smith MA, Grover GJ. Cardioprotective effect of diazoxide and its interaction with mitochondrial ATP-sensitive K+ channels. Possible mechanism of cardioprotection. Circ Res 1997; 81(6):1072-1082.

Griendling KK, FitzGerald GA. Oxidative stress and cardiovascular injury: Part II: animal and human studies. Circulation 2003; 108: 2034-2040.

Griffiths EJ, Halestrap AP. Protection by Cyclosporin A of ischemia/reperfusion-induced damage in isolated rat hearts. $\mathrm{J}$ Mol Cell Cardiol 1993; 25: 1461-1469.

Griffiths EJ, Halestrap AP: Mitochondrial nonspecific pores remain closed during cardiac ischaemia,but open upon reperfusion. Biochem J 1995; 307: 93-98.

Gross ER, Hsu AK, Gross GS. Opioid-induced cardioprotection occurs via glycogen synthase kinase 3 ßeta inhibition during reperfusion in intact rat hearts. Circ Res 2004; 94: 960966.

Grover GJ, Dzwonczyk S, Monticello TM. Comparative cardioprotective effects of cromakalim and diltiazem in ischemic hypertrophied rat hearts. Am J Physiol 1996; 270: H174H182.

Grover GJ, Garlid KD. ATP-Sensitive potassium channels: a review of their cardioprotective pharmacology. J Mol Cell Cardiol 2000; 32(4):677-95.

Halestrap AP, Clarke SJ, Javadov SA. Mitochondrial permeability transition pore opening during myocardial reperfusion-a target for cardioprotection. Cardiovasc Res 2004; 61: 372-385.

Halestrap AP. Mitochondria and reperfusion injury of the heart-A holey death but not beyond salvation. J Bioenerg Biomembr 2009; 41: 113-121.

Halliwell, B. Lipid peroxidation, antioxidants and cardiovascular disease: how should we move forward? Cardiovasc Res 2000; 47: 410-418.

Haneda T, Ichihara K, Abiko Y, Onodera S. Functional and metabolic responses to ischemia in the perfused heart isolated from normotensive and spontaneously hypertensive rats. Jpn Circ J 1986; 50(7):607-613. 
Hardt SE, Sadoshima J. Glycogen synthase kinase-3beta: a novelk regulador of cardiac hypertrophy and development. Circ Res 2002; 90(10): 1055-1063.

Hare JM, Stamler JS. NO/redox disequilibrium in the failing heart and cardiovascular system, J Clin Invest 2005; 115: 509-517.

Harwood AJ. Regulation of GSK-3: a cellular multiprocessor. Cell 2001; 105(7): 821-4.

Hausenloy DJ, Yellon DM. New directions for protecting the heart against ischaemiareperfusion injury: targeting the Reperfusion Injury Salvage Kinase (RISK)-pathway. Cardiovasc Res 2004; 61: 448-460.

Hausenloy DJ, Yellon DM, Mani-Babu S. Preconditioning protects by inhibiting the mitochondrial permeability transition. Am J Physiol Heart Circ Physiol 2004; 287: 841-849.

Hausenloy DJ, Yellon DM. Preconditioning and postconditioning: united at reperfusion. Pharmacol Ther 2007; 116: 173-191.

Hausenloy DJ, Ong SB, and Yellon DM, The mitochondrial permeability transition pore as a target for preconditioning and postconditioning. Basic Res Cardiol 2009; 104: 189-202. Hoffmeister HM, Ströbele M, Beyer ME, Kazmaier S, Fischer M, Bässler A, Seipel L. Inotropic response of stunned hypertrophied myocardium: responsiveness of hypertrophied and normal postischemic isolated rat hearts to calcium and dopamine stimulation. Cardiovasc Res 1998; 38(1):149-157.

Inserte J, Garcia-Dorado D, Ruiz-Meana M, Padilla F, Barrabes JA, Pina P, Agullo L, Piper $\mathrm{HM}$, Soler-Soler J. Effect of inhibition of $\mathrm{Na}(+) / \mathrm{Ca}(2+)$ exchanger at the time of myocardial reperfusion on hypercontracture and cell death. Cardiovasc Res 2002; 55: 739-748.

Jennings RB, Schaper J, Hill ML, Steenbergen C Jr, Reimer KA. Effect of reperfusion late in the phase of reversible ischemic injury. Changes in cell volume, electrolytes, metabolites, and ultrastructure. Circ Res 1985; 56: 262-278.

Jennings RB, Murry CE, Steenbergen C Jr, Reimer KA. Development of cell injury in sustained acute ischemia. Circulation 1990; 82:SII2-12.

Jin ZQ, Zhou HZ, Cecchini G, Gray MO, Karliner JS. MnSOD in mouse heart: acute responses to ischemic preconditioning and ischemia-reperfusion injury. Am J Physiol Heart Circ Physiol 2005; 288: 2986-2994. 
Johnatty SE, Dyck JR, Michael LH, Olson EN, Abdellatif M. Identification of genes regulated during mechanical load-induced cardiac hypertrophy. J Mol Cell Cardiol 2000; 32(5):805-815.

Jope RS. Lithium and GSK-3 $\beta$ : one inhibitor, two inhibitory actions, multiple outcomes. Trends Pharmacol Sci 2003; 24: 441-443.

Jope RS, Johnson GV. The glamour and gloom of glycogen synthase kinase-3. Trends Biochem Sci 2004; 29(2): 95-102.

Juhaszova M, Zorov DB, Kim SH. Glycogen synthase kinase- $3 \beta$ mediates convergence of protection signaling to inhibit the mitochondrial permeability transition pore. $\mathrm{J}$ Clin Invest 2004; 113: 1535-1549.

Kalaycioglu S, Sinci V, Imren Y, Oz E. Metoprolol prevents ischemia-reperfusion injury by reducing lipid peroxidation. Jpn Circ J 1999; 63: 718-721.

Ketterer B. Detoxication reactions of glutathione and glutathione transferases. Xenobiotica 1986; 16(10-11): 957-973.

Kevin LG, Camara AK, Riess ML, Novalija E, Stowe DF. Ischemic preconditioning alters realtime measure of $\mathrm{O} 2$ radicals in intact hearts with ischemia and reperfusion. Am $\mathrm{J}$ Physiol Heart Circ Physiol 2003; 284: H566-H574.

Kim JS, He L, Qian T, Lemasters JJ. Role of the mitochondrial permeability transition in apoptotic and necrotic death after ischemia/reperfusion injury to hepatocytes. Curr Mol Med 2003; 3: 527-535.

Kin H, Zhao ZQ, Sun HY, Wang NP, Corvera JS, Halkos ME, Kerendi F, Guyton RA, VintenJohansen J. Postconditioning attenuates myocardial ischemia-reperfusion injury by inhibiting events in the early minutes of reperfusion, Cardiovasc Res 2004; 62: 74-85.

Klaunig JE, Kamendulis LM. The role of oxidative stress in carcinogenesis. Ann Rev Pharmacol Toxicol 2004; 44: 239-267.

Kloner RA, Ganote CE, Whalen DA Jr, Jennings RB. Effect of a transient period of ischemia on myocardial cells. II. Fine structure during the first few minutes of reflow. Am J Pathol 1974; 74: 399-422.

Kroemer G, Galluzzi L, Brenner C. Mitochondrial membrane permeabilization in cell death. Physiol Rev 2007(1):99-163. 
Laskey WK. Brief repetitive balloon occlusions enhance reperfusion during percutaneous coronary intervention for acute myocardial infarction: a pilot study. Catheter Cardiovasc Interv 2005; 65: 361-367.

Lecour S. Activation of the protective Survivor Activating Factor Enhancement (SAFE) pathway against reperfusion injury: Does it go beyond the RISK pathway? J Mol Cell Cardiol 2009; 1:32-40.

Leichtweis S, Ji LL. Glutathione deficiency intensifies ischaemia-reperfusion induced cardiac dysfunction and oxidative stress. Acta Physiol Scand 2001; 172: 1-10.

Levitsky S. Protecting the myocardial cell during coronary revascularization. Circulation 2006; 114: S339-S343.

Levy D, Garrison RJ, Savage DD, Kannel WB, Castelli WP. Prognostic implications of echocardiographically determined left ventricular mass in the Framingham Heart Study. N Engl J Med 1990; 322:1561-1566.

Li H, Li Q, Du X, Sun Y, Wang X, Kroemer G, Blomgren K, Zhu C. Lithium-mediated longterm neuroprotection in neonatal rat hypoxia-ischemia is associated with antiinflammatory effects and enhanced proliferation and survival of neural stem/progenitor cells. J Cereb Blood Flow Metab 2011; 31(10):2106-2115.

Liu Y, Ytrehus K, Downey JM. Evidence that translocation of protein kinase C is a key event during ischemic preconditioning of rabbit myocardium. J Mol Cell Cardiol 1994; 26: 661-668.

Loor G, Kondapalli J, Iwase H, Chandel NS, Waypa GB, Guzy RD, Vanden Hoek TL, Schumacker PT. Mitochondrial oxidant stress triggers cell death in simulated ischemiareperfusion. Biochim Biophys Acta 2011(7):1382-1394.

Martindale JJ, Metzger JM. Uncoupling of increased cellular oxidative stress and myocardial ischemia reperfusion injury by directed sarcolemma stabilization. $\mathrm{J}$ Mol Cell Cardiol 2014; 67:26-37.

Mason RB, Pluta RM, Walbridge S, Wink DA, Oldfield EH, Boock RJ. Production of reactive oxygen species after reperfusion in vitro and in vivo: protective effect of nitric oxide, J. Neurosurg 2000; 93: 99-107.

McCord, J. M.; Fridovich, I. Superoxide dismutase. An enzymic function for erythrocuprein (hemocuprein). J Biol Chem 1969; 244(22): 6049-6055. 
Mela L, Seitz S. Isolation of mitochondria with emphasis on heart mitochondria from small amounts of tissue. Methods Enzymol 1979; 55:39-46.

Mocanu MM, Yellon DM. PTEN, the Achilles' heel of myocardial ischaemia/reperfusion injury? Br J Pharmacol 2007; 150: 833-838.

Montuschi P, Barnes PJ, Roberts LJ. Isoprostanes: markers and mediators of oxidative stress. Faseb J 2004; 18: 1791-80o.

Miura T, Miki T. GSK-3 $\beta$, a therapeutic target for cardiomyocyte protection. Circ J 2009; 73: 184-1192.

Miyamoto S, Murphy AN, and Brown JH. Akt mediates mitochondrial protection in cardiomyocytes through phosphorylation of mitochondrial hexokinase-II. Cell Death Differ 2008; 15: 521-529.

Murphy E, Steenbergen C. Preconditioning: the mitochondrial connection. Annu Rev Physiol 2007; 69: 51-67.

Murphy E, Steenbergen C. Mechanisms underlying acute protection from cardiac ischemia reperfusion injury. Physiol Rev 2008; 88: 581-609.

Murry CE, Jennings RB, Reimer KA: Preconditioning with ischemia: a delay of lethal cell injury in ischemic myocardium. Circulation 1986; 74: 1124-1136.

Nakagawa C, Asayama J, Katamura M, Matoba S, Keira N, Kawahara A, Tsuruyama K, Tanaka T, Kobara M, Akashi K, Ohta B, Tatsumi T, Nakagawa M. Myocardial stretch induced by increased left ventricular diastolic pressure preconditions isolated perfused hearts of normotensive and spontaneously hypertensive rats. Basic Res Cardiol 1997; 92(6): 410416.

Newaz MA, Nawal NN. Effect of gamma-tocotrienol on blood pressure, lipid peroxidation and total antioxidant status in spontaneously hypertensive rats (SHR). Clin Exp Hypertens. 1999; 21(8): 1297-1313.

Nishihara M, Miura T, Miki T. Modulation of the mitochondrial permeability transition pore complex in GSK-3 $\beta$-mediated myocardial protection. JMol Cell Cardiol 2007; 43: 564570.

Nishino Y, Webb IG, Davidson SM. Glycogen synthase kinase-3 $\beta$ inactivation is not required for ischemic preconditioning or postconditioning in the mouse Circ Res 2008; 103: 307-314. 
Obame FN, Plin-Mercier C, Assaly R, et al: Cardioprotective effect of morphine and a blocker of glycogen synthase kinase $3 \beta$, SB216763 [3-2,4-dichlorophenyl)-4(1-methyl-1Hindol-3-yl)-1H-pyrrole-2,5-dione], via inhibition of the mitochondrial permeability transition pore. J Pharmacol Exp Ther 2008; 326: 252-258.

Okamoto K, Aoki K. Development of a strain of spontaneously hypertensive rats. Japan Circ J 1963; 27: 282-293.

O'Rourke B. Evidence for mitochondrial $\mathrm{K}^{+}$channels and their role in cardioprotection. Circ Res 2004; 94(4):420-432.

Ott M, Gogvadze V, Orrenius S, Zhivotovsky B. Mitochondria, oxidative stress and cell death. Apoptosis 2007; 12: 913-922.

Pagel PS, Krolikowski JG, Neff DA et al. Inhibition of glycogen synthase kinase enhances isoflurane-induced protection against myocardial infarction during early reperfusion in vivo. Anesth Analg 2006; 102: 1348-1354.

Pantos CI, Davos CH, Carageorgiou HC, Varonos DV, Cokkinos DV. Ischaemic preconditioning protects against myocardial dysfunction caused by ischaemia in isolated hypertrophied rat hearts. Basic Res Cardiol 1996; 91(6):444-449.

Pap P, Cooper GM. Role of glycogen synthase kinase- $3 \beta$ in the phosphatidylinositol3kinase/Akt cell survival pathway. J Biol Chem 1998; 273: 19929-19932.

Papaharalambus CA, Griendling KK. Basic mechanisms of oxidative stress and reactive oxygen species in cardiovascular injury. Trends Cardiovasc Med 2007; 17: 48-54.

Pastorino JG, Hoek JB, Shulga N. Activation of glycogen synthase kinase $3 \beta$ disrupts the binding of hexokinase II to mitochondria by phosphorylating voltage-dependent anion channel and potentiates chemotherapy-induced cytotoxicity. Cancer Res 2005; 65: 10545-10554.

Penna C, Tullio F, Merlino A, Moro F, Raimondo S, Rastaldo R, Perrelli MG, Mancardi D, Pagliaro P. Postconditioning cardioprotection against infarct size and post-ischemic systolic dysfunction is influenced by gender. Basic Res Cardiol 2008; 8: 762-768.

Penna C, Tullio F, Moro F, Folino A, Merlino A, Pagliaro P. Effects of a protocol of ischemic postconditioning and/or captopril in hearts of normotensive and hypertensive rats. Basic Res Cardiol 2010(2):181-192. 
Perrelli MG, Pagliaro P, Penna C. Ischemia/reperfusion injury and cardioprotective mechanisms: Role of mitochondria and reactive oxygen species. World J Cardiol 2011; 6:186-200.

Piper HM, Garcia-Dorado D, Ovize M. A fresh look at reperfusion injury. Cardiovasc Res 1998; 38: 291-300.

Ravingerová T, Slezák J, Tribulová J, Džurba A, Uhrík B, Ziegelhöffer A. Reactive oxygen species contribute to high incidence of reperfusion-induced arrhythmias in isolated rat heart. Life Sci 1999; 65: 1927-1930.

Reimer KA, Lowe JE, Rasmussen MM, Jennings RB. The wavefront phenomenon of ischemic cell death. Myocardial infarct size vs duration of coronary occlusion in dogs. Circulation 1977; 56: 786-794.

Ruiz-Meana M, Núñez E, Miro-Casas E, Martínez-Acedo P, Barba I, Rodriguez-Sinovas A, Inserte J, Fernandez-Sanz C, Hernando V, Vázquez J, Garcia-Dorado D. Ischemic preconditioning protects cardiomyocyte mitochondria through mechanisms independent of cytosol. J Mol Cell Cardiol 2014; 68:79-88.

Russell RR 3rd, Li J, Coven DL, Pypaert M, Zechner C, Palmeri M, Giordano FJ, Mu J, Birnbaum MJ, Young LH. AMP-activated protein kinase mediates ischemic glucose uptake and prevents postischemic cardiac dysfunction, apoptosis, and injury. J Clin Invest 2004; 4:495-503.

Sack MN, Yellon DM. Insulin therapy as an adjunct to reperfusion after acute coronary ischemia: a proposed direct myocardial cell survival effect independent of metabolic modulation. J Am Coll Cardiol 2003; 41(8): 1404-1407.

Schillaci G, Verdecchia P, Porcellati C, Cuccurullo O, Cosco C, Perticone F. Continuous relation between left ventricular mass and cardiovascular risk in essential hypertension. Hypertension 2000; 35: 580-586.

Sedlak J, Lindsay R. Estimation of total, protein-bound, and nonprotein sulfhydryl groups in tissue with Ellman's Reagent. Anal Biochem 1958; 25: 192-205.

Slodzinski MK, Aon MA, O'Rourke B. Glutathione oxidation as a trigger of mitochondrial depolarization and oscillation in intact hearts. J Mol Cell Cardiol 2008; 45: 650-660.

Smith CC, Mocanu MM, Davidson SM, Wynne AM, Simpkin JC, Yellon DM. Leptin, the obesity-associated hormone, exhibits direct cardioprotective effects. Br J Pharmacol 2006; 149:5-13. 
Snoeckx LH, van der Vusse GJ, Coumans WA, Willemsen PH, Reneman RS. Differences in_ischaemia_tolerance between hypertrophied hearts of adult and aged spontaneously hypertensive rats. Cardiovasc Res 1993; 27(5): 874-881.

Staat P, Rioufol G, Piot C. Postconditioning the human heart. Circulation 2005; 112: 21432148.

Steenbergen C, Murphy E, Levy L, London RE. Elevation in cytosolic free calcium concentration early in myocardial ischemia in perfused rat heart. Circ Res 1987; 60: 700-707.

Tani M, Neely JR. Role of intracellular $\mathrm{Na}+$ in $\mathrm{Ca}+$ overload and depressed recovery of ventricular function of reperfused ischemic rat hearts. Possible involvement of $\mathrm{H}+\mathrm{Na}+$ and $\mathrm{Na}^{+}-\mathrm{Ca}^{2+}$ exchange. Circ Res 1989; 65: 1045-1056.

Terashima Y, Sato T, Yano T, Maas O, Itoh T, Miki T, Tanno M, Kuno A, Shimamoto K, Miura T. Roles of phospho-GSK- $3 \beta$ in myocardial protection afforded by activation of the mitochondrial K ATP channel. J Mol Cell Cardiol 2010;49(5):762-770.

Thibault H, Piot C, Staat P. Long-term benefit of postconditioning. Circulation 2008; 117: 1037-1044.

Tong H, Imahashi K, Steenbergen C. Phosphorylation of glycogen synthase kinase- $3 \beta$ during preconditioning through a phosphatidylinositol-3-kinase-dependent pathway is cardioprotective. Circ Res 2002; 90: 377-379.

Tumberlake DS, O'conner DT, Parmer RJ. Molecular genetics of esential hypertension: recent resultes and emerging strategies. Curr Opin Nephrl Hypertens 2001; 19: 1-11.

Vanden Hoek TL, Becker LB, Shao Z, Li C, Schumacker PT, Reactive oxygen species released from mitochondria during brief hypoxia induce preconditioning in cardiomyocytes. $\mathrm{J}$ Biol Chem 1998; 273: 18092-18098.

van der Vliet A, O'Neill CA, Cross CE, Koostra JM, Volz WG, Halliwell B, Louie S. Determination of low-molecular-mass antioxidant concentrations in human respiratory tract lining fluids. Am J Physiol 1999; 276: 289-296.

Valko M, Leibfritz D, Moncol J, Cronin MT, Mazur M, Telser J. Free radicals and antioxidants in normal physiological functions and human disease. Int $\mathrm{J}$ Biochem Cell Biol 2007; 39: 44-84. 
Vanlangenakker N1, Vanden Berghe T, Krysko DV, Festjens N, Vandenabeele P. Molecular mechanisms and pathophysiology of necrotic cell death. Curr Mol Med 2008; 3:207220.

Vaziri ND, Sica DA. Lead-induced hypertension: role of oxidative stress. Curr Hypertens Rep 2004; 6: 314-320.

Venardos KM, Perkins A, Headrick J, Kaye DM. Myocardial ischemia-reperfusion injury, antioxidant enzyme systems, and selenium: a review. Curr Med Chem 2007; 14: 15391549.

Viña J, Gimenez A, Puertes IR, Gasco E, Viña JR. Impairment of cysteine synthesis from methionine in rats exposed to surgical stress. Br J Nutr 1992; 68: 421-429.

Wagner C1, Ebner B, Tillack D, Strasser RH, Weinbrenner C. Cardioprotection by ischemic postconditioning is abrogated in hypertrophied myocardium of spontaneously hypertensive rats. J Cardiovasc Pharmacol 2013; 61(1):35-41.

Weihrauch D, Krolikowski JG, Bienengraeber M, Kersten JR, Warltier DC, Pagel PS. Morphine enhances isoflurane-induced postconditioning against myocardial infarction: the role of phosphatidylinositol-3-kinase and opioid receptors in rabbits. Anesth Analg 2005; 101:942-949.

Weiss JN, Korge P, Honda HM. Role of the mitochondrial permeability transition in myocardial disease. Circ Res 2003; 93: 292-301.

Whelan RS, Kaplinskiy V, Kitsis RN. Cell death in the pathogenesis of heart disease: mechanisms and significance. Annu Rev Physiol 2010; 72:19-44.

Xu J, Culman J, Blume A, Brecht S, Gohlke P. Chronic treatment with a low dose of lithium protects the brain against ischemic injury by reducing apoptotic death. Stroke 2003; 34:1287-1292.

Yadav HN, Singh M, Sharma PL. Involvement of GSK-3 $\beta$ in attenuation of the cardioprotective effect of ischemic preconditioning in diabetic rat heart. Mol Cell Biochem 2010; 343: 75-81.

Yano T, Miki T, Tanno M. Hypertensive hypertrophied myocardium is vulnerable to infarction and refractory to erythropoietin-induced protection. Hypertension 2011; 57: 110-115.

Yao Z, Gross GJ. Activation of ATP-sensitive potassium channels lowers threshold for ischemic preconditioning in dogs. Am J Physiol 1994; 267 (2): H1888-H1894. 
Yao Z, Mizumura T, Mei DA, Gross GJ. KATP channels and memory of ischemic preconditioning in dogs: synergism between adenosine and KATP channels. Am J Physiol 1997; 272: H334-H342.

Yellon DM, Baxter GF, Garcia-Dorado D. Ischaemic preconditioning: present position and future directions. Cardiovasc Res 1998; 37: 21-33.

Yellon DM, Downey JM. Preconditioning the myocardium: from cellular physiology to clinical cardiology. Physiol Rev 2003; 83: 1113-1151.

Zhai P, Sciarretta S, Galeotti J, Volpe M, and Sadoshima J. Differential roles of GSK- $3 \beta$ during myocardial ischemia and ischemia/reperfusion. Circ Res 2011; 109: 502-511.

Zhang L, Jia HM, Vinten-Johansen J. Reduction in myocardial infarct size by postconditioning in patients after percutaneous coronary intervention. $\mathrm{J}$ Invasive Cardiol 2007; 19: 424-430.

Zhao ZQ, Corvera JS, Halkos ME. Inhibition of myocardial injury by ischemic postconditioning during reperfusion: comparison with ischemic preconditioning. Am J Physiol Heart Circ Physiol 2003; 285: H579-H588.

Zhu M, Feng J, Lucchinetti E. Ischemic postconditioning protects remodeled myocardium via the $\mathrm{PI} 3 \mathrm{~K}-\mathrm{PKB} / \mathrm{Akt}$ reperfusion injury salvage kinase pathway. Cardiovasc Res 2006; 72: 152-162.

Zurashvili T, Cordón-Barris L, Ruiz-Babot G, Zhou X, Lizcano JM, Gómez N, Giménez-Llort L, Bayascas JR. Interaction of PDK1 with phosphoinositides is essential for neuronal differentiation but dispensable for neuronal survival. Mol Cell Biol 2013; 33:10271040. 